Florida International University FIU Digital Commons

$6-25-2015$

\title{
A Spatial and Temporal Analysis of Land Use and Water Quality in Southern Miami Dade County
}

Mario Londono

Florida International University, mlond001@fiu.edu

DOI: 10.25148 /etd.FIDC000127

Follow this and additional works at: https://digitalcommons.fiu.edu/etd

Part of the Environmental Health and Protection Commons, Environmental Monitoring Commons, Natural Resources and Conservation Commons, Natural Resources Management and Policy Commons, and the Water Resource Management Commons

\section{Recommended Citation}

Londono, Mario, "A Spatial and Temporal Analysis of Land Use and Water Quality in Southern Miami Dade County" (2015). FIU Electronic Theses and Dissertations. 2174.

https://digitalcommons.fiu.edu/etd/2174 


\section{FLORIDA INTERNATIONAL UNIVERSITY}

Miami, Florida

\section{A SPATIAL AND TEMPORAL ANALYSIS OF LAND USE AND WATER QUALITY IN SOUTHERN MIAMI DADE COUNTY}

A thesis submitted in partial fulfillment of

the requirements for the degree of

MASTER OF SCIENCE

in

ENVIRONMENTAL STUDIES

by

Mario Londoño 
To: Dean Michael R. Heithaus

College of Arts and Sciences

This thesis, written by Mario Londoño, and entitled A Spatial and Temporal Analysis of Land Use and Water Quality in Southern Miami Dade County, having been approved in respect to style and intellectual content, is referred to you for judgment.

We have read this thesis and recommend that it be approved.

Assefa Melesse

Henry Briceño

Jed Redwine

Jeff Onsted, Major Professor

Date of Defense: June 25, 2015

The thesis of Mario Londoño is approved.

Dean Michael R. Heithaus

College of Arts and Sciences

Dean Lakshmi N. Reddi

University Graduate School

Florida International University, 2015 


\section{ABSTRACT OF THE THESIS \\ A SPATIAL AND TEMPORAL ANALYSIS OF LAND USE AND WATER QUALITY \\ IN SOUTHERN MIAMI DADE COUNTY \\ by \\ Mario Londoño}

Florida International University, 2015

Miami, Florida

Professor Jeff Onsted, Major Professor

This thesis research employs a multi-pronged analysis approach to contribute to the existing knowledge regarding land use and water quality in southern Miami Dade County. Nutrient concentrations for TP, NOx-N, and NH3-N were evaluated for water quality monitoring stations across seven canals for two time periods: 1990-2003 and 2009-2014. Overall, the sites did not surpass the mandated TP threshold but a number of sites exceeded the NOx-N and NH3-N criteria set by multiple government agencies. Statistical tests demonstrated that the sites had differing distributions, not sharing similar median concentrations. Land use classifications were derived for the area interest for the years 1994 and 2013. Regression models relating land use classifications to nutrient concentrations at various spatial scales provided mixed results. Lastly, a trend analysis for nutrient concentrations at the stations for 1990-2003 and 2009-2014 demonstrated that there were either no trends or a decreasing trend at most sites. 


\section{TABLE OF CONTENTS}

CHAPTER

PAGE

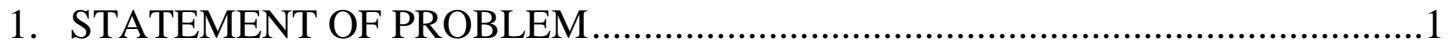

2. LITERATURE REVIEW ……………………………..................................4

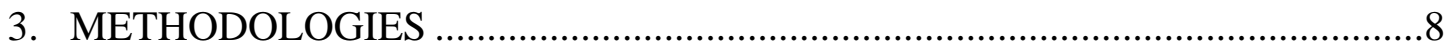

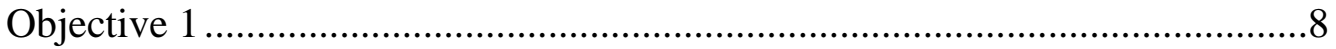

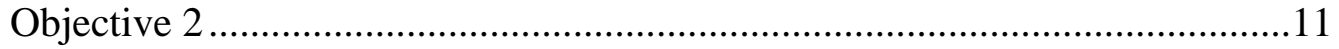

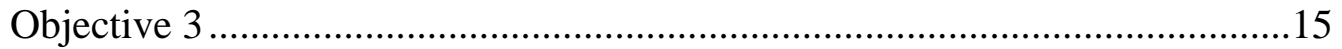

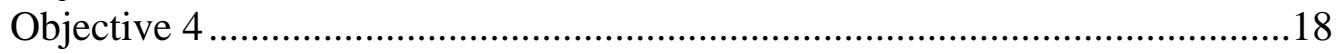

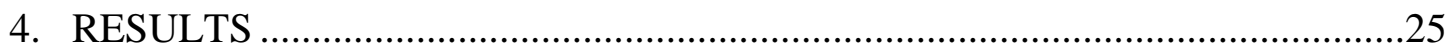

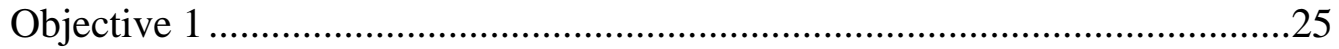

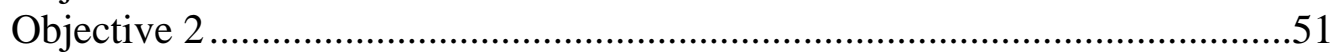

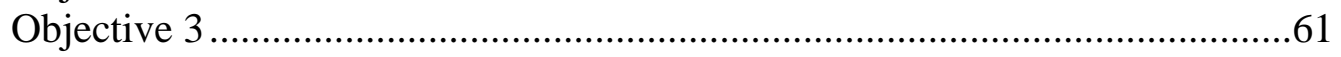

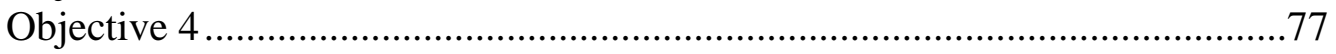

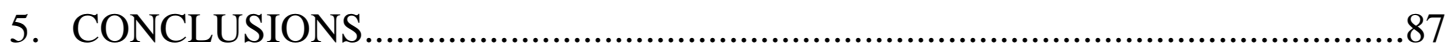

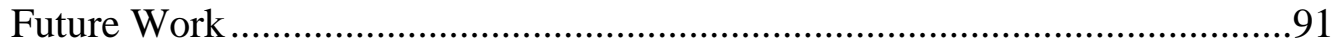

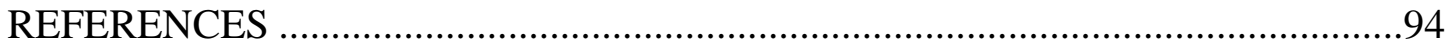




\section{LIST OF TABLES}

TABLE

PAGE

1. Summary statistics for TP concentrations (mg/L) 1990-2003 ............................29

2. Shapiro-Wilk test for normality for TP concentrations $1990-2003$.......................30

3. Summary statistics table for TP concentrations $2009-2014$................................33

4. Shapiro-Wilk test for normality for TP concentrations 2009-2014 _....................34

5. Summary statistics table for NOx-N concentrations 1990-2003 ..........................37

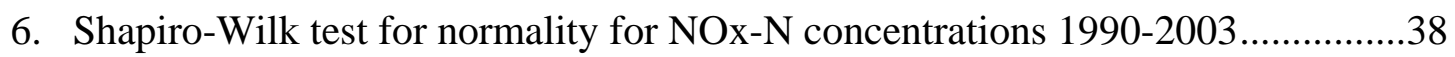

7. Summary statistics table for NOx-N concentrations 2009-2014 .........................41

8. Shapiro-Wilk test for normality for NOx-N concentrations 2009-2014...............42

9. Summary statistics table for NH3-N concentrations 1990-2003 .........................45

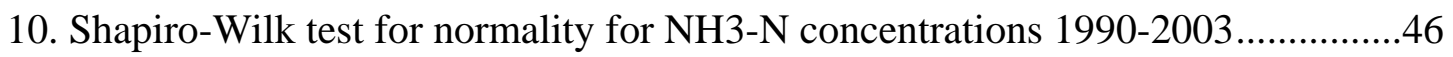

11. Summary statistics table for NH3-N concentrations 2009-2014 ........................49

12. Shapiro-Wilk test for normality for NH3-N concentrations 2009-2014.................50

13. Kruskal-Wallis test results for stations’ nutrient concentrations (1990-2003) ......52

14. Pairwise comparison for TP concentrations among stations (1990-2003) ............53

15. Pairwise comparison for NOx-N concentrations among stations (1990-2003) .....54

16. Pairwise comparison for NH3-N concentrations among stations (1990-2003) .....56

17. Kruskal-Wallis test results for stations’ nutrient concentrations (2009-2014) ......57

18. Pairwise comparison for TP concentrations among stations (2009-2014) ............57

19. Pairwise comparison for NOx-N concentrations among stations (2009-2014) .....59

20. Pairwise comparison for NH3-N concentrations among stations (1990-2003) .....60

21. K-means clustering analysis results for 1994 land use at Watershed scale 
22. K-means clustering results for 2014 land use at Watershed scale .68

23. K-means clustering results for 1994 land use at Canal Buffer scale .70

24. K-means clustering results for 2013 land use at Canal Buffer .70

25. K-means clustering results for 1994 land use at WQ Station Buffer scale .73

26. K-means clustering results for 2013 land use at WQ Station Buffer scale .74

27. Regression model results for nutrients at watershed scale (1990-2003)................75

28. Regression model results for nutrients at watershed scale (2009-2014)...............76

29. Regression model results for nutrients at canal buffer scale (1990-2003)............76

30. Regression model results for nutrients at canal buffer scale (2009-2014).............76

31. Regression model results for nutrients at WQ station buffer scale (1990-2003)...77

32. Regression model results for nutrients at WQ station buffer scale (2009-2014)...77

33. Seasonal Kendall trend test results for TP concentrations (1990-2003)...............79

34. Seasonal Kendall trend test results for NOx-N concentrations (1990-2003) ........81

35. Seasonal Kendall trend test results for NH3-N concentrations (1990-2003) ........82

36. Seasonal Kendall trend test results for TP concentrations (2009-2014)...............84

37. Seasonal Kendall trend test results for NOx-N concentrations (2009-2014) ........85

38. Seasonal Kendall trend test results for NH3-N concentrations (2009-2014) ........86 


\section{LIST OF FIGURES}

FIGURE

PAGE

1. Map of water quality stations in the canals of the study region...........................27

2. Scatterplot of range vs. standard deviation TP concentrations 1990-2003.............31

3. Scatterplot of range vs. standard deviation TP concentrations 2009-2014............35

4. Scatterplot of range vs. standard deviation NOx-N concentrations 1990-2003 ....39

5. Scatterplot of range vs. standard deviation NOx-N concentrations 2009-2014 ....43

6. Scatterplot of range vs. standard deviation NH3-N concentrations 1990-2003 ....47

7. Scatterplot of range vs. standard deviation NH3-N concentrations 2009-2014 ....51

8. Box-plots of TP concentrations for water quality stations (1990-2003)................53

9. Box-plots of NOx-N concentrations for water quality stations (1990-2003) ........55

10. Box-plots of NH3-N concentrations for water quality stations (1990-2003) ........56

11. Box-plots of TP concentrations for water quality stations (2009-2014)................58

12. Box-plots of NOx-N concentrations for water quality stations (2009-2014) ........59

13. Box-plots of NH3-N concentrations for water quality stations (2009-2014) ........61

14. Map of land use classifications in Southern Miami Dade County for 1994 ..........62

15. Map of land use classifications in Southern Miami Dade County for 2013 ..........63

16. Shared legend for land use maps displayed in Figures 14 and 15 ......................64

17. Map of watersheds in Southern Miami Dade County ........................................66

18. Map of canal buffers in Southern Miami Dade County .....................................69

19. Map of water quality buffers in Southern Miami Dade County ...........................72 


\section{ABBREVIATIONS AND ACRONYMS}

DERM

NH3-N

NOx-N

SFWMD

TP
Department of Environmental Resource Management

Ammonia nitrogen

Nitrate/nitrite-nitrogen

South Florida Water Management District

Total phosphorous 


\section{CHAPTER 1: STATEMENT OF PROBLEM}

Research involving land use and water quality can be challenging and complex. Over the last twenty years numerous watersheds throughout the United States have been subjects of case studies seeking to better understand the connection between the two. In South Florida, the quality of inland and offshore waters has been critically analyzed by federal, state, and local government entities as well as by research institutions. Some papers have described the relationships between land use and water quality in the region (Lietz 1999; Caccia \& Boyer 2007). However, these studies identified correlations between land use and water quality utilizing broad categorizations of land use in South Florida. For instance, land use types were distinguished only as agricultural or urban. The problem with such a classification is that it is too broad. There may be a possibility that different types of agriculture can result in different water quality impacts and therefore a higher categorical resolution is necessary to better delineate the connection between land use and water quality. In addition, these studies sought to identify nutrient loading into Biscayne Bay from the major coastal canals in the region utilizing water quality data from the mouth of the canals. By employing land use datasets of greater detail and including all water quality data found along the canals there is the potential to gain a better understanding of the dynamics of land use and water quality within Miami Dade County. This research seeks to address this current deficiency in knowledge by performing a more detailed analysis on land use and water quality in Miami Dade County. The following research questions and hypothesis will guide this thesis.

- Question: What is the status of nutrient concentrations in the canals of southern Miami Dade County that flow through agricultural lands? 
○ Hypothesis: Nutrient concentrations in the canals will differ, considering the different land use practices. There will be differences between canals that flow through urban-residential areas and canals that flow through agricultural lands. Certain types of agricultural practices may influence water quality at specific sites. Those land use practices related to specific sites will be identified.

- Question: Do the nutrient concentrations among the canals differ from each other?

○ Hypothesis: The nutrient concentrations across not only the canals, but across canal sites will differ considering the different land use compositions at each site.

- Question: What are the dominant land use types/land use syndromes for the canals being analyzed? Can the land use syndromes predict nutrient concentrations for the canals? Does spatial scale play a role?

○ Hypothesis: Land use syndromes for the canals will differ as a consequence of different combination of land uses. Land use syndromes can predict nutrient concentrations as land use is related to water quality. The finer the spatial scale, the more relevant the results.

- Question: Is there a trend for the nutrient concentrations at the canals and their corresponding sampling sites? 
○ Hypothesis: There will be detectable trends for nutrient concentrations at the canals and sites considering the land use change the study region has undergone. 


\section{CHAPTER 2: LITERATURE REVIEW}

In the late 19th century much of South Florida's land cover remained in a natural state. Prior to development, the indigenous populations that inhabited South Florida had altered the landscape through hunting, foraging, and fire activities, all of which was done without significantly compromising the ecological integrity of the Everglades watershed (Soleski 2001). In 1900, the region’s political leaders focused on the need for artificial drainage networks that lowered the water table and drained wetlands, encouraging human settlement and agricultural use (Holden et al. 2004). These activities were proposed to create a more navigable and economically productive environment (Briceño et al., 2011) but came at the cost of environmental degradation. The conversion of natural land in the Everglades tremendously impacted the natural hydrologic regime, leading to wetland loss, reduced bird populations, disruption of hydroperiods, invasion of exotic species, and declines in aquifer recharge (Browder et al. 1994). By 1917, the major canals: Miami, North New River, Hillsboro and West Palm Beach were completed, flowing from Lake Okeechobee to the coast (Davis \& Ogden 1994). After the successful implementation of these canals, others followed, thus draining much of the historic Everglades. The hydrology of the system became extensively managed through the construction of weirs, levees, spillways, and pump stations (Abtew et al. 2010). Canals now run through a variety of land use types, including high intensity urban areas and agricultural lands. Their flood control capabilities have enabled the continuing growth of urbanization in South Florida. By the 1970s, a continuous and expanding strip of urban areas was present from Palm Beach County to southern Miami Dade County, along the Atlantic coastal ridge (Solecki 2001). 
Research shows water quality and land use are closely related when considering modified environments. Strong relationships have been observed between land use types and the quantity and quality of water available for runoff, stream flow, groundwater flow, and the biological and chemical processes in receiving water bodies (Alberti 2008; Gbureck \& Folmar 1999; Changnon \& Demissie 1996). The removal of vegetative surfaces can modify runoff capabilities, the water balance, hydrologic cycle, surface water temperatures and nutrient retention capabilities of a specific place (Grimm et al. 2005; Groffman et al. 2005; Walsh et al. 2005; LeBlanc et al. 1997). Runoff that comes from highly developed urban areas may contain rubber fragments and heavy metals while runoff originating from agricultural lands may be enriched with nutrients and sediments (Tong \& Cheng 2002). Contaminants that cause water quality impairments such as nitrogen, phosphorus, and fecal coliform bacteria have been observed in high amounts in lands used for agricultural purposes (Broussard \& Turner 2009; Alberti 2008; Fisher et al 2000; Mander et al. 1998). In rural watersheds of developed countries, increasing concentrations of phosphorous and nitrogen have been attributed to the conversion of natural lands for agricultural purposes and perpetual fertilizer usage (Ierodiaconou et al. 2005; Mattikalli \& Richards 1996). Lysimeter experiments have demonstrated the increase of nitrate leaching due to intensified agricultural practices (Meissner et al. 1999). Nitrogen pollution has also been documented in urban areas, originating from runoff coming from fertilized lawns, malfunctioning septic tanks, and wastewater treatment plants (Alberti 2008; Kaye et al. 2006; Law et al. 2004).

Nutrients found in water bodies originate from both natural and anthropogenic sources. The most commonly monitored nutrients are phosphorous and nitrogen, which 
exist in both organic and inorganic forms (Lietz 1999). When water bodies receive excessive loads of total nitrogen and phosphorous eutrophication occurs (Mitsch \& Gosselink 2007). The affected water body may experience inordinate algal production, undesirable odor problems caused by sulfur-reducing bacteria (which turns sulfate into sulfide and generates hydrogen sulfide), and oxygen depletion that leads to hypoxic or anoxic conditions, resulting in fish kills (Lietz 1999). The Everglades evolved in a low phosphorous environment, which determined the plants that could compete successfully and helped shape the ecosystem into a mosaic of sawgrass, wet prairies, and open water sloughs dotted by tree islands (Wetzel 2002; Mitsch \& Gosselink 2007). The canal network of South Florida has allowed land uses that introduce excess phosphorous into the Everglades, and these same canals often deliver nutrient loads that promote the excess growth of cattail that crowds out other native Everglades flora (Flaig \& Reddy 1995). Also, the higher levels of phosphorus in surface waters lead to the increased growth of organisms such as algae and duckweed, which changes the habitat of aquatic and nonaquatic wildlife (Bates et al. 2002). In the case of nitrogen, it is mostly found as total organic nitrogen (TON) in the Everglades and near-shore waterbodies, but oxidized forms of inorganic nitrogen such as nitrate, nitrite, and ammonia have been observed as well (Briceño et al. 2013; Lietz 1999). High levels of ammonia have been collected from the Black Creek Canal (C1 canal), which flows out into Biscayne Bay, as a result of leachate from the South Dade landfill (Lietz 1999; Caccia \& Boyer 2007).

Southern Florida’s freshwater drainage canals are primarily utilized to manage water in agricultural, urban, and water conservation areas, collecting large amounts of urban and agricultural runoff that is discharged into the Atlantic Ocean and Gulf of 
Mexico (Key et al. 2003; Miles \& Pfeuffer 1997). As a result, water bodies such as Biscayne Bay have been detrimentally impacted. A century of extensive population growth has accelerated coastal and water resource development, leading to environmental changes to the bay (Caccia \& Boyer 2005). Some of these changes that have been documented include algal blooms, seagrass die-offs, localized pollution problems, and periods of hypersalinity (SFWMD 1995). Several canals draining landfills, urban, and agricultural areas empty into the southern part of Biscayne Bay (Caccia \& Boyer 2007). The land adjacent to this part of the bay is where agriculture is concentrated in MiamiDade County (Howie 1986). The southern portion of the bay experiences leachate pollution from the South Dade landfill, nutrient enrichments from agricultural runoff, highly polluted sediments from the Military Canal that serves the Homestead Air Force Base, and altered both quantities and seasonal timing of freshwater inputs from the canals (Caccia \& Boyer 2005).

Understanding the history and development of the region and recognizing documented correlations between land use and water quality in other case studies illustrates the relevance of conducting such research. This research seeks to address a knowledge gap created from local studies utilizing broad resolutions of land use categorizations by employing land use datasets of finer detail. It will enable performing a more detailed analysis on land use and water quality for southern Miami Dade County that can ultimately better delineate the connection between the two. 


\section{CHAPTER 3: METHODOLOGIES}

\section{Objective 1}

The first objective of the research is to determine the status of nutrient concentrations for stations in canals that transect Miami Dade County's agricultural lands. In order to do this, a table was derived that provides summary statistics for the water quality constituents of total phosphorous (TP), nitrate-nitrite (NOx-N), and ammonia (NH3-N) from each station's data period of record. Tabulating a summary statistic for each set of observations is intended to summarize the data as simply as possible using a large amount of information. These tables easily depict measures of central tendency, spread, and distribution shape for each set of observations, which can then be compared amongst each other. Water quality studies conducted in the region have made use of summary statistic tables to communicate basic information about the nutrient concentrations in the canals and Biscayne Bay. Lietz (2000) calculated summary statistics for concentrations of several nitrogen and phosphorous species at 15 coastal canal sites in Miami Dade County. Caccia and Boyer (2005) derived summary statistics for a variety of water quality parameters at numerous monitoring stations throughout Biscayne Bay from 1994-2003. Carey et al. (2011) provided summary statistics for total phosphorous, nitrate-nitrite, and ammonia for six water quality monitoring sites in the Biscayne Bay watershed from 1992-2006. One of the limitations of using a summary statistic table is that it is only as good as the data that comprises it. In some cases publicly available data from government entities and research institutions that have already undergone standard quality assurance and quality control need to be further revised in order to avoid inaccurate data results. In the case of this analysis, it entailed searching for outlier data 
that for example, are unrealistically high or far below minimum detection limits, therefore requiring explanations to justify keeping or deleting such records.

One unique statistical summary applied to summarize nutrient data is the ShapiroWilk test for normality (Shapiro \& Wilk 1965). This nonparametric test determines a dataset is normally distributed or not. The test uses the hypothesis testing format on which many other statistical tests are based on. The null hypothesis (Ho) states that the distribution function $F(x)$ is a normal distribution function with unspecified mean and variance (Conover 1999). The alternative hypothesis (Ha) states $F(x)$ is non-normal. In order to calculate the test statistic, some necessary steps must be taken. First, $D$ must be determined as shown in Equation 1:

$$
D=\sum_{i=1}^{n}\left(X_{i}-\bar{X}\right)^{2}
$$

where: $\bar{X}$ is the sample mean

$$
n \text { is the observed sample size }
$$

The sample is then ordered from smallest to largest as shown below,

$$
X^{(1)} \leq X^{(2)} \ldots \leq X^{(n)}
$$

Also, for the observed sample size $n$, coefficients for the Shapiro-Wilk test must be looked up which are provided in statistical textbooks and integrated in computer statistical software (Conover 1999). The Shapiro-Wilk test statistic $T_{3}$ is derived as shown in Equation 2:

$$
T_{3}=\frac{1}{D}\left[\sum_{i=1}^{k} a_{i}\left(X^{(n-i+1)}-X^{(i)}\right)\right]^{2}
$$

where: $X^{(i)}$ represents the ith order statistic 
$a_{i}$ is for placing the coefficients of the test $a_{1}, a_{2}, \ldots a_{k}$ $k$ approximates $n / 2$

For this test, the null hypothesis (Ho) at the level of significance $\alpha$ if $T_{3}$ is less than the $\alpha$ quantile provided by the Quantiles of the Shapiro-Wilk Test Statistic table, available in statistics textbooks and on computer statistics software programs. The p-values can be determined by running the test in programs such as RStudio to determine if the resulting test statistic is significant and whether or not the null hypothesis can be rejected. For this analysis, the Shapiro-Wilk test was performed on RStudio Version 0.98.507 (R Core Team 2012), using a level of significance of $\alpha=0.05$.

The water quality data were generated from samples collected and processed by the Miami Dade County Department of Environmental Resource Management (DERM). The majority of data were gathered from grab samples and analyzed by following EPA methods 365.1, 353.2, and 350.1 for TP, NOx-N, and NH3-N respectively (USEPA 2014). The water quality data were downloaded into Excel spreadsheets from the South Florida Water Management District (SFWMD) DBHYDRO online environmental database. As mentioned earlier, the data need to be revised because in some cases the quality control and assurance performed by the data collector/provider may not thoroughly eliminate all erroneous records. One way to address this is by searching and deleting records that are unrealistically high or well below the minimum detection limits.

Once the summary statistic table is assembled the water quality monitoring stations can be compared to each other. In addition, it was determined which stations are not meeting water quality criteria on the basis of standards set by the United States Environmental Protection Agency (USEPA), Florida Department of Environmental 
Protection (FDEP), and SFWMD. The threshold for TP is $0.052 \mathrm{mg} / \mathrm{L}$ following the agreed upon criteria proposed by both EPA and FDEP (USEPA 2013). For NOx-N and NH3-N the thresholds used will be derived from the SFWMD Biscayne Bay Surface Water Improvement and Management (SWIM) Plan. The NOx-N threshold is $0.05 \mathrm{mg} / \mathrm{L}$ (for Biscayne National Park) while the NH3-N threshold is $0.05 \mathrm{mg} / \mathrm{L}$ (throughout Biscayne Bay) and $0.01 \mathrm{mg} / \mathrm{L}$ (within Biscayne National Park) (Abbott et al. 2005; SFWMD 1995). For NH3-N, both thresholds were used for the summary statistics table. These NOx-N and NH3-N nutrient criteria were also used by Carey et al. (2011) for the Biscayne Bay watershed study regarding nutrient discharges into the bay.

\section{Objective 2}

The second objective is to determine whether or not the water quality stations have similar distribution functions of nutrient concentrations of TP, NOx-N, and NH3-N. In order to accomplish this, the data for each corresponding water quality station need to be ranked by degree of nutrient impairment. The Kruskal-Wallis nonparametric statistic test (Kruskal \& Wallis 1952) was employed for this purpose. It shows if the water quality stations all have the same median or if one group’s median differs from another (Helsel \& Hirsch 1993). The test is an extension of the Mann-Whitney test for two independent samples, the difference being that the Kruskal-Wallis version analyzes more than two independent samples (Conover 1999). Graves et al. (2005) used the nonparametric test to determine differences of nutrient concentrations in runoff from select land use categories in Florida's Indian River Lagoon watershed. Heckathorn and Deetz (2012) employed the test to ascertain whether the median concentrations of selected water quality constituents sampled for a particular water year(s) differed from other water years. For this analysis, 
it is hypothesized that the water quality stations will be dissimilar because of the differing land use compositions. For example, it may be expected that a water quality station on a canal surrounded by row and field croplands may yield larger observations of NOx-N concentrations than a station in a canal bisecting an area of urban-residential land usage. Therefore, the distribution of nutrient concentrations for all of the water quality stations will not be identical. This nonparametric test follows the hypothesis testing procedure that defines a null and alternative hypothesis. For this analysis, the null hypothesis (Ho) stipulated median concentrations are equal for each of the water quality stations. The alternative hypothesis (Ha) stated median concentrations for at least one of the water quality stations differs from the others. The resulting test statistic for the Kruskal-Wallis test and corresponding p-value is compared to the level of significance, which indicates the probability that a difference among the stations' median nutrient concentrations exists. For this analysis, if the p-value for the test statistic is below the level of significance of 0.05 then the null hypothesis will be rejected meaning the distributions of the station's median concentrations are not all identical. The Kruskal-Wallis test statistic is derived from Equations 3, 4, 5, 6, and 7:

$$
N=\sum_{i=1}^{k} n_{i}
$$

$$
\begin{aligned}
& \text { where: } \\
& \begin{array}{c}
N=\text { total number of observations } \\
n_{i}=\text { size of random sample } \\
k=\text { random sample from population } \\
R_{i}=\sum_{j=1}^{n i} R\left(X_{i j}\right)
\end{array}
\end{aligned}
$$




$$
\begin{aligned}
& \text { where: } \\
& \qquad \begin{array}{l}
i=1,2, \ldots, k \\
X_{i j}=i \text { th random sample of size } n_{i} \\
R\left(X_{i j}\right)=\text { rank assigned to } X_{i j}
\end{array}
\end{aligned}
$$

The test statistic $T$ is defined by Equation 5 as:

$$
T=\frac{12}{N(N+1)} \sum_{i=1}^{k} \frac{R_{i}^{2}}{n_{i}}-3(N+1)
$$

If there are ties, then the following correction formula (Equation 6) is used:

$$
\begin{array}{cl}
C=1-\frac{\sum_{i=1}^{G} t_{i}{ }^{3}-t_{i}}{N^{3}-N} & \\
\text { where: } & G=\text { number of groupings of different tied ranks } \\
& t_{i}=\text { number of tied values within group } i \text { tied at a particular } \\
& \text { value }
\end{array}
$$

Therefore, the test statistic (corrected for ties) is now defined in Equation 7 as:

$$
T^{*}=\frac{T}{C}
$$

If the null hypothesis can be rejected, then it can be determined which pairs of water quality stations differ by employing a pairwise comparison procedure that utilizes the following inequality equation, Equation 8 devised by Sachs (1997):

$$
\begin{aligned}
& \left|\frac{R_{i}}{n_{i}}-\frac{R_{j}}{n_{j}}\right|>\sqrt{C \chi^{2}{ }_{k-1, \alpha}\left[\frac{N(N+1)}{12}\right]\left[\frac{1}{n_{i}}+\frac{1}{n_{j}}\right]} \\
& \text { where: } \quad R_{i} \text { and } R_{j} \text { are the rank sums of two samples }
\end{aligned}
$$

If this inequality is satisfied then it can be said that water quality stations $i$ and $j$ are different in terms of their distributions. Also, box-plots depicting the nutrient 
concentrations for each water quality station in each time period were constructed to provide a graphical representation of the water quality stations' distributions.

The period of record for each water quality station was revised to ensure that comparisons are being made for data recorded in the same time period. This attention to detail can enhance the accuracy of the test's results. The strength of using the KruskalWallis test is that it is nonparametric, meaning that no assumptions are made about the distribution of the data (Conover 1999). Water quality data can be subject to the effects of seasonality such as varying rainfall, therefore eliminating the possibility of normal distributions in the data (Helsel \& Hirsh 1993). In the case of South Florida precipitation amounts are distinguished by the wet and dry seasons.

The water quality data used in this analysis were collected and processed by Miami Dade County DERM and is available for download from the SFWMD DBHYDRO online database. However, the data for each water quality station was also checked to see if the periods of records matched and revised for time periods for which no data were collected or recorded. The Kruskal-Wallis test along with post-hoc analysis with pairwise comparisons was performed on RStudio Version 0.98.507 (R Core Team 2012) for the water quality stations' concentrations of TP, NOx-N, and NH3-N for the time periods of 1990-2003 and 2009-2014. Although the majority of the water quality stations analyzed in this thesis are situated in canals that run through the primary sector of lands devoted to agricultural purposes in Miami Dade County, the analysis has the potential to provide evidence that nutrient concentrations vary among different types of agricultural land use categories. 


\section{Objective 3}

The third objective was to determine what the dominant land use types are that may influence nutrient concentrations at the water quality stations in southern Miami Dade County. Considering that this area of the county is where the county's agricultural lands are situated, close attention was paid to the specific types of agricultural land categorizations as it they help to explain the occurrence of long term nutrient concentrations at specific sites with compromising water quality thresholds. To carry out this objective, both spatial and non-spatial data were integrated together and applied to statistical procedures to develop a relevant result. Land use classification data in geospatial formats for the years 1994 and 2013 from the Miami Dade County GIS library underwent the following geoprocessing functions in the ESRI ArcGIS Version 10.2 software. First, the land use geospatial files were "clipped” to a watershed boundary feature class from the South Florida Water Management District (SFWMD) Arc Hydro Enhanced Database (AHED), a set of 1000 meter buffers that surround the canals that contain the water quality stations, and a set of 500 meter buffers that encircle each water quality station. Therefore, land use categories were summarized at three different spatial scales. Each water quality station is located on a specific watershed, on a specific canal, with a specific land use classifications surrounding it. That means that each water quality station has land use summaries calculated for each of the three spatial scales through the application of the clip and summary statistics functions in ArcMap. For the canal buffers, the distance from the midline of the canal and the edge of the buffer is 1000 meters on each side. For the water quality station buffer, the similarly measured diameter of the buffer is 500 meters. The land use classifications are embedded in the land use dataset 
spatial files obtained from the Miami Dade County GIS library. These GIS files specifically use the Miami Dade County Department of Planning and Zoning Land Use Numeric Classification. Each feature/record in the spatial files has a three digit county numeric classification and land use category description to indicate what specific land use a particular feature is displaying.

Once the land use summaries at all three scales were compiled for the water quality stations, the K-means clustering process was utilized to identify land use syndromes for the water quality stations at each of the three scales. The clustering method is intended to automatically partition a dataset with $n$ observations into $k$ groups using a specialized, multistep algorithm (McQueen 1967). The following function (Equation 9) is used when performing the clustering process:

$$
\begin{aligned}
& J=\sum_{j=1}^{k} \sum_{i=1}^{n}\left\|x_{i}^{(j)}-c_{j}\right\|^{2} \\
& \text { where: }\left\|x_{i}^{(j)}-c_{j}\right\|^{2} \text { is the measure of distance between chosen data point } x_{i}^{(j)} \text { and } \\
& \text { cluster center } c_{j}
\end{aligned}
$$

The function indicates the distance of $n$ data points from their corresponding clustering centers (McQueen 1967). In the K-means clustering procedure, $k$ initial cluster centers are selected and selected clusters are refined in an iterative process where the data point is assigned to its closest cluster center and, when all the observations have been assigned a cluster center, the positions of the $k$ cluster centers get recalculated (Wagstaff et al. 2001). The process continues until there is no further movement by the $k$ cluster centers. 
After the K-means cluster analysis was completed, the water quality stations had a corresponding land use syndrome at three spatial scales (watershed, $1000 \mathrm{~m}$ canal buffer, and 500 meter station site buffer). The last step to complete the analysis was to develop linear regression models that relate the land use syndromes/clusters to mean nutrient concentrations. The response variable of mean nutrient concentrations was derived from the summary statistics calculated for each station's nutrient concentrations in Objective 1. The regression models were constructed for the three different spatial scales for the nutrient constituents of TP, NOx-N, and NH3-N, for the two time periods of 1990-2003 and 2009-2014. That is the primary reason for employing two land use spatial files from two different time periods. The intention is to develop land use syndromes that can match the time period extent for which the water quality data has been collected and analyzed. As it can be recalled, the water quality data has a data gap from 2004-2008; therefore it was best to separate the complete datasets for each water quality parameter into two distinct time series. The significance of developing these regression models is to see if the land use syndromes for each accompanying spatial scale are adequate for predicting water quality concentrations. Depending on the results, these regression models can identify whether any or all of the spatial scales are most relevant to understanding the connection between land use and water quality.

In order for these regression models to function appropriately, it must be understood that the regressors used will be the land use syndromes/cluster groups. That means that the independent/explanatory variables for the models are categorical variables. Since categorical variables have no natural scale of measurement, they are designated a set of levels in order to explain the effect they may have on the response 
variable (Montgomery et al. 2012). Indicator variables are used for this purpose. In general, these indicator variables take on the values of 0 and 1 to identify the classes of the qualitative variable. For example, at the watershed scale, the given mean nutrient concentrations vis-a-vis the land use syndromes for that scale, there are two land use syndromes to consider (cluster A and cluster B). Then the regressor variable $(x 1)$ that represents the cluster group will define observations with cluster A as 0 and cluster B as 1. From there, the regression model can be fitted accordingly and the model criteria examined. Qualitative variables with $a$ levels are generally represented by $a-1$ indicator variables that take on values of 0 or 1 (Montgomery et al. 2012). Both of the K-means clustering analysis and regression modeling was carried out in RStudio Version 0.98.507 (R Core Team 2012).

\section{Objective 4}

The last objective was to identify the temporal trends of the water quality constituents TP, NOx-N, and NH3-N for each of the water quality stations analyzed in the previous objectives. A seasonal Kendall test is required to carry out the water quality analysis of change over time at each station. This nonparametric statistical test calculates the Mann-Kendall test for each predefined season separately and combines the results at the end (Helsel \& Hirsch 1993). In other words, the test determines if there is a monotonic trend in a time series that contains seasonal variation. In this analysis, time series data presents nutrient concentrations for TP, NOx-N, and NH3-N for corresponding sampling dates at specific water quality stations. Therefore, the X defines the sampling date (from earliest to latest) and Y defines nutrient concentrations at mg/L. Miller et al. (2004) employed the seasonal Kendall test to determine the long-term trends 
of specific conductance, chloride, and total nitrogen in Big Cypress National Preserve and Everglades National Park. The seasonal Kendall test is dependent on the use of Kendall's rank correlation coefficient designated as tau $(\tau)$, therefore it is important to understand the contributing variables and equations upon which the seasonal Kendall test is built. The first is Kendall's rank correlation coefficient (when there are no ties), which can be written out as shown in Equation 10:

$$
\tau=\frac{S}{D}
$$

where: $\quad S=$ (number of concordant pairs) - (number of discordant pairs)

$$
D=n(n-1) / 2
$$

A pair of observations such as $\left(\mathrm{X}_{1}, \mathrm{Y}_{1}\right)$ and $\left(\mathrm{X}_{2}, \mathrm{Y}_{2}\right)$ are considered concordant if both members of one observation are larger than the members of the other observation while a discordant pair is one in which two numbers in one observation differ in opposite directions from the members in the other observation (Conover 1999). For example pairs (2.1,4.2) and $(3.3,6.3)$ would be considered concordant while pairs $(3.1,5.3)$ and $(4.2,3.7)$ would be considered discordant. A more precise way of determining if a pair of bivariate observations is concordant or discordant is provided in the following:

$$
\begin{aligned}
& \text { if } \frac{Y_{j}-Y_{i}}{X_{j}-X_{i}}>0 \text {, the pairs are concordant } \\
& \text { if } \frac{Y_{j}-Y_{i}}{X_{j}-X_{i}}<0 \text {, the pairs are discordant }
\end{aligned}
$$

However, when the data contains ties, there will be situations where, for example, $\mathrm{Y}_{1}=\mathrm{Y}_{2}$ and therefore: 


$$
\text { if } \frac{Y_{j}-Y_{i}}{X_{j}-X_{i}}=0 \text {, the pair is } 1 / 2 \text { concordant and } 1 / 2 \text { discordant }
$$

The equation for Kendall's rank correlation coefficient when considering ties is now as shown in Equation 11:

$$
\begin{aligned}
\tau=\frac{N_{c}-N_{d}}{N_{c}+N_{d}} & \\
\text { where: } & \mathrm{N}_{\mathrm{c}}=\text { number of concordant pairs } \\
& \mathrm{N}_{\mathrm{d}}=\text { number of discordant pairs }
\end{aligned}
$$

The Mann Kendall trend test was developed by Henry B. Mann (1945) to test for a monotonic trend in a time series by using Kendall's rank correlation coefficient. The test is performed on a set of observations that contain $\mathrm{X}$ and $\mathrm{Y}$ variables, where $\mathrm{X}$ represents time. The test is one of significance with a null and alternative hypothesis (only the two-sided hypothesis test will be presented). The null hypothesis states that there is no trend, meaning no correlation between $\mathrm{X}$ (time) and $\mathrm{Y}$, (Ho: $\tau=0$ ). The alternative hypothesis states that there is a trend, which could be increasing or decreasing, meaning $\mathrm{X}$ (time) and $\mathrm{Y}$ are correlated, (Ha: $\tau \neq 0$ ). In order to determine if the resulting Kendall tau value is significant, a test statistic (Equation 12) is derived that utilizes the $S$ value used in the equation for Kendall's rank correlation coefficient (number of concordant pairs - number of discordant pairs) and the variance of the $\mathrm{S}$ value (Equation 13) that is used when there are ties (Helsel 2005; Valz et al. 1995). The test statistic Zs is determined as shown in Equation 12:

$$
\begin{aligned}
& Z_{s}=\frac{S-1}{\sqrt{\operatorname{Var}(S)}}, \text { if } S>0 \\
& Z_{s}=0, \text { if } S=0 S=0
\end{aligned}
$$




$$
\begin{aligned}
& Z_{s}=\frac{S+1}{\sqrt{\operatorname{Var}(S)}}, \text { if } S<0 \\
& S<0
\end{aligned}
$$

where: $S$ = (number of concordant pairs - number of discordant pairs; $\mathrm{N}_{\mathrm{c}}-\mathrm{Nd}_{\mathrm{d}}$ )

$$
\begin{aligned}
& \left\{\frac{1}{18} n(n-1)(2 n+5)-\sum t_{i}\left(t_{i}-1\right)\left(2 t_{i}+5\right)-\sum u_{i}\left(u_{i}-1\right)\left(2 u_{i}+5\right)\right\} \\
\operatorname{Var}(S)=\quad & \left.+\frac{1}{9 n(n-1)(n-2)}\left\{\sum t_{i}\left(t_{i}-1\right)\left(t_{i}-2\right)\right\} \sum u_{i}\left(u_{i}-1\right)\left(u_{i}-2\right)\right\} \\
& +\frac{1}{2 n(n-1)}\left\{\sum t_{i}\left(t_{i}-1\right)\right\}\left\{u_{i}\left(u_{i}-1\right)\right\}
\end{aligned}
$$

and: $\quad t_{i}=$ number of distinct ties among the X's

$$
u_{i}=\text { number of distinct ties among the Y's }
$$

The null hypothesis (Ho) can be rejected at $\alpha$ level of significance if $\left|Z_{s}\right|>Z_{1-\alpha / 2}$ where $Z_{1-\alpha / 2}$ is the critical value from a standard normal distribution (Helsel \&Hirsch 1993). As shown earlier, the test statistic consist of the Kendall S value being standardized, which allows the resulting test statistic, $Z_{s}$, to be compared against the table of standard normal distribution critical values.

Now that Kendall's tau and the Mann-Kendall test have been explained, the seasonal Mann-Kendall test can be better understood. The seasonal Mann-Kendall test, developed by Hirsch et al (1982), is essentially the Mann-Kendall test accounting for seasonal variation for a time series. In the seasonal Kendall test, the Kendall S value is computed separately for each defined season and summed up, resulting in the overall statistic $S_{k}$. The test statistic is defined as $Z_{S k}$ and is obtained in a similar fashion to how 
the $Z_{s}$ test statistic for Mann-Kendall test was derived (see Equation 12). The difference is that the Kendall S values for each season are summed up and the variances of each of the Kendall S values for each season are summed up prior to completing the standardization and obtaining $Z_{S k}$ (Helsel \& Hirsch 1993). As in the Mann-Kendall test, the significance of the test statistic, $Z_{s k}$, is determined by evaluating it against the critical values table of the standard normal distribution. The following provides the mathematical equations (Equations 14, 15, and 16) to the seasonal Kendall test:

$$
\tau=\frac{\sum_{i=1}^{s} S_{i}}{\sum_{i=1}^{s} D_{i}}
$$

where: $s=$ seasonal period, $S_{i}$ and $D_{i}$ are the Kendall S value and denominators for the $i$-th season

$$
S_{k}=\sum_{i=1}^{m} S_{i}
$$

where: $m=$ season, $S_{i}=$ Kendall S value for each season

$$
\begin{aligned}
& Z_{S k}=\frac{S_{k}-1}{\sqrt{\operatorname{Var}\left(S_{k}\right)}}, \text { if } S_{k}>0 \\
& Z_{S k}=0, \text { if } S_{k}=0 \\
& Z_{S k}=\frac{S_{k}+1}{\sqrt{\operatorname{Var}\left(S_{k}\right)}}, \text { if } S_{k}<0
\end{aligned}
$$

As in the case of the Mann-Kendall test, the null hypothesis (given seasonality, there is no trend; no correlation between $\mathrm{X}$ (time) and $\mathrm{Y} ; \tau=0$ ) is rejected at $\alpha$ level of significance if $\left|Z_{S k}\right|>Z_{1-\alpha / 2}$ where $Z_{1-\alpha / 2}$ is the critical value from a standard normal distribution. 
Using the seasonal Kendall test to determine the trends of nutrient concentrations at the water quality monitoring stations is crucial for this analysis when taking into consideration South Florida's distinct wet and dry seasons. Seasonal variations in precipitation, light availability, and application of fertilizer are examples of potential causes of variation to concentrations of surface waters that can be compensated for when analyzing time series to detect trends in Y over time (Helsel \& Hirsch 1993).

For this analysis, the two-sided hypothesis of the seasonal Kendall test will be used for each water quality station in the two time periods of 1990-2003 and 2009-2014. The null hypothesis (Ho) will be that there is no trend between $\mathrm{X}$ (time) and $\mathrm{Y}$ (nutrient concentrations). The alternative hypothesis will be that there is a trend between $\mathrm{X}$ and $\mathrm{Y}$ which may be increasing or decreasing ( $\mathrm{X}$ and $\mathrm{Y}$ are correlated). The level of significance for this test will be 0.05 , therefore if the resulting p-value corresponding to the test statistic is below 0.05 , then the null hypothesis will be rejected. The reason for using the two-sided hypothesis is that some stations could have increasing trends of nutrient concentrations while others could have decreasing trends. Thus, it is more convenient and creates less confusion to perform the two-sided test uniformly across all the water quality stations. The test was implemented with two defined seasons. The wet season will correspond to data sampled in the months of June 1st through October 31st while the dry season corresponds to sampled data collected from November $1^{\text {st }}$ through May 31st. The seasonal Kendall tests will be performed on R Studio Version 0.98 .507 (R Core Team 2012).

The datasets used in this analysis are the same ones utilized in Objectives 1 and 2. The water quality data were collected and processed by Miami Dade County DERM. The 
seasonal Kendall test was implemented for the water quality stations for two separate time periods because the full datasets contains a data gap from 2004-2008. The significance behind this method of analysis is that it may potentially result in an outcome that shows that the water quality trends for stations complement the land use types and land use changes that surround them. 


\section{CHAPTER 4: RESULTS}

\section{Objective 1}

Summary statistics for TP, NOx, and NH3 concentrations were calculated for 18 water quality stations located in seven different canals for the years of 1990 through 2003. The stations used were BL01, BL02, BL03, and BL12 in the Black Creek Canal (C-1); CD02 and CD09 in the Cutler Drain Canal (C-100); GL02 and GL03 in the Goulds Canal; MI03 in the Military Canal; MW01, MW04, and MW13 in the Mowry Canal (C103); PR01, PR03, and PR08 in the Princeton Canal (C-102); and lastly, SP01, SP04, and SP08 in the Snapper Creek Canal (C-2). Figure 1 provides a map showing the locations of all the water quality stations in the canals. Summary statistics were also calculated for the same nutrient parameters for the time period of 2009 through 2014. However, this was only performed for 14 of the 18 stations used in the $1990-2013$ period. This is because four of the stations (CD09, MW13, PR08, and SP08) had no recorded data from 2009-2014. In addition, station CD05 in the Cutler Drain Canal was included in the 20092014 summary statistics table to serve as a proxy for station CD09, bringing the total number of stations used for the 2009-2014 time period to 15. Furthermore, the ShapiroWilk test for normality was used to determine whether the nutrient data for each station in each time period was normally distributed or not. The test was performed on RStudio using the shapiro.test() function. The results were tabulated in separate tables. Lastly, scatterplots were constructed that display the range versus the standard deviation for the nutrient concentrations of the water quality stations for each time period. The relationship between the range and standard deviation for a dataset is obvious; the range is the difference between the smallest and largest observation in a dataset while the standard 
deviation is the square root of the average of the squares of deviations of the observations from the mean (Moore et al. 2012). The standard deviation is a more sophisticated measure of spread than the range but it can be seen how the standard deviation is somewhat dependent on the range. The standard deviation will be large when the observations of a dataset are widely spread apart from the mean. The reason why it is important to display these scatterplots is because they demonstrate the significance of sampling frequency and sampling intervals in regards to water quality analysis. As mentioned earlier, seasonality can have an effect on water quality data. This seasonality criterion, which is evident in South Florida due to the distinction between wet and dry seasons, implies the importance of taking an adequate amount of water quality samples within an appropriate sampling interval. However, it is common knowledge that although increasing the amount of water quality samples is beneficial it is can also be costprohibitive. The water quality data used for this research came from a number of different water quality stations throughout southern Miami Dade. The stations did not all have the same number of water quality samples taken and in some cases differed in sampling intervals for certain time periods. Observing the fitted line to the scatterplots may indicate, perhaps, if there is a threshold of standard deviation values or range values that are related to the necessary amount of water quality samples taken. As the number of water quality samples increases, we would expect for the dataset's range and standard deviations to increase up to a certain point where this increase eventually is minimized. It is also possible for these plots to not illustrate these patterns at all. It may turn out that these are better suited to demonstrate that certain stations contain extreme values or possible outliers that can skew results despite the number of water quality samples taken 


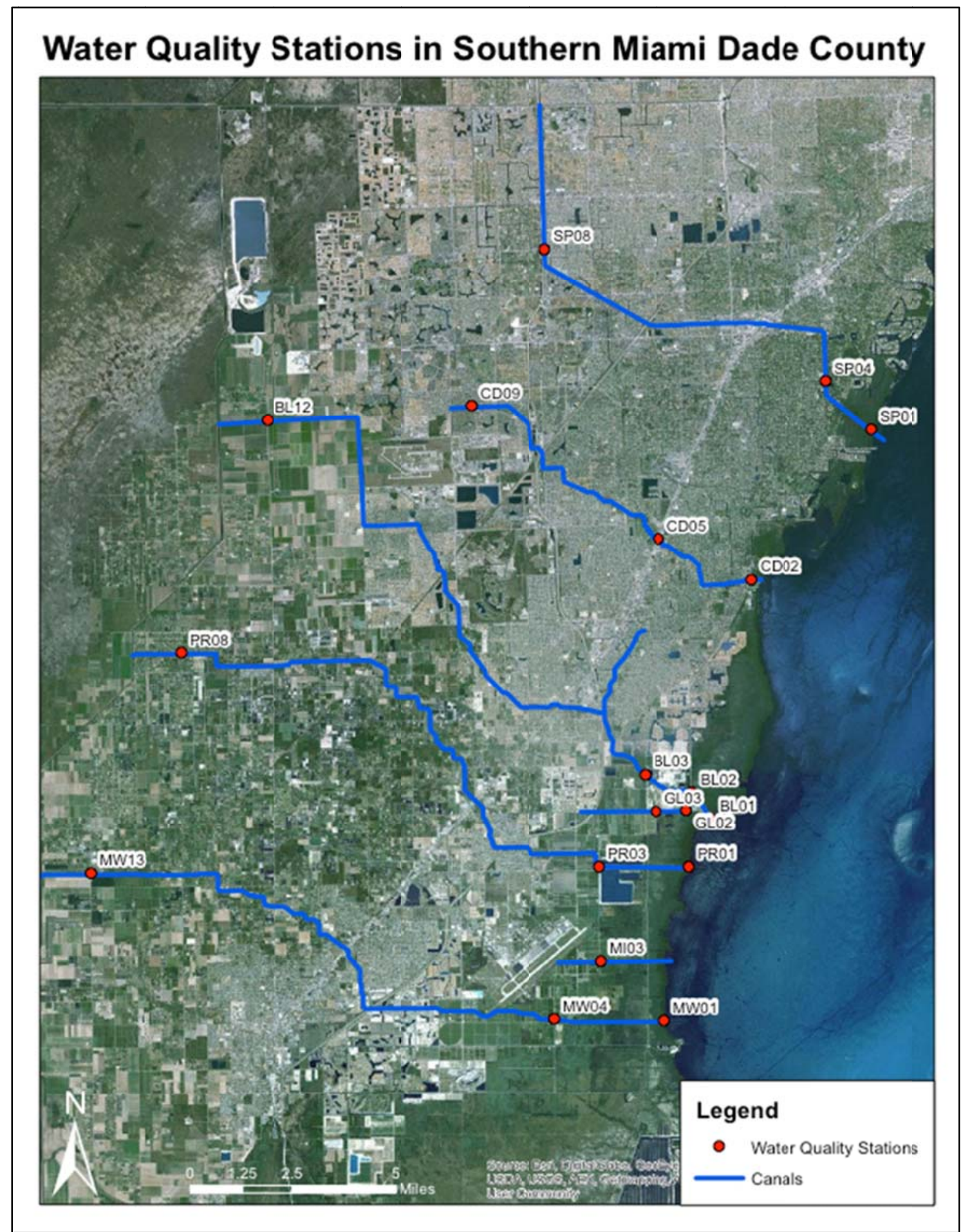

Figure 1: Map of water quality stations in the canals of the study region 
and therefore would not be helpful in determining the appropriate sampling frequencies and sampling intervals.

The summary statistics table for TP from 1990-2003 depicted in Table 1 shows that none of the water quality stations surpassed the TP threshold of $0.052 \mathrm{mg} / \mathrm{L}$. The stations with the highest geometric mean were GL03 (0.0205 mg/L) and GL02 (0.0202 mg/L), both of which are located on the Goulds Canal. Each station's geometric mean was greater than its median, which is an indication that the data for each station may not be normally distributed. In fact, the Shapiro-Wilk test for normality was performed on each station's dataset. The test's null hypothesis that the population is normally distributed was rejected for each station. The p-values for each station were well below the level of significance of 0.01 . These results are shown in Table 2 . The scatterplot of range values versus standard deviations for TP from 1990-2003 (Figure 2) shows that the relationship between the two variables is linear. As the standard deviation increases the range values increase linearly. In this particular case, the range values increase by 10.5 $\mathrm{mg} / \mathrm{L}$ as the standard deviation increases by one unit. 
Table 1: Summary statistics table for TP concentrations (mg/L) 1990-2003

\begin{tabular}{|c|c|c|c|c|c|}
\hline Station & Canal & mean & median & range & standard deviation \\
\hline BL01 & Black Creek (C1) & 0.0116 & 0.008 & 0.055 & 0.0094 \\
\hline BL02 & Black Creek (C1) & 0.0119 & 0.01 & 0.041 & 0.0073 \\
\hline BL03 & Black Creek (C1) & 0.0075 & 0.006 & 0.033 & 0.0061 \\
\hline BL12 & Black Creek (C1) & 0.0109 & 0.006 & 0.316 & 0.0318 \\
\hline CD02 & Cutler Drain & 0.0096 & 0.007 & 0.037 & 0.0076 \\
\hline CD09 & Cutler Drain & 0.0064 & 0.004 & 0.041 & 0.0069 \\
\hline GL02 & Goulds & 0.0202 & 0.018 & 0.198 & 0.0189 \\
\hline GL03 & Goulds & 0.0205 & 0.0125 & 0.431 & 0.0424 \\
\hline MI03 & Military & 0.0116 & 0.01 & 0.041 & 0.0069 \\
\hline MW01 & Mowry (C103) & 0.0105 & 0.008 & 0.039 & 0.0081 \\
\hline MW04 & Mowry (C103) & 0.0079 & 0.004 & 0.101 & 0.0142 \\
\hline MW13 & Mowry (C103) & 0.0087 & 0.004 & 0.189 & 0.0207 \\
\hline PR01 & Princeton (C102) & 0.0116 & 0.009 & 0.1001 & 0.0124 \\
\hline PR03 & Princeton (C102) & 0.0067 & 0.003 & 0.123 & 0.0148 \\
\hline PR08 & Princeton (C102) & 0.0124 & 0.005 & 0.257 & 0.0314 \\
\hline SP01 & Snapper Creek (C2) & 0.0098 & 0.007 & 0.105 & 0.0114 \\
\hline SP04 & Snapper Creek (C2) & 0.014 & 0.006 & 0.326 & 0.0355 \\
\hline SP08 & Snapper Creek (C2) & 0.0139 & 0.007 & 0.373 & 0.0392 \\
\hline
\end{tabular}


Table 2: Shapiro-Wilk test for normality for TP concentrations 1990-2013

\begin{tabular}{cccc}
\hline Station & Canal & Shapiro-Wilk Test statistic W & p-value \\
\hline BL01 & Black Creek (C1) & 0.7283 & $3.11 \mathrm{E}-13$ \\
BL02 & Black Creek (C1) & 0.8446 & $1.22 \mathrm{E}-09$ \\
BL03 & Black Creek (C1) & 0.8327 & $8.06 \mathrm{E}-10$ \\
BL12 & Black Creek (C1) & 0.2079 & $<2.2 \mathrm{e}-16$ \\
CD02 & Cutler Drain & 0.8691 & $3.62 \mathrm{E}-08$ \\
CD09 & Cutler Drain & 0.7607 & $1.37 \mathrm{E}-10$ \\
GL02 & Goulds & 0.4335 & $<2.2 \mathrm{e}-16$ \\
GL03 & Goulds & 0.2824 & $<2.2 \mathrm{e}-16$ \\
MI03 & Military & 0.8854 & $5.12 \mathrm{E}-08$ \\
MW01 & Mowry (C103) & 0.8362 & $2.93 \mathrm{E}-09$ \\
MW04 & Mowry (C103) & 0.4078 & $<2.2 \mathrm{e}-16$ \\
MW13 & Mowry (C103) & 0.3017 & $<2.2 \mathrm{e}-16$ \\
PR01 & Princeton (C102) & 0.6319 & $1.53 \mathrm{E}-14$ \\
PR03 & Princeton (C102) & 0.3481 & $<2.2 \mathrm{e}-16$ \\
PR08 & Princeton (C102) & 0.3319 & $<2.2 \mathrm{e}-16$ \\
SP01 & Snapper Creek (C2) & 0.5307 & $<2.2 \mathrm{e}-16$ \\
SP04 & Snapper Creek (C2) & 0.2608 & $<2.16$ \\
SP08 & Snapper Creek (C2) & 0.2094 & \\
\hline
\end{tabular}




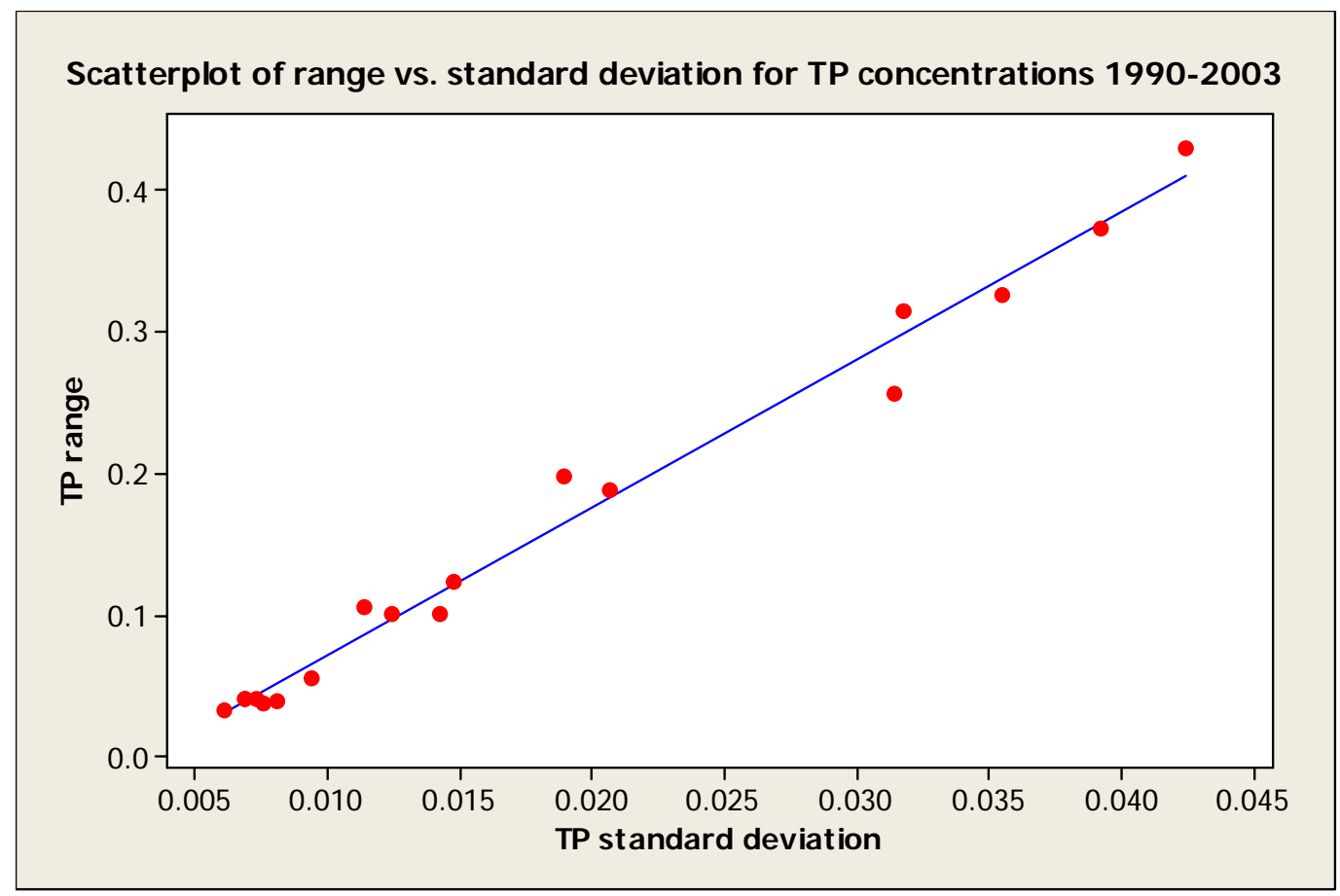

Figure 2: Scatterplot of range vs. standard deviation TP concentrations 1990-2003

For the time period of 2009-2014, the summary statistics table (Table 3) also shows that none of the water quality stations surpassed the TP threshold. The stations with the highest mean were GL02 (0.0123 mg/L) in the Goulds Canal and CD02 (0.0101 $\mathrm{mg} / \mathrm{L}$ ) in the Cutler Drain Canal. The mean for each station was also greater than its corresponding median, except for station MW04, which had a mean equal to the median. Utilizing the Shapiro-Wilk test for normality, it was determined that no station had a normally distributed dataset as seen in Table $4(\mathrm{p}<0.01)$. The $\mathrm{p}$-values for each station were below the level of significance of 0.01 . On another note, the TP mean concentration of the water quality stations was higher in the time period of 1990-2003 than in 20092014 with the exception of one site. Station CD02 in the Cutler Drain Canal had a higher TP mean concentration from 2009-2014 (0.0101 mg/L) than in 1990-2013 (0.0096 $\mathrm{mg} / \mathrm{L}$ ), a statistically significant but not biologically meaningful difference. The 
scatterplot of range values versus standard deviations for TP from 2009-2014 (Figure 3) shows that the relationship between the two variables is linear. As the standard deviation increases the range values increase linearly. For this scenario, the range values increase by 7.8898 as the standard deviation increases by one unit. This scatterplot also indicates that one of the observation points/water quality stations may contain possible extreme values or outliers. The presence of outliers becomes more evident when identifying the station that has the highest range and standard deviation values, represented by the scatterplot point farthest away from the rest (see Figure 3). The scatterplot point that reflects this potential for outlier presence is station CD02, which has a standard deviation of 0.0096 and a range of 0.077 for this time period. The mean of TP concentrations for station CD02 is $0.0101 \mathrm{mg} / \mathrm{L}$, the second highest mean of all the stations. The only station with a higher mean is GL02 $(0.0123 \mathrm{mg} / \mathrm{L})$, which has a standard deviation of 0.005 and a range of 0.022. As seen in Figure 1, station CD02 is surrounded by the residential land uses found within Palmetto Bay's village limits while station GL02 is surrounded by row and crop fields, plant nurseries, and a major landfill on the Goulds Canal. The stark difference in land uses between the two stations and the differences in the means, ranges, and standard deviations can help explain how station CD02 may contain outliers that require closer examination. 
Table 3: Summary statistics table for TP concentrations 2009-2014

\begin{tabular}{cccccc}
\hline Station & Canal & mean & median & range & standard deviation \\
& & & & & \\
\hline BL01 & Black Creek (C1) & 0.0076 & 0.007 & 0.0192 & 0.0033 \\
BL02 & Black Creek (C1) & 0.0077 & 0.007 & 0.014 & 0.0028 \\
BL03 & Black Creek (C1) & 0.0058 & 0.005 & 0.009 & 0.002 \\
BL12 & Black Creek (C1) & 0.0068 & 0.006 & 0.01 & 0.0025 \\
CD02 & Cutler Drain & 0.0101 & 0.008 & 0.077 & 0.0096 \\
CD05 & Cutler Drain & 0.0095 & 0.008 & 0.029 & 0.0056 \\
GL02 & Goulds & 0.0123 & 0.011 & 0.022 & 0.005 \\
GL03 & Goulds & 0.0089 & 0.008 & 0.03 & 0.0049 \\
MI03 & Military & 0.0065 & 0.006 & 0.015 & 0.0028 \\
MW01 & Mowry (C103) & 0.0065 & 0.006 & 0.012 & 0.0024 \\
MW04 & Mowry (C103) & 0.004 & 0.004 & 0.006 & 0.0014 \\
PR01 & Princeton (C102) & 0.0067 & 0.006 & 0.011 & 0.0024 \\
PR03 & Princeton (C102) & 0.0055 & 0.004 & 0.039 & 0.0066 \\
SP01 & Snapper Creek (C2) & 0.0072 & 0.007 & 0.012 & 0.0023 \\
SP04 & Snapper Creek (C2) & 0.007 & 0.006 & 0.02 & 0.0032 \\
\hline & & & & & \\
\hline
\end{tabular}


Table 4: Shapiro-Wilk test for normality for TP concentrations 2009-2014

\begin{tabular}{cccc}
\hline Station & Canal & Shapiro-Wilk Test statistic W & p-value \\
\hline BL01 & Black Creek (C1) & 0.7869 & $4.47 \mathrm{E}-08$ \\
BL02 & Black Creek (C1) & 0.8926 & $4.24 \mathrm{E}-05$ \\
BL03 & Black Creek (C1) & 0.8189 & $4.90 \mathrm{E}-07$ \\
BL12 & Black Creek (C1) & 0.905 & $1.79 \mathrm{E}-04$ \\
CD02 & Cutler Drain & 0.3738 & $4.82 \mathrm{E}-15$ \\
CD05 & Cutler Drain & 0.7829 & $4.31 \mathrm{E}-08$ \\
GL02 & Goulds & 0.9164 & $5.50 \mathrm{E}-04$ \\
GL03 & Goulds & 0.7153 & $9.18 \mathrm{E}-11$ \\
MI03 & Military & 0.8853 & $1.34 \mathrm{E}-06$ \\
MW01 & Mowry (C103) & 0.7947 & $4.10 \mathrm{E}-08$ \\
MW04 & Mowry (C103) & 0.8933 & $1.29 \mathrm{E}-04$ \\
PR01 & Princeton (C102) & 0.9291 & $1.82 \mathrm{E}-03$ \\
PR03 & Princeton (C102) & 0.4787 & $8.25 \mathrm{E}-13$ \\
SP01 & Snapper Creek (C2) & 0.9402 & $5.06 \mathrm{E}-03$ \\
SP04 & Snapper Creek (C2) & 0.7589 & $1.78 \mathrm{E}-08$ \\
\hline & & & \\
\hline
\end{tabular}




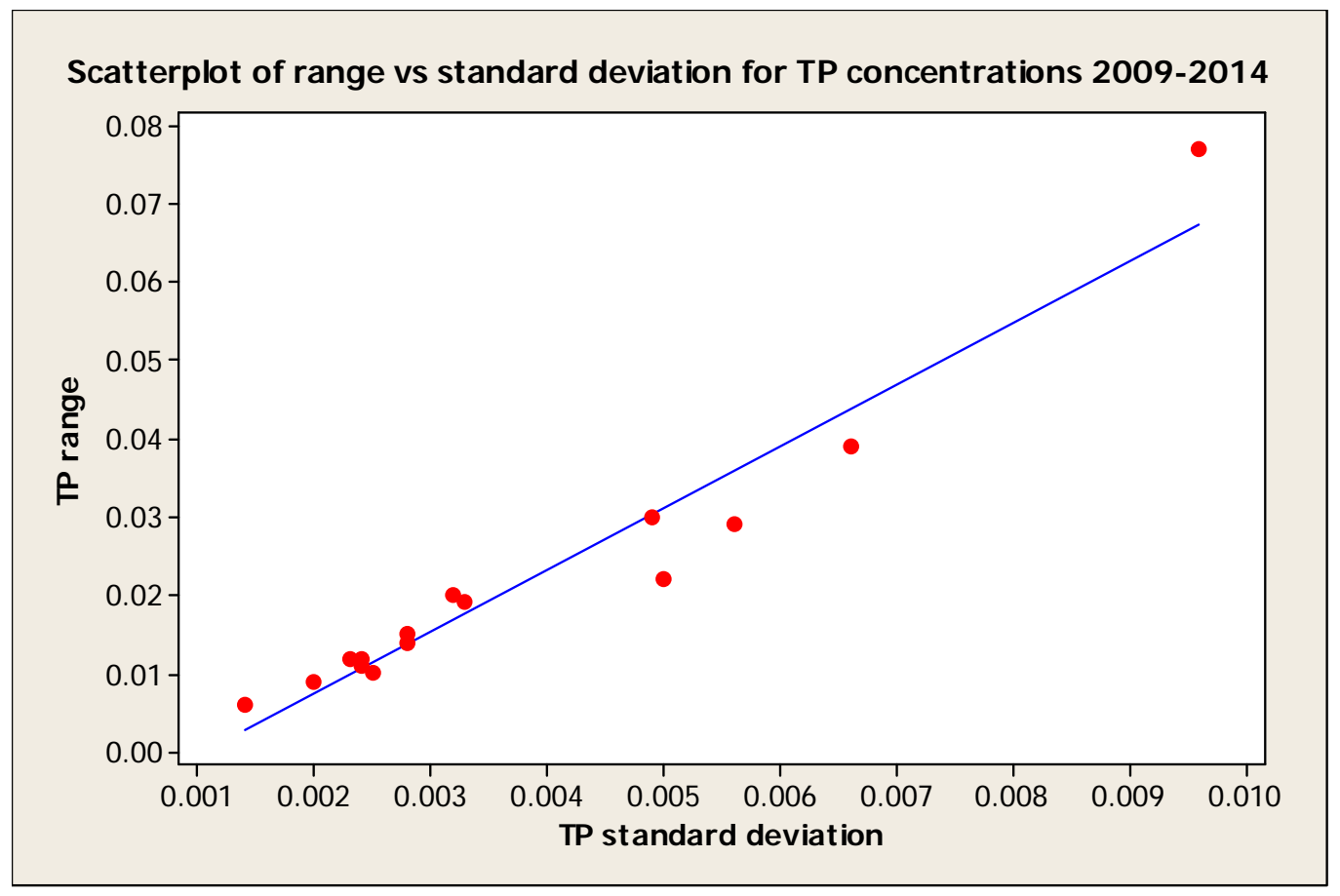

Figure 3: Scatterplot of range vs. standard deviation TP concentrations 2009-2014

In the case of NOx-N, the summary statistics provided in Table 5 for 1990-2003 shows that all of the stations' means surpassed the NOx-N threshold of $0.05 \mathrm{mg} / \mathrm{L}$ except for station BL12 (0.0222 mg/L) in the Black Creek Canal. The stations with the highest geometric mean were PR03 (4.044 mg/L) in the Princeton Canal and MW04 (2.2264 $\mathrm{mg} / \mathrm{L}$ ) in the Mowry Canal. Station PR03 was also the only station that had a median (4.15 mg/L) greater than its mean. Furthermore, Table 6 demonstrated that station MW04 was the only one for which the null hypothesis for the Shapiro-Wilk test for normality could not be rejected at a level of significance of $0.01(\mathrm{p}$-value $=0.0528)$. The scatterplot of range values versus standard deviations for NOx-N from 1990-2003 in Figure 4 shows that the relationship between the two variables is linear. The range values increase by 4.5099 as the standard deviation increases by one unit. What this particular scatterplot shows is that the water quality stations with low standard deviations and low ranges are 
associated for the most part in areas established by urban and residential land uses. The stations that correspond to larger standard deviations and larger ranges are located in areas that are dominated by agricultural land uses such as row and field croplands, plant nurseries, and groves. 
Table 5: Summary statistics table for NOx-N concentrations 1990-2003

\begin{tabular}{cccccc}
\hline Station & Canal & mean & median & range & standard deviation \\
\hline BL01 & Black Creek (C1) & 0.1456 & 0.09 & 0.84 & 0.1563 \\
BL02 & Black Creek (C1) & 0.1477 & 0.1 & 0.83 & 0.1578 \\
BL03 & Black Creek (C1) & 0.2332 & 0.22 & 0.86 & 0.1632 \\
BL12 & Black Creek (C1) & 0.0222 & 0.003 & 0.55 & 0.0853 \\
CD02 & Cutler Drain & 0.1237 & 0.09 & 0.47 & 0.108 \\
CD09 & Cutler Drain & 0.1176 & 0.08 & 0.58 & 0.1052 \\
GL02 & Goulds & 0.1327 & 0.09 & 0.69 & 0.1313 \\
GL03 & Goulds & 1.6564 & 1.48 & 4.97 & 0.9544 \\
MI03 & Military & 0.6613 & 0.61 & 1.89 & 0.4309 \\
MW01 & Mowry (C103) & 0.6182 & 0.34 & 2.74 & 0.6515 \\
MW04 & Mowry (C103) & 2.2264 & 2.175 & 4.46 & 0.6366 \\
MW13 & Mowry (C103) & 0.1063 & 0.04 & 2.43 & 0.3019 \\
PR01 & Princeton (C102) & 1.5161 & 0.9 & 4.46 & 1.29 \\
PR03 & Princeton (C102) & 4.0444 & 4.15 & 5.28 & 0.7307 \\
PR08 & Princeton (C102) & 0.144 & 0.04 & 2.83 & 0.4198 \\
SP01 & Snapper Creek (C2) & 0.0592 & 0.03 & 0.42 & 0.0713 \\
SP04 & Snapper Creek (C2) & 0.1532 & 0.14 & 0.37 & 0.0691 \\
SP08 & Snapper Creek (C2) & 0.054 & 0.04 & 0.31 & 0.0567 \\
\hline & & & & & \\
\hline
\end{tabular}


Table 6: Shapiro-Wilk test for normality for NOx-N concentrations 1990-2003

\begin{tabular}{cccc}
\hline Station & Canal & Shapiro-Wilk Test statistic W & p-value \\
\hline BL01 & Black Creek (C1) & 0.751 & $3.20 \mathrm{E}-13$ \\
BL02 & Black Creek (C1) & 0.7553 & $4.26 \mathrm{E}-13$ \\
BL03 & Black Creek (C1) & 0.9063 & $3.81 \mathrm{E}-07$ \\
BL12 & Black Creek (C1) & 0.3682 & $5.15 \mathrm{E}-16$ \\
CD02 & Cutler Drain & 0.9045 & $1.71 \mathrm{E}-06$ \\
CD09 & Cutler Drain & 0.8399 & $1.88 \mathrm{E}-09$ \\
GL02 & Goulds & 0.7814 & $3.40 \mathrm{E}-12$ \\
GL03 & Goulds & 0.9314 & $7.94 \mathrm{E}-06$ \\
MI03 & Military & 0.9583 & $1.09 \mathrm{E}-03$ \\
MW01 & Mowry (C103) & 0.8503 & $3.22 \mathrm{E}-09$ \\
MW04 & Mowry (C103) & 0.9765 & $5.28 \mathrm{E}-02$ \\
MW13 & Mowry (C103) & 0.3118 & $<2.2 \mathrm{e}-16$ \\
PR01 & Princeton (C102) & 0.8745 & $2.03 \mathrm{E}-08$ \\
PR03 & Princeton (C102) & 0.8971 & $4.56 \mathrm{E}-07$ \\
PR08 & Princeton (C102) & 0.3452 & $<2.2 \mathrm{e}-16$ \\
SP01 & Snapper Creek (C2) & 0.8086 & $6.96 \mathrm{E}-10$ \\
SP08 & Snapper Creek (C2) & 0.9519 \\
\hline
\end{tabular}




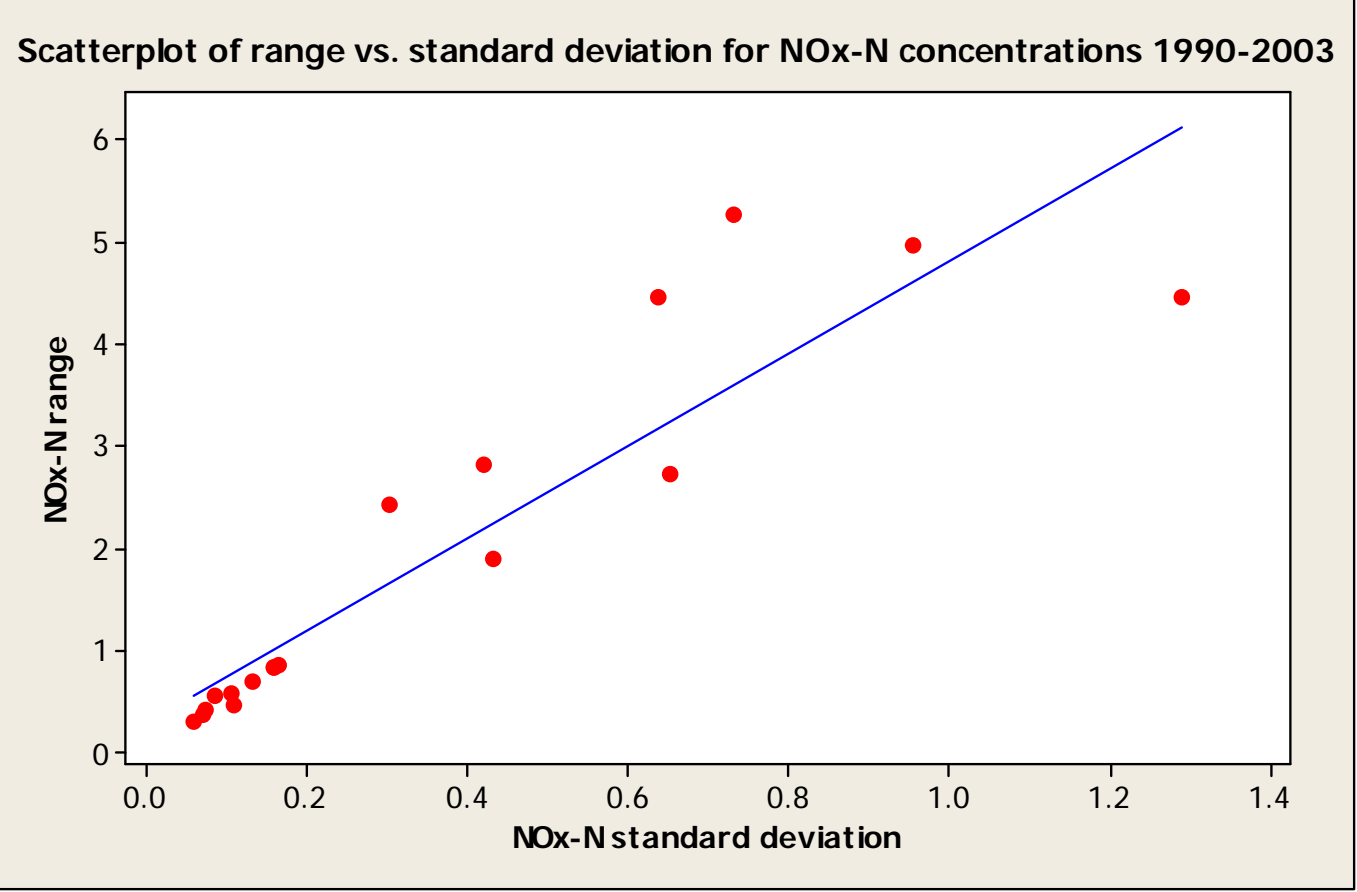

Figure 4: Scatterplot of range vs. standard deviation NOx-N concentrations 1990-2003

For the 2009-2014 time period, Table 7 illustrates that only one station's mean did not surpass the $0.05 \mathrm{mg} / \mathrm{L}$ NOx-N threshold: CD05 (0.0454 mg/L) in the Cutler Drain Canal. Once again, the stations with highest geometric mean were PR03 (4.2503 mg/L) and MW04 (1.8228 mg/L). Stations PR03 and MW04 were also the only stations that had median concentrations higher than their mean concentrations. As was the case in the 1990-2003 time period, Table 8 shows that station MW04 was the only one for which the Shapiro-Wilk test for normality null hypothesis could not be rejected at a level of significance of 0.01 (p-value $=0.2654)$. Comparing the time periods of 1990-2003 and 2009-2014 demonstrated that GL03 in the Goulds Canal, MW01 and MW04 in the Mowry Canal, and SP04 in the Snapper Creek Canal were the only stations that had lower NOx mean concentrations in 1990-2003 than in 2009-2014. The scatterplot of range values versus standard deviations for NOx-N from 2009-2014 in Figure 5 shows a 
positive/increasing linear relationship between the two variables. In this plot, the range values increase by 3.4997 as the standard deviation increases by one unit. This scatterplot illustrates a similar story to that of the scatterplot for NOx-N in 1990-2003. Water quality stations with low standard deviations and low ranges are located in areas surrounded by urban and residential land uses. The stations with larger standard deviations and larger ranges are found in areas that are dominated by agricultural land uses. Also, the stations with the highest standard deviation and ranges were the ones with the highest NOx-N mean concentrations (PR01 and PR03 along the Princeton Canal). This was the case for both time periods of 1990-2003 and 2009-2014. 
Table 7: Summary statistics for NOx-N concentrations 2009-2014

\begin{tabular}{cccccc}
\hline Station & Canal & mean & median & range & standard deviation \\
\hline BL01 & Black Creek (C1) & 0.3161 & 0.2285 & 1.051 & 0.2874 \\
BL02 & Black Creek (C1) & 0.3699 & 0.29 & 1.19 & 0.3076 \\
BL03 & Black Creek (C1) & 0.4861 & 0.4 & 1.35 & 0.3266 \\
BL12 & Black Creek (C1) & 0.0679 & 0.02 & 0.46 & 0.1062 \\
CD02 & Cutler Drain & 0.1581 & 0.14 & 0.42 & 0.1121 \\
CD05 & Cutler Drain & 0.0454 & 0.03 & 0.25 & 0.0471 \\
GL02 & Goulds & 0.3193 & 0.245 & 1.19 & 0.2561 \\
GL03 & Goulds & 0.5377 & 0.2 & 3.22 & 0.7808 \\
MI03 & Military & 1.0636 & 1 & 4.36 & 0.5954 \\
MW01 & Mowry (C103) & 0.5984 & 0.56 & 1.82 & 0.429 \\
MW04 & Mowry (C103) & 1.8228 & 1.88 & 3.09 & 0.5346 \\
PR01 & Princeton (C102) & 1.7994 & 1.575 & 4.11 & 1.4089 \\
PR03 & Princeton (C102) & 4.2503 & 4.62 & 4.46 & 1.1048 \\
SP01 & Snapper Creek (C2) & 0.0944 & 0.08 & 0.59 & 0.0875 \\
SP04 & Snapper Creek (C2) & 0.1223 & 0.11 & 0.25 & 0.061 \\
\hline
\end{tabular}


Table 8: Shapiro-Wilk test for normality for NOx-N concentrations 2009-2014

\begin{tabular}{cccc}
\hline Station & Canal & Shapiro-Wilk Test statistic W & p-value \\
\hline BL01 & Black Creek (C1) & 0.8651 & $1.18 \mathrm{E}-05$ \\
BL02 & Black Creek (C1) & 0.8723 & $1.71 \mathrm{E}-05$ \\
BL03 & Black Creek (C1) & 0.9056 & 0.0003069 \\
BL12 & Black Creek (C1) & 0.5806 & $7.09 \mathrm{E}-10$ \\
CD02 & Cutler Drain & 0.9245 & $8.57 \mathrm{E}-04$ \\
CD05 & Cutler Drain & 0.6238 & $2.96 \mathrm{E}-08$ \\
GL02 & Goulds & 0.8833 & $3.41 \mathrm{E}-05$ \\
GL03 & Goulds & 0.6045 & $6.61 \mathrm{E}-13$ \\
MI03 & Military & 0.7339 & $2.49 \mathrm{E}-11$ \\
MW01 & Mowry (C103) & 0.9189 & $6.21 \mathrm{E}-04$ \\
MW04 & Mowry (C103) & 0.9754 & $2.65 \mathrm{E}-01$ \\
PR01 & Princeton (C102) & 0.878 & $2.27 \mathrm{E}-05$ \\
PR03 & Princeton (C102) & 0.7889 & $5.02 \mathrm{E}-08$ \\
SP01 & Snapper Creek (C2) & 0.6488 & $4.17 \mathrm{E}-10$ \\
SP04 & Snapper Creek (C2) & 0.9108 & $3.76 \mathrm{E}-04$ \\
\hline
\end{tabular}




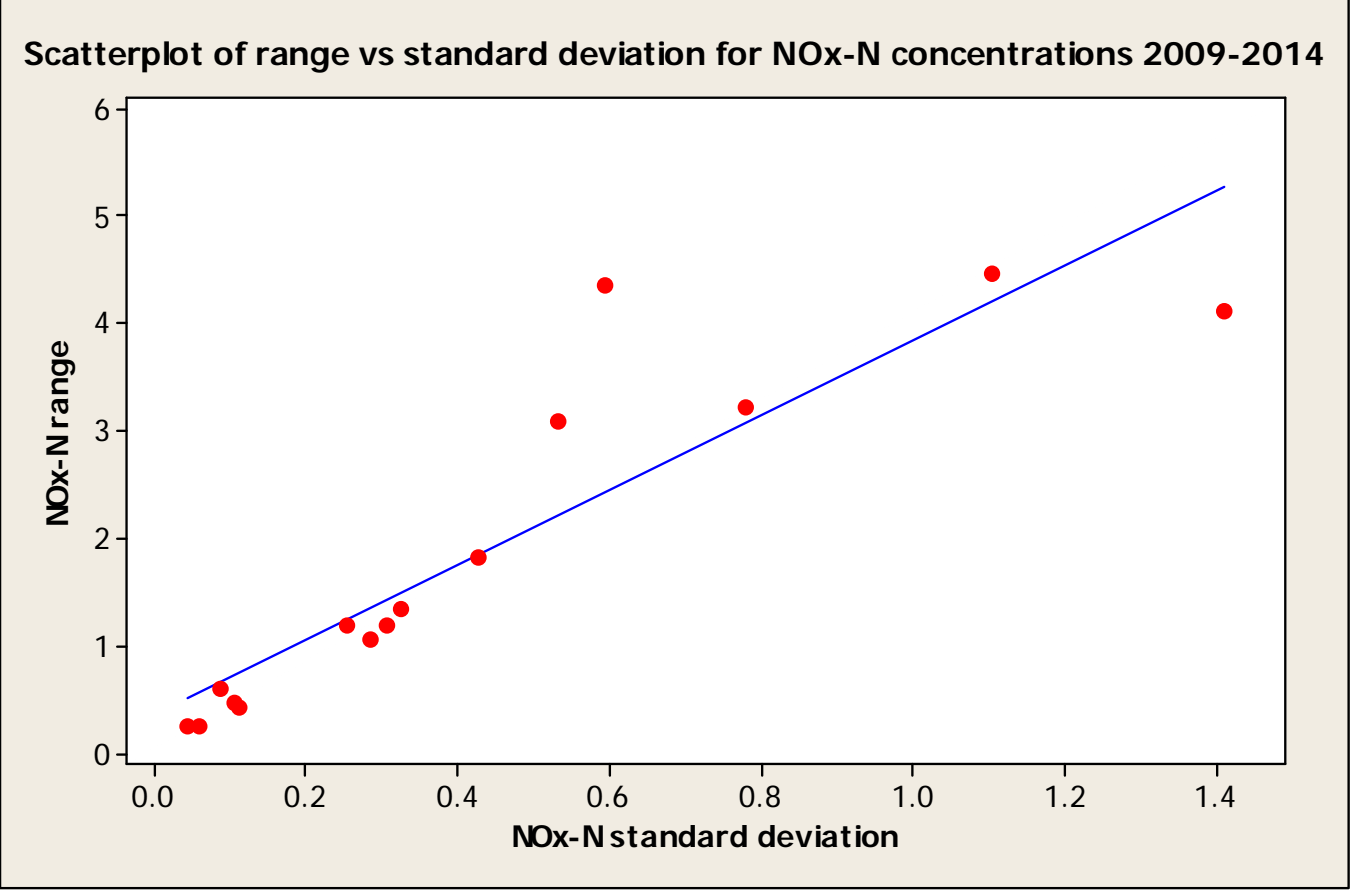

Figure 5: Scatterplot of range vs. standard deviation NOx-N concentrations 2009-2014

The results for NH3-N concentrations from 1990-2003 shown in Table 9 illustrate that all of the water quality stations violate the $0.01 \mathrm{mg} / \mathrm{L} \mathrm{NH3-N}$ threshold that is meant for Biscayne National Park. Using the $0.05 \mathrm{mg} / \mathrm{L}$ threshold that is recommended for Biscayne Bay, stations CD02, CD09, MI03, MW04, and PR03 have means that do not surpass the threshold. Station GL02 in the Gould Canals had a geometric mean of 3.1166 mg/L, the highest out of all the stations. With the exception of three stations (BL12, MW13, and PR08), all of the stations had means greater than their medians. Only two stations (MW13 and SP08) could not reject the null hypothesis of the Shapiro-Wilk test at a level of significance of 0.01 (see Table 10). The scatterplot of range values versus standard deviations for NH3-N from 1990-2003 found in Figure 6 shows a positive/increasing linear relationship between the two variables. For this plot, the range values increase by 6.3401 as the standard deviation increases by one unit. What can be 
seen in this scatterplot is that the majority of the standard deviations span from 0.05 to 0.1 while the majority of the range values span from 0.2 to 2 . However, there is one station with a standard deviation and range value extremely different from the rest. Station GL02 on the Goulds Canal has a standard deviation of 3.322 and range of 21.01. As stated earlier, the NH3-N mean concentration of this station was highest among all water quality stations. The land use feature that may be affecting the NH3-N concentration results for this station is the presence of the South Dade Landfill (see Figure 1). This landfill has been identified as a source of ammonium contamination to southern Biscayne Bay (Caccia \& Boyer 2005). What is interesting about this is that it appears station GL02 in the only station from 4 other ones in the nearby area that displays these large summary statistics numbers. As seen in Figure 1, Stations BL01, BL02, BL03, and GL03 all are found nearby the South Dade Landfill but these stations do not display the large values that station GL02 does. 
Table 9: Summary statistics for NH3-N concentrations 1990-2003

\begin{tabular}{cccccc}
\hline Station & Canal & mean & median & range & standard deviation \\
\hline BL01 & Black Creek (C1) & 0.2761 & 0.23 & 1.79 & 0.2196 \\
BL02 & Black Creek (C1) & 0.2664 & 0.205 & 3.7 & 0.3464 \\
BL03 & Black Creek (C1) & 0.09 & 0.03 & 0.48 & 0.1122 \\
BL12 & Black Creek (C1) & 0.3859 & 0.415 & 0.74 & 0.1394 \\
CD02 & Cutler Drain & 0.0387 & 0.03 & 0.28 & 0.0462 \\
CD09 & Cutler Drain & 0.036 & 0.03 & 0.53 & 0.063 \\
GL02 & Goulds & 3.1166 & 2.145 & 21.01 & 3.3222 \\
GL03 & Goulds & 0.4543 & 0.11 & 6.46 & 0.9966 \\
M103 & Military & 0.0489 & 0.03 & 0.42 & 0.0575 \\
MW01 & Mowry (C103) & 0.0631 & 0.06 & 0.37 & 0.0479 \\
MW04 & Mowry (C103) & 0.0273 & 0.02 & 0.19 & 0.0296 \\
MW13 & Mowry (C103) & 0.257 & 0.26 & 0.59 & 0.127 \\
PR01 & Princeton (C102) & 0.1405 & 0.11 & 1.01 & 0.1278 \\
PR03 & Princeton (C102) & 0.0449 & 0.03 & 0.36 & 0.0501 \\
PR08 & Princeton (C102) & 0.2803 & 0.31 & 0.67 & 0.1458 \\
SP01 & Snapper Creek (C2) & 0.0732 & 0.06 & 0.4 & 0.0544 \\
SP04 & Snapper Creek (C2) & 0.0888 & 0.07 & 0.36 & 0.0778 \\
SP08 & Snapper Creek (C2) & 0.3258 & 0.32 & 0.55 & 0.1041 \\
\hline
\end{tabular}


Table 10: Shapiro-Wilk test for normality for NH3-N concentrations 1990-2003

\begin{tabular}{cccc}
\hline Station & Canal & Shapiro-Wilk Test statistic W & p-value \\
\hline BL01 & Black Creek (C1) & 0.7428 & $1.88 \mathrm{E}-13$ \\
BL02 & Black Creek (C1) & 0.3904 & $<2.2 \mathrm{E}-16$ \\
BL03 & Black Creek (C1) & 0.8072 & $1.08 \mathrm{E}-10$ \\
BL12 & Black Creek (C1) & 0.9666 & 0.007374 \\
CD02 & Cutler Drain & 0.8902 & $8.72 \mathrm{E}-07$ \\
CD09 & Cutler Drain & 0.5627 & $1.29 \mathrm{E}-15$ \\
GL02 & Goulds & 0.7257 & $4.83 \mathrm{E}-14$ \\
GL03 & Goulds & 0.4548 & $<2.2 \mathrm{E}-16$ \\
MI03 & Military & 0.7878 & $1.34 \mathrm{E}-11$ \\
MW01 & Mowry (C103) & 0.8937 & $1.89 \mathrm{E}-07$ \\
MW04 & Mowry (C103) & 0.916 & $1.87 \mathrm{E}-05$ \\
MW13 & Mowry (C103) & 0.9851 & $2.63 \mathrm{E}-01$ \\
PR01 & Princeton (C102) & 0.7011 & $7.46 \mathrm{E}-14$ \\
PR03 & Princeton (C102) & 0.8063 & $1.20 \mathrm{E}-09$ \\
PR08 & Princeton (C102) & 0.9678 & $9.26 \mathrm{E}-03$ \\
SP01 & Snapper Creek (C2) & 0.8444 & $1.51 \mathrm{E}-09$ \\
SP04 & Snapper Creek (C2) & Snapper Creek (C2) & 0.9249 \\
\hline
\end{tabular}




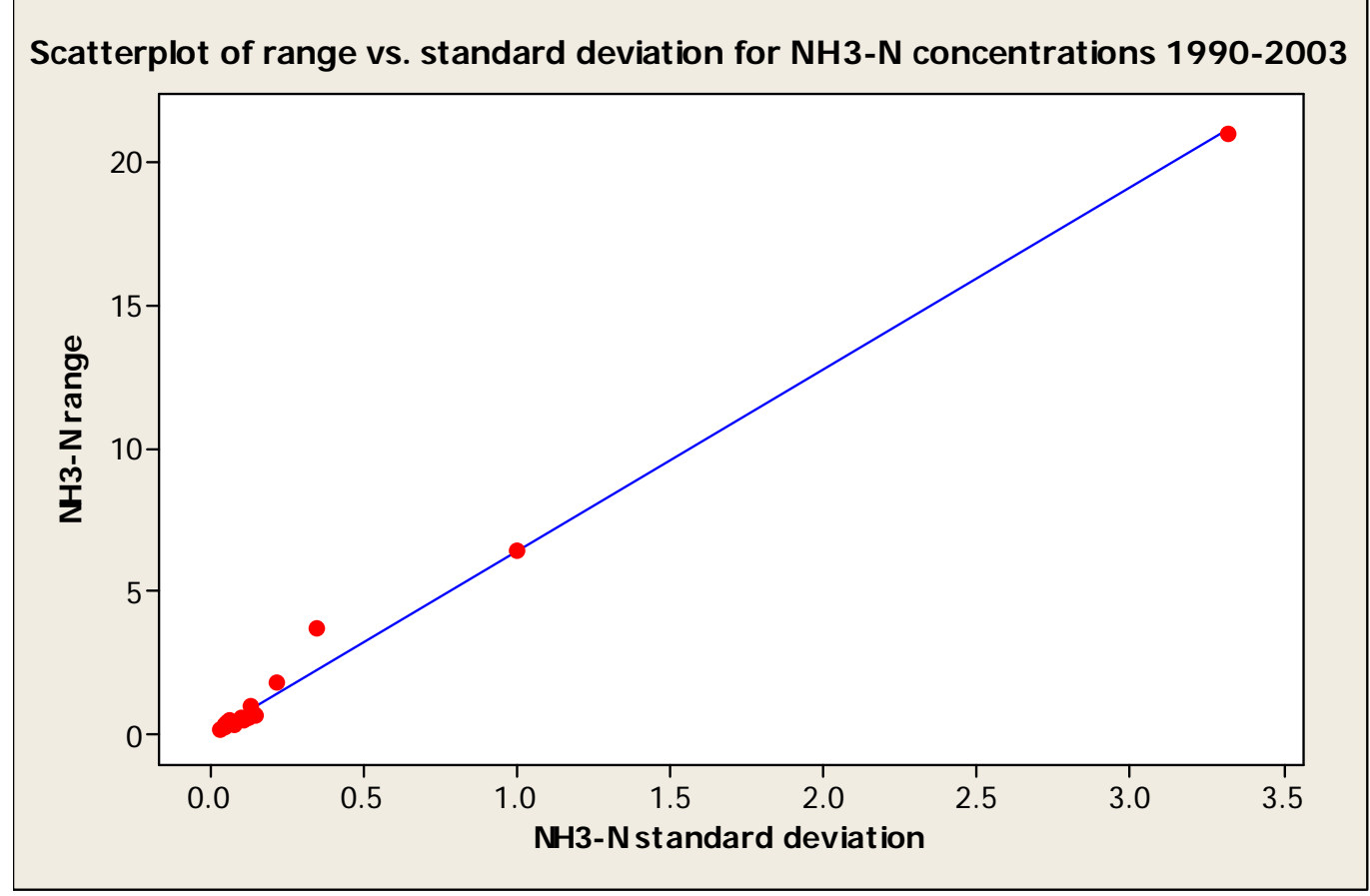

Figure 6: Scatterplot of range vs. standard deviation NH3-N concentrations 1990-2003

Table 11 demonstrates that in the period of 2009-2014, NH3-N concentrations at every station exceeded the $0.01 \mathrm{mg} / \mathrm{L}$ threshold for Biscayne National Park. Utilizing the Biscayne Bay threshold of $0.05 \mathrm{mg} / \mathrm{L}$ for NH3-N, stations CD02, CD05, MW04, and PR03 are the only stations with means below the threshold. The station with the highest mean was once again GL02 in the Gould Canal $(0.7603 \mathrm{mg} / \mathrm{L})$. The geometric mean was greater than the median for each station in this time period. However, Table 12 shows that the Shapiro-Wilk test for normally distributed concentrations at a 0.01 level of significance could not be rejected for four stations (BL12, GL02, MW01, and SP04). In addition, stations GL03, MI03, MW01, MW04, SP01, and SP04 have mean concentrations higher in this time period compared to 1990-2003. The scatterplot of range values versus standard deviations for NH3-N from 2009-2014 in Figure 7 shows a positive/increasing linear relationship between the two variables. The range values 
increase by 4.6130 as the standard deviation increases by one unit. As was the case with the scatterplot with NH3-N concentrations from 1990-2003, one station displays a standard deviation and range very different from the rest of the stations. However, in this case, it was station GL03 in the Goulds Canal with the highest standard deviation and range. This station also had the second highest NH3-N mean concentration $(0.634 \mathrm{mg} / \mathrm{L})$ for the time period. This station is also found nearby the South Dade Landfill. 
Table 11: Summary statistics for NH3-N concentrations 2009-2014

\begin{tabular}{cccccc}
\hline Station & Canal & mean & median & range & standard deviation \\
\hline BL01 & Black Creek (C1) & 0.1261 & 0.1 & 0.6 & 0.0923 \\
BL02 & Black Creek (C1) & 0.1235 & 0.105 & 0.488 & 0.088 \\
BL03 & Black Creek (C1) & 0.0602 & 0.04 & 0.18 & 0.0512 \\
BL12 & Black Creek (C1) & 0.253 & 0.24 & 0.44 & 0.115 \\
CD02 & Cutler Drain & 0.0346 & 0.03 & 0.08 & 0.0219 \\
CD05 & Cutler Drain & 0.0234 & 0.02 & 0.06 & 0.0126 \\
GL02 & Goulds & 0.7603 & 0.72 & 1.85 & 0.4455 \\
GL03 & Goulds & 0.634 & 0.433 & 3.4 & 0.7137 \\
MI03 & Military & 0.1015 & 0.08 & 0.33 & 0.0679 \\
MW01 & Mowry (C103) & 0.0733 & 0.07 & 0.12 & 0.0329 \\
MW04 & Mowry (C103) & 0.0282 & 0.025 & 0.07 & 0.0159 \\
PR01 & Princeton (C102) & 0.1205 & 0.11 & 0.38 & 0.0716 \\
PR03 & Princeton (C102) & 0.0338 & 0.03 & 0.11 & 0.0295 \\
SP01 & Snapper Creek (C2) & 0.0921 & 0.08 & 0.22 & 0.042 \\
SP04 & Snapper Creek (C2) & 0.1154 & 0.11 & 0.24 & 0.0674 \\
\hline & & & & & \\
\hline
\end{tabular}


Table 12: Shapiro-Wilk test for normality for NH3 concentrations 2009-2014

\begin{tabular}{cccc}
\hline Station & Canal & Shapiro-Wilk Test statistic W & p-value \\
\hline BL01 & Black Creek (C1) & 0.6545 & $8.26 \mathrm{E}-11$ \\
BL02 & Black Creek (C1) & 0.7857 & $4.19 \mathrm{E}-08$ \\
BL03 & Black Creek (C1) & 0.8683 & $5.34 \mathrm{E}-06$ \\
BL12 & Black Creek (C1) & 0.9711 & $1.44 \mathrm{E}-01$ \\
CD02 & Cutler Drain & 0.8654 & $1.63 \mathrm{E}-05$ \\
CD05 & Cutler Drain & 0.8168 & $3.86 \mathrm{E}-06$ \\
GL02 & Goulds & 0.9543 & $2.33 \mathrm{E}-02$ \\
GL03 & Goulds & 0.792 & $5.42 \mathrm{E}-09$ \\
MI03 & Military & 0.8036 & $1.79 \mathrm{E}-09$ \\
MW01 & Mowry (C103) & 0.9531 & $1.31 \mathrm{E}-02$ \\
MW04 & Mowry (C103) & 0.8346 & $1.81 \mathrm{E}-05$ \\
PR01 & Princeton (C102) & 0.8997 & $1.13 \mathrm{E}-04$ \\
PR03 & Princeton (C102) & 0.7577 & $2.05 \mathrm{E}-06$ \\
SP01 & Snapper Creek (C2) & 0.9042 & $1.47 \mathrm{E}-04$ \\
SP04 & Snapper Creek (C2) & 0.9496 & $1.88 \mathrm{E}-02$ \\
\hline
\end{tabular}




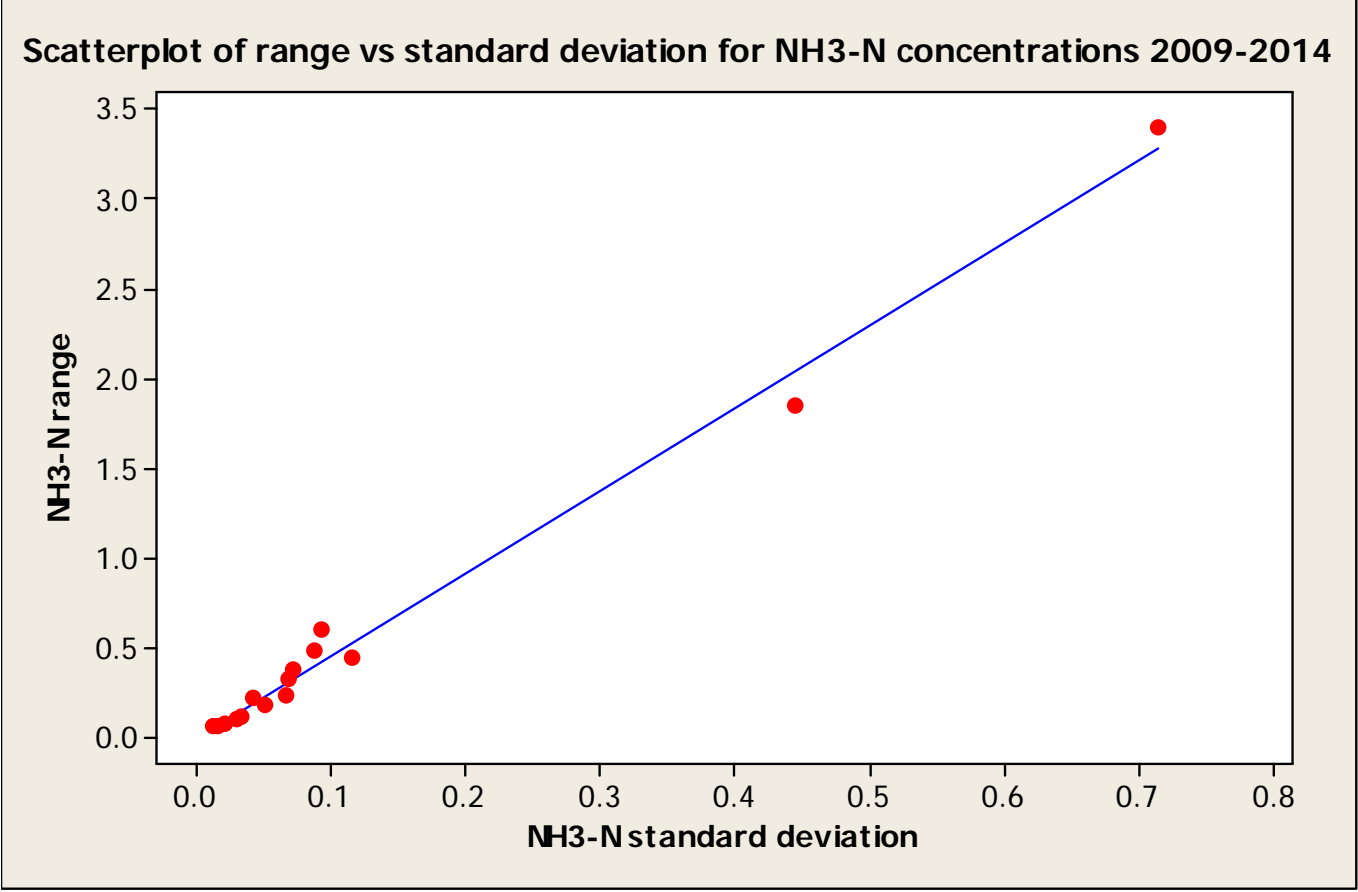

Figure 7: Scatterplot of range vs. standard deviation NH3-N concentrations 2009-2014

\section{Objective 2}

The Kruskal-Wallis nonparametric statistical test was performed on the 18 previously described water quality stations for the years of 1990 through 2003 to determine if the distributions of TP, NOx-N, and NH3-N concentrations differed among the stations. The Kruskal-Wallis test was also carried out for the same 15 water quality stations analyzed in Objective 1 for the time period of 2009 through 2014. However, as explained in the results for Objective 1, this was only performed for 14 of the 18 stations used in the 1990-2013 period.

The iterations of the Kruskal-Wallis test were performed using the kruskal.test() function with RStudio. For the time period of 1990-2003, the null hypothesis (Ho: Median concentrations are equal for all of the water quality stations) was rejected for TP, NOx-N, and NH3-N concentrations at a level of significance of 0.05. In fact, the null 
hypothesis could be rejected for each of the water quality constituents at a much lower level of significance considering how small the p-values were for each test. The results are provided in Table 13.

Table 13: Kruskal-Wallis test results for stations' nutrient concentrations (1990-2003)

\begin{tabular}{cccc}
\hline Time period & Nutrient constituent & Kruskal-Wallis test statistic & p-value \\
\hline \multirow{2}{*}{$1990-2003$} & TP & 410.4448 & $<2.2 \mathrm{e}-16$ \\
& NOx-N & 1255.765 & $<2.2 \mathrm{e}-16$ \\
& NH3-N & 1229.176 & $<2.2 \mathrm{e}-16$ \\
\hline
\end{tabular}

Since the null hypothesis could be rejected for each nutrient concentration, the post-hoc analysis involving pairwise comparisons was performed to determine what pairs of water quality stations differ. This post-hoc analysis was performed on RStudio using the posthoc.kruskal.nemenyi.test() function which essentially calculates a level of significance corresponding to the estimated chi-square statistic shown in Equation 8 presented in Chapter 3 for Objective 2 (Pohlert 2014). A level of significance of 0.05 was chosen as the determinant of differences between water quality stations. Therefore, if a pairwise comparison between two stations resulted in a p-value below 0.05 , then it was determined that the two stations differed significantly.

The pairwise comparisons for TP concentrations in the period 1990-2003 show that station GL02 on the Goulds Canal differed significantly from 14 other stations. Station GL03 on the Goulds Canal differed significantly from 7 other stations while station PR03 in the Princeton Canal differed significantly from 6 other stations. Station CD09 on the Cutler Drain Canal differed significantly from 5 other stations and so did station MI03 in the Military Canal and station MW04 in the Mowry Canal. The rest of the pairwise comparison results and complete summary are provided in Table 14. In 
addition, Figure 8 provides a box-plot graph of TP concentrations for each water quality station for the time period was constructed to provide a graphical representation of each water quality stations’ distribution.

Table 14: Pairwise comparison for TP concentrations among stations (1990-2003)

\begin{tabular}{|c|c|c|c|c|c|c|c|c|c|c|c|c|c|c|c|c|c|}
\hline & BL01 & BL02 & BLO3 & BL12 & CD02 & CD09 & GLO2 & GL03 & MI03 & MW01 & 1 MW04 & MW13 & PR01 & PR03 & PR0\& & SP01 & SP04 \\
\hline BL01 & & - & - & - & - & - & - & - & - & - & -1 & & - & & & - & \\
\hline $\mathrm{BLO2}$ & & - & - & - & - & - & - & - & - & - & - & - & - & - & - & - & - \\
\hline BLO3 & & & - & - & - & - & - & $1-$ & $1-$ & $1-$ & - & - & $1-$ & - & - & - & - \\
\hline BL12 & & & & - & - & - & - & $1-$ & $1-$ & - & - & - & - & - & - & - & - \\
\hline CD02 & & & & & - & - & - & - & - & - & - & - & - & - & - & - & - \\
\hline CD099 & & & & & & - & - & - & - & - & - & - & - & - & - & - & - \\
\hline GL02 & & & & & & & - & - & - & - & - & - & - & - & - & - & - \\
\hline GLO3 & & & & & & & & - & - & - & - & - & - & - & - & - & - \\
\hline MI03 & & & & & & & & & - & - & - & - & - & - & - & - & - \\
\hline MW01 & & & & & & & & & & - & - & - & - & - & - & - & - \\
\hline MW04 & & & & & & & & & & & - & - & - & - & - & - & - \\
\hline MW13 & & & & & & & & & & & & - & - & - & - & - & - \\
\hline \begin{tabular}{|l|} 
PR01 \\
\end{tabular} & & & & & & & & & & & & & - & - & - & - & - \\
\hline PR03 & & & & & & & & & & & & & & - & - & - & - \\
\hline PR08 & & & & & & & & & & & & & & & - & - & - \\
\hline SP01 & & & & & & & & & & & & & & & & - & - \\
\hline SPO4 & & & & & & & & & & & & & & & & & - \\
\hline SP08 & & & & & & & & & & & & & & & & & \\
\hline 00 & & & & & & & & $.05)$ & & & & & sian & ficantl & $\mathrm{v}(\mathrm{p}$ & lue & 0.05 \\
\hline
\end{tabular}

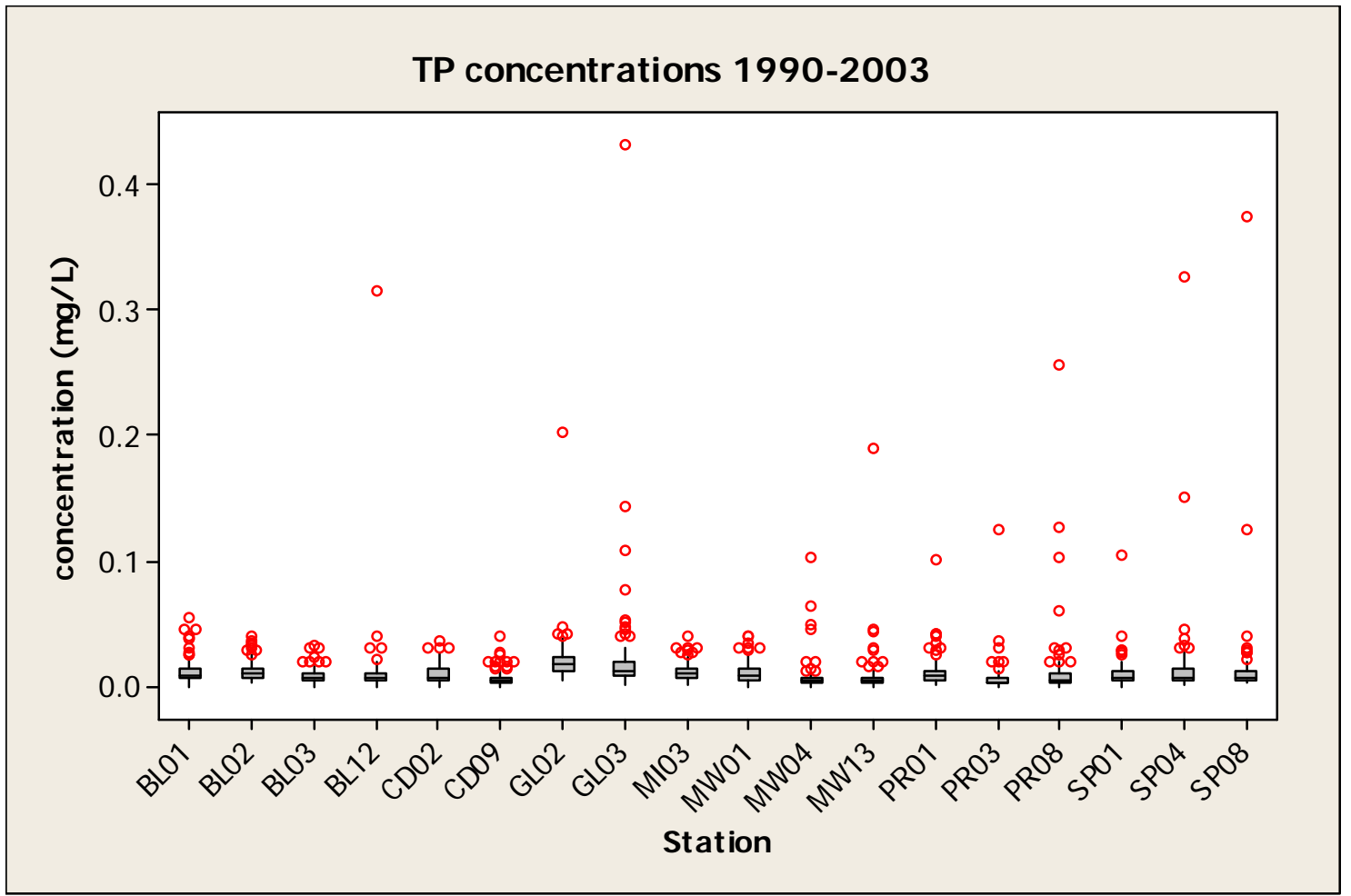

Figure 8: Box-plots of TP concentrations for water quality stations (1990-2003) 
The pairwise comparisons for NOx-N concentrations in the period 1990-2003 demonstrates that station PR03 on the Princeton Canal differed significantly from 15 other water quality stations. Station PR01, also on the Princeton Canal, differed significantly from 13 other stations. Station BL12 on the Black Creek Canal, station GL03 on the Goulds Canal, and station MW04 on the Mowry Canal, all differed significantly from 13 other stations. The rest of the pairwise comparison results and complete summary are provided in Table 15. The box-plots for NOx-N concentrations for this time period illustrate very well how different the distributions of the aforementioned stations are from the rest of the data (see Figure 9).

Table 15: Pairwise comparison for NOx-N concentrations among stations (1990-2003)

\begin{tabular}{|c|c|c|c|c|c|c|c|c|c|c|c|c|c|c|c|c|c|}
\hline & BL01 & BL02 & BL03 & BL12 & CD02 & CD09 & GL02 & GL03 & MI03 & MW01 & MW04 & MW13 & PR01 & \begin{tabular}{|l|} 
PR03 \\
\end{tabular} & PR08 & SP01 & SP04 \\
\hline BL01 & - & - & $\mid-$ & 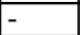 & \begin{tabular}{|l|}
- \\
\end{tabular} & $\mid-$ & $\mid-$ & - & - & - & - & - & - & - & - & - & - \\
\hline BL02 & & - & - & - & - & - & - & - & - & - & - & - & - & - & - & - & - \\
\hline BL03 & & & - & - & - & - & - & - & - & - & - & - & - & - & - & - & - \\
\hline BL12 & & & & - & - & - & - & - & - & - & - & - & - & - & - & - & - \\
\hline CD02 & & & & & - & - & - & - & - & - & - & - & - & - & - & - & - \\
\hline CD09 & & & & & & - & - & - & - & - & - & - & - & - & - & - & - \\
\hline GL02 & & & & & & & - & - & - & - & - & - & - & - & - & - & - \\
\hline GL03 & & & & & & & & - & - & - & - & - & - & - & - & - & - \\
\hline MI03 & & & & & & & & & - & - & - & - & - & - & - & - & - \\
\hline MW01 & & & & & & & & & & $\begin{array}{l}- \\
-\end{array}$ & - & - & - & - & - & - & - \\
\hline MW04 & & & & & & & & & & & - & - & - & - & - & - & - \\
\hline MW13 & & & & & & & & & & & & - & - & - & - & - & - \\
\hline PR01 & & & & & & & & & & & & & - & - & - & - & - \\
\hline PR03 & & & & & & & & & & & & & & - & - & - & - \\
\hline PR08 & & & & & & & & & & & & & & & - & - & - \\
\hline SP01 & & & & & & & & & & & & & & & & - & - \\
\hline SP04 & & & & & & & & & & & & & & & & & - \\
\hline SP08 & & & & & & & & & & & & & & & & & \\
\hline Green & $=$ stat & ions d & o not & differ & 70 & ntl & $(p-y$ & $e>0$ & & Red $=$ & stati & רs dif & rsign & fican & $(p-1$ & lue $<$ & $0.05)$ \\
\hline
\end{tabular}




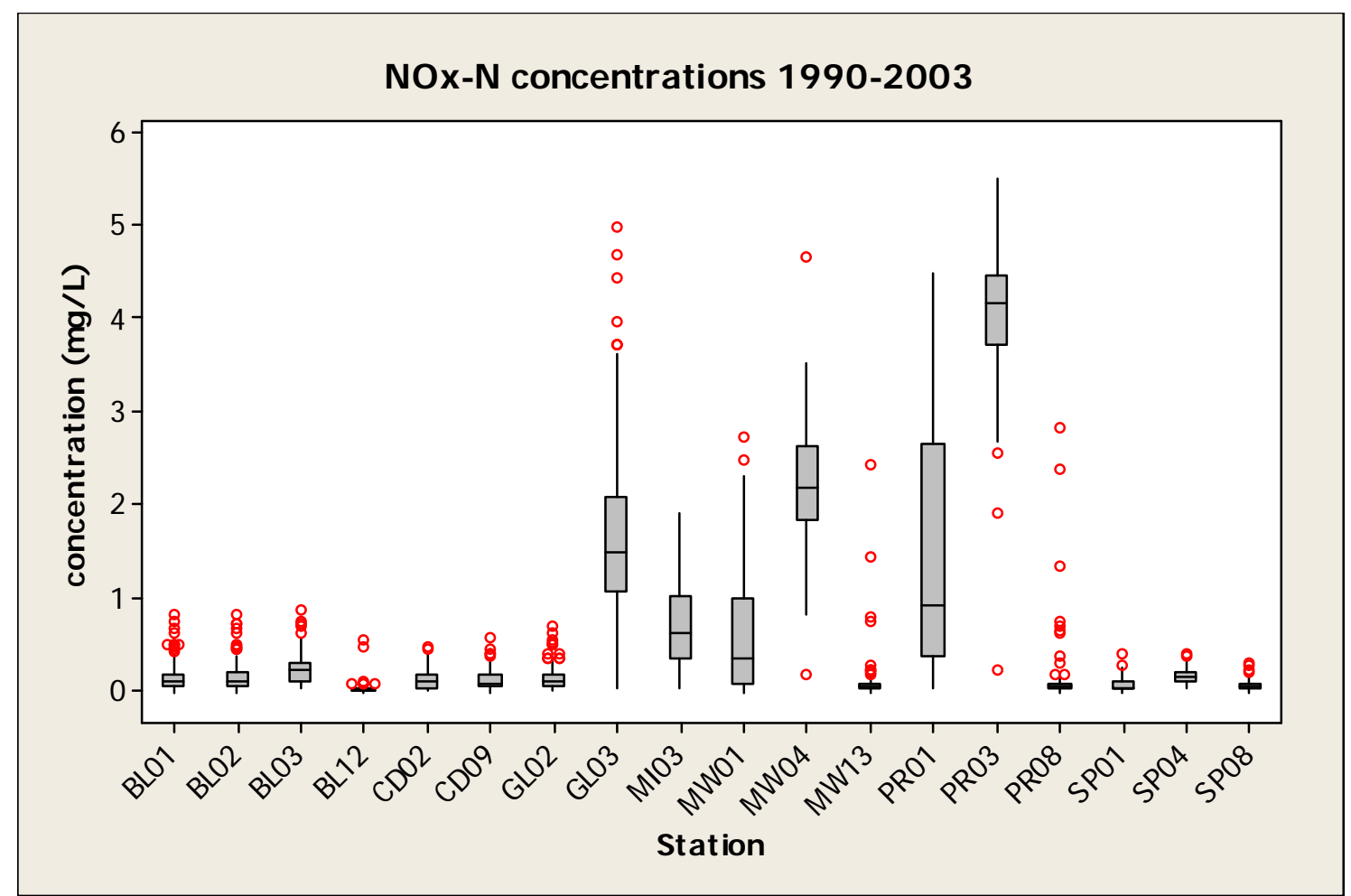

Figure 9: Box-plots of NOx-N concentrations for water quality stations (1990-2003)

For NH3-N concentrations in the period of 1990-2003, the pairwise comparisons show that station GL02, on the Goulds Canal, differed significantly from 15 other water quality stations. Station BL12 on the Black Creek Canal and station SP08 on the Snapper Creek Canal both differed significantly from 11 other stations. Also, stations BL01 and BL02, located in close proximity the South Dade Landfill, on the Black Creek Canal, both differed significantly from 10 other stations. The rest of the pairwise comparison results are provided in Table 16. The box-plots for 1990-2003 NH3-N concentrations depict very well how different the distributions of these stations are from the other water quality stations (see Figure 10). 
Table 16: Pairwise comparisons for NH3-N concentrations among stations (1990-2003)

\begin{tabular}{|c|c|c|c|c|c|c|c|c|c|c|c|c|c|c|c|c|c|}
\hline & BL01 & BL02 & BL03 & BL12 & CD02 & CD09 & GL02 & GL03 & MI03 & MW01 & MW04 & MW13 & \begin{tabular}{|l|} 
PR01 \\
\end{tabular} & \begin{tabular}{|l|} 
PR03 \\
\end{tabular} & \begin{tabular}{|l|} 
PR08 \\
\end{tabular} & \begin{tabular}{|l|} 
SP01 \\
\end{tabular} & SP04 \\
\hline BL01 & - & - & - & - & - & - & - & $\mid-$ & - & - & - & - & \begin{tabular}{|l|}
- \\
\end{tabular} & - & $\mid-$ & 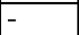 & - \\
\hline BL02 & & $\begin{array}{lll}- & - \\
\end{array}$ & - & - & - & - & - & - & - & - & - & - & - & - & - & - & - \\
\hline BL03 & & & - & - & - & - & - & - & $\begin{array}{lll}- & -1\end{array}$ & - & - & - & {$\left[\begin{array}{lll}- & \\
\end{array}\right.$} & - & - & - & - \\
\hline BL12 & & & & $\begin{array}{lll}- & \\
\end{array}$ & - & - & - & - & $\begin{array}{lll}- & \\
\end{array}$ & - & - & - & - & - & - & - & - \\
\hline CD02 & & & & & - & - & - & - & - & - & - & - & - & - & - & - & - \\
\hline CD09 & & & & & & E & - & - & - & - & - & - & - & - & - & - & - \\
\hline GL02 & & & & & & & - & - & - & - & - & - & - & - & - & - & - \\
\hline GL03 & & & & & & & & - & - & - & - & - & - & - & - & - & - \\
\hline MI03 & & & & & & & & & $\begin{array}{lll}- & -1\end{array}$ & - & - & - & - & - & - & - & - \\
\hline MW01 & & & & & & & & & & - & - & - & E & - & - & - & - \\
\hline MW04 & & & & & & & & & & & - & - & - & - & - & - & - \\
\hline MW13 & & & & & & & & & & & & - & - & - & - & - & - \\
\hline \begin{tabular}{|l|} 
PR01 \\
\end{tabular} & & & & & & & & & & & & & - & $\begin{array}{lll}- & \\
\end{array}$ & - & - & - \\
\hline PR03 & & & & & & & & & & & & & & $\begin{array}{lll}- & - \\
\end{array}$ & - & - & - \\
\hline $\begin{array}{l}\text { PR08 } \\
\end{array}$ & & & & & & & & & & & & & & & - & - & - \\
\hline SP01 & & & & & & & & & & & & & & & & - & - \\
\hline SP04 & & & & & & & & & & & & & & & & & - \\
\hline SP08 & & & & & & & & & & & & & & & & & \\
\hline
\end{tabular}

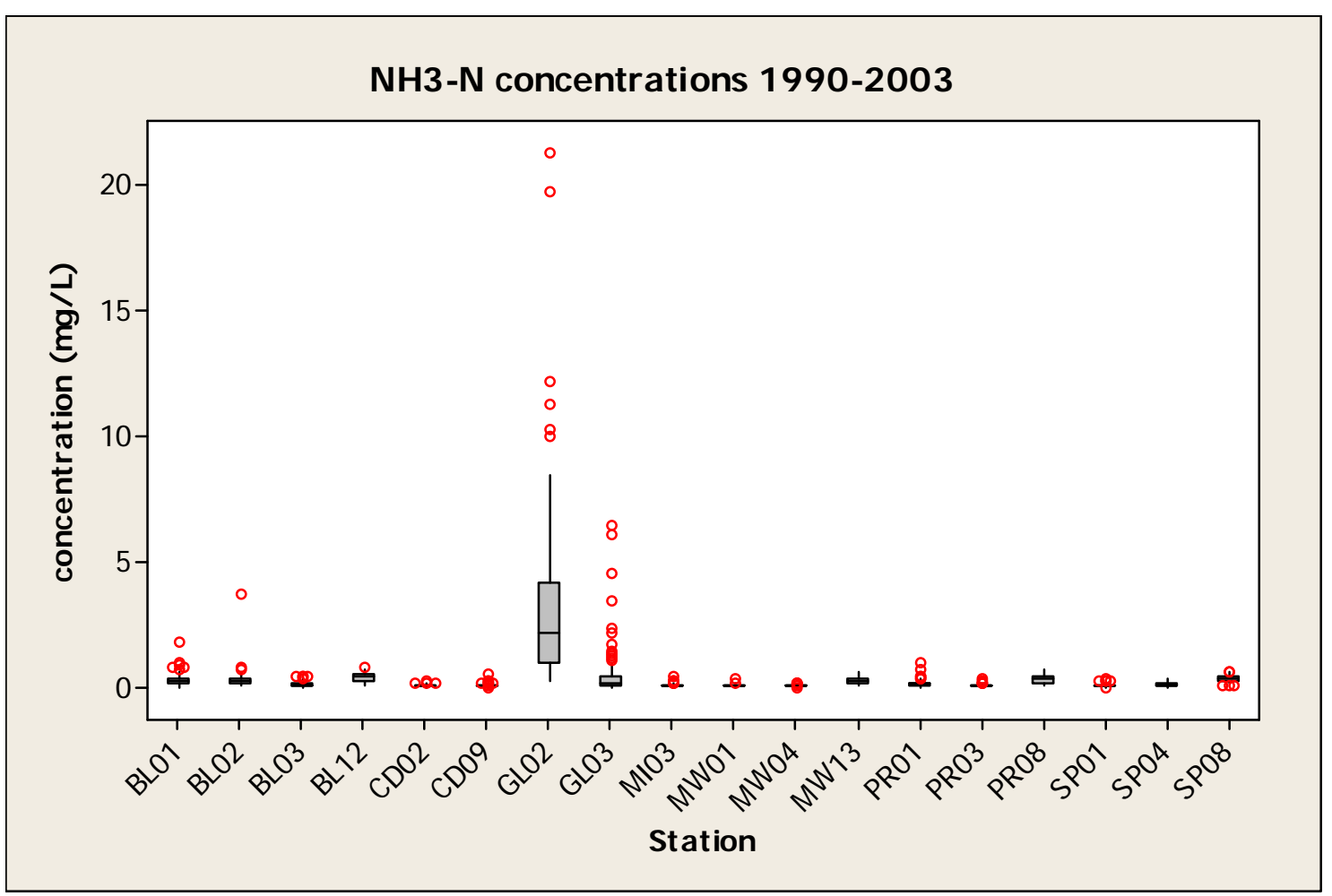

Figure 10: Box-plots of NH3-N concentrations for water quality stations (1990-2003)

For the time period of 2009-2014, the null hypothesis (Ho: Median concentrations are equal for all of the water quality stations) was also rejected for TP, NOx-N, and NH3$\mathrm{N}$ concentrations at a level of significance of 0.05. As was the case in the 1990-2003 time 
period, the null hypothesis could be rejected for each of the water quality constituents at a much lower level of significance. The results are can be found in Table 17.

Table 17: Kruskal-Wallis test results for stations' nutrient concentrations (2009-2014)

\begin{tabular}{cccc}
\hline Time period & Nutrient constituent & Kruskal-Wallis test statistic & $\mathrm{p}$-value \\
\hline \multirow{2}{*}{$2009-2014$} & TP & 281.1348 & $<2.2 \mathrm{e}-16$ \\
& NOx-N & 594.9263 & $<2.2 \mathrm{e}-16$ \\
& NH3-N & 511.4893 & $<2.2 \mathrm{e}-16$ \\
\hline
\end{tabular}

Once again, the null hypothesis could be rejected for each nutrient concentration and the post-hoc analysis involving pairwise comparisons was performed to determine what pairs of water quality stations differ using a level of significance of 0.05 . For TP concentrations in this time period, the pairwise comparisons showed that station MW04, on the Mowry Canal, differed significantly from 12 out of the 14 other stations. Station GL02, on the Goulds Canal, differed significantly from 10 other stations while station PR03, on the Princeton Canal, differed significantly from 7 other stations. Table 18 presents the results of all the pairwise comparisons. The box-plots of TP concentrations for the 15 stations in the 2009-2014 time period are found in Figure 11.

Table 18: Pairwise comparisons for TP concentrations among stations (2009-2014)

\begin{tabular}{|c|c|c|c|c|c|c|c|c|c|c|c|c|c|c|}
\hline & BL01 & BL02 & BL03 & BL12 & CD02 & CD05 & GLO2 & GL03 & MIO3 & MW01 & MW04 & PR01 & PR03 & SP01 \\
\hline BL01 & -8 & -8 & -8 & & - & -8 & - & -9 & -5 & & - & & & \\
\hline $\mathrm{BLO2}$ & & - & - & - & - & - & - & - & - & & - & - & - & \\
\hline BLO3 & & & - & - & - & - & - & - & - & - & - & |- & |- & - \\
\hline BL12 & & & & - & - & - & - & - & - & - & - & [- & - & \\
\hline CD02 & & & & & - & - & - & - & - & - & - & - & 1- & - \\
\hline CD05 & & & & & & - & - & - & - & - & - & |- & 1- & - \\
\hline GL02 & & & & & & & & - & - & - & - & - & - & - \\
\hline GL03 & & & & & & & & - & - & - & |- & |- & - & - \\
\hline MI03 & & & & & & & & & - & & |- & |- & - & \\
\hline MW01 & & & & & & & & & & - & - & - & 1- & - \\
\hline MW04 & & & & & & & & & & & - & - & - & \\
\hline PR01 & & & & & & & & & & & & - & - & \\
\hline PR03 & & & & & & & & & & & & & - & \\
\hline SP01 & & & & & & & & & & & & & & \\
\hline SP04 & & & & & & & & & & & & & & \\
\hline $\begin{array}{l}\text { Green } \\
\text { Bed }\end{array}$ & stat & ss d & ot d & ers & ificat & tly (p & value & $0.05)$ & & & & & & \\
\hline
\end{tabular}




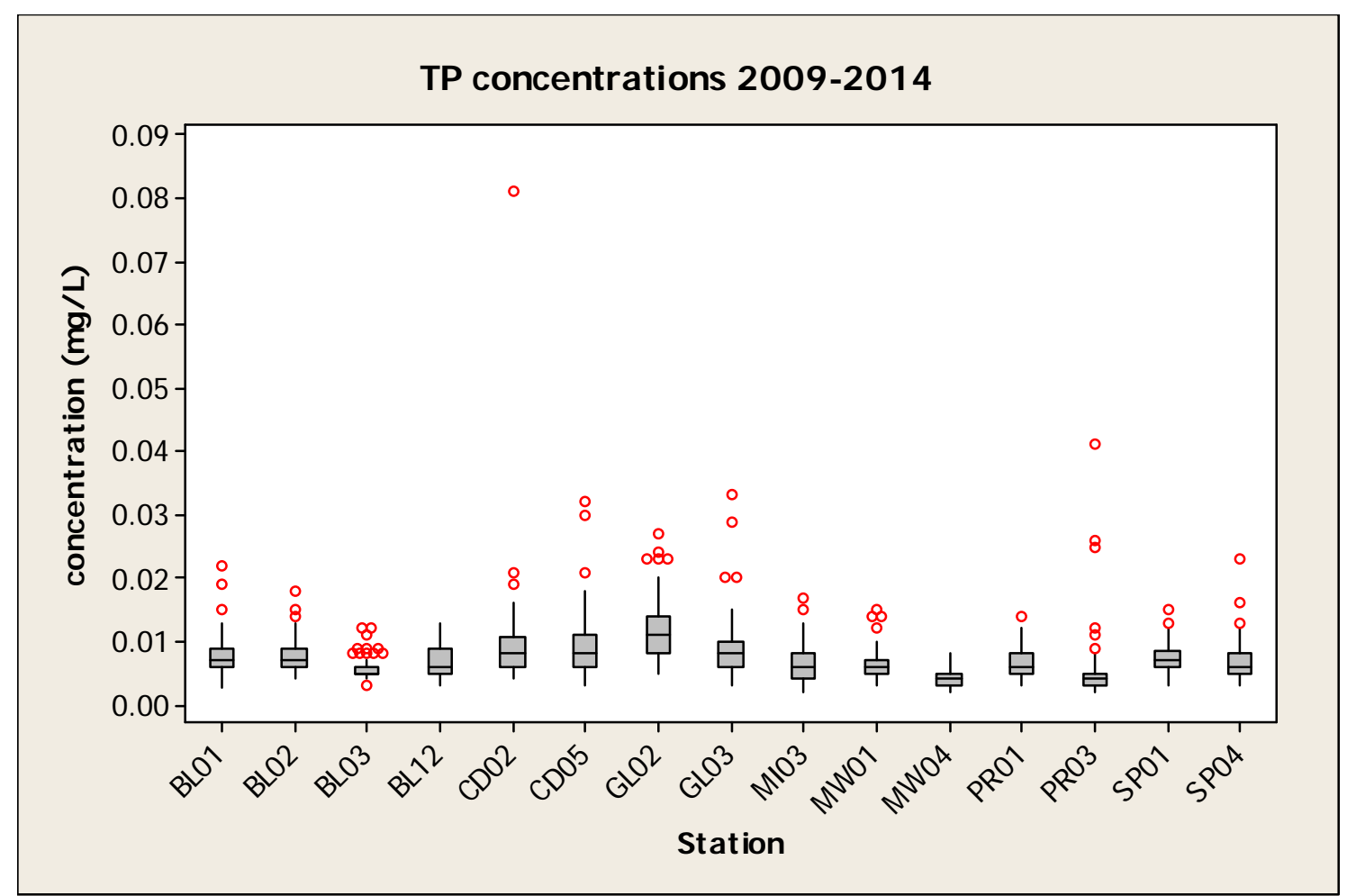

Figure 11: Box-plots of TP concentrations for water quality stations (2009-2014)

In the case of NOx-N concentrations for this time period, the pairwise comparisons demonstrate that station MW04, on the Mowry Canal, and station PR03, on the Princeton Canal, both differed significantly from 11 other stations. Also, station BL12, on the Black Creek Canal, and station MI03, on the Military Canal, differed significantly from 9 other stations. A complete summary of the rest of the pairwise results is provided in Table 19 and the box-plots for NOx-N concentrations for each station can be found in Figure 12 to help illustrate the evident differences in the distributions among the water quality stations. 
Table 19: Pairwise comparisons for NOx-N concentrations among stations (2009-2014)

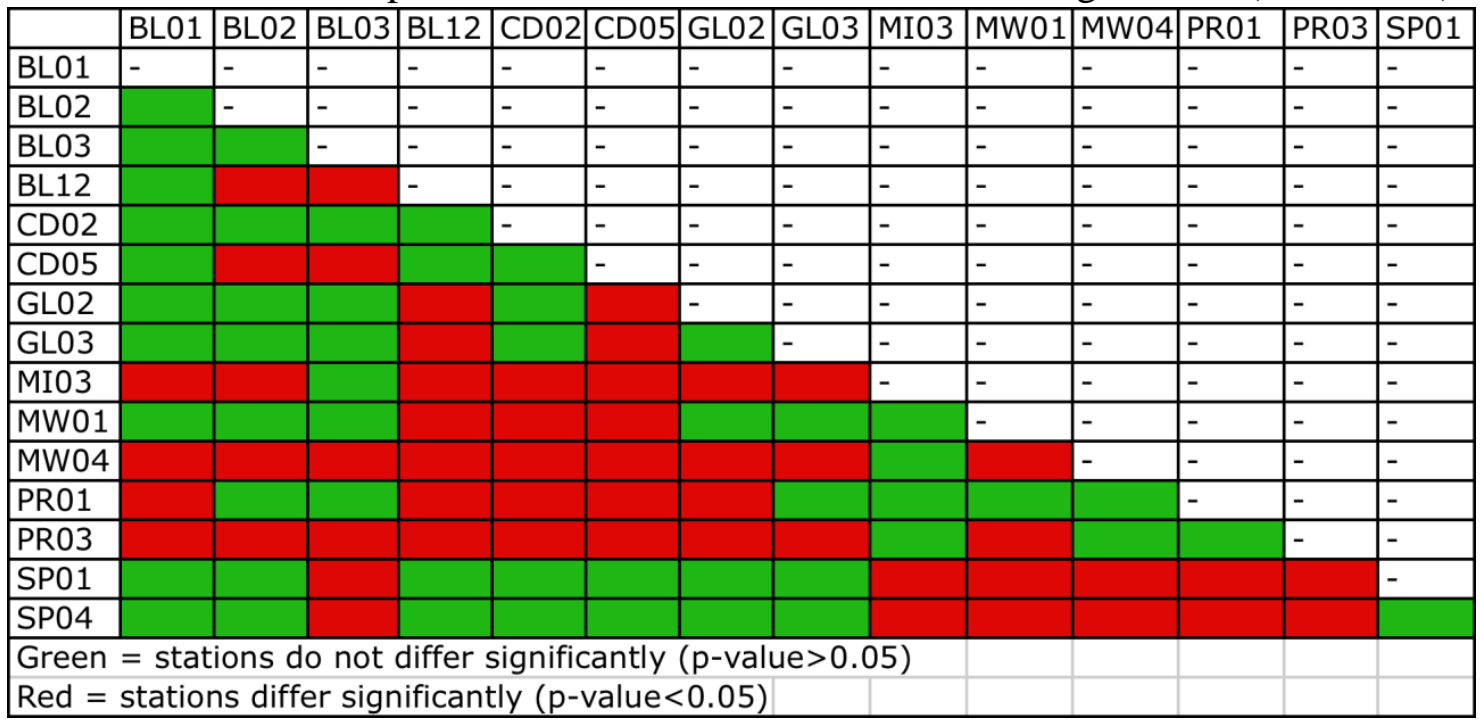

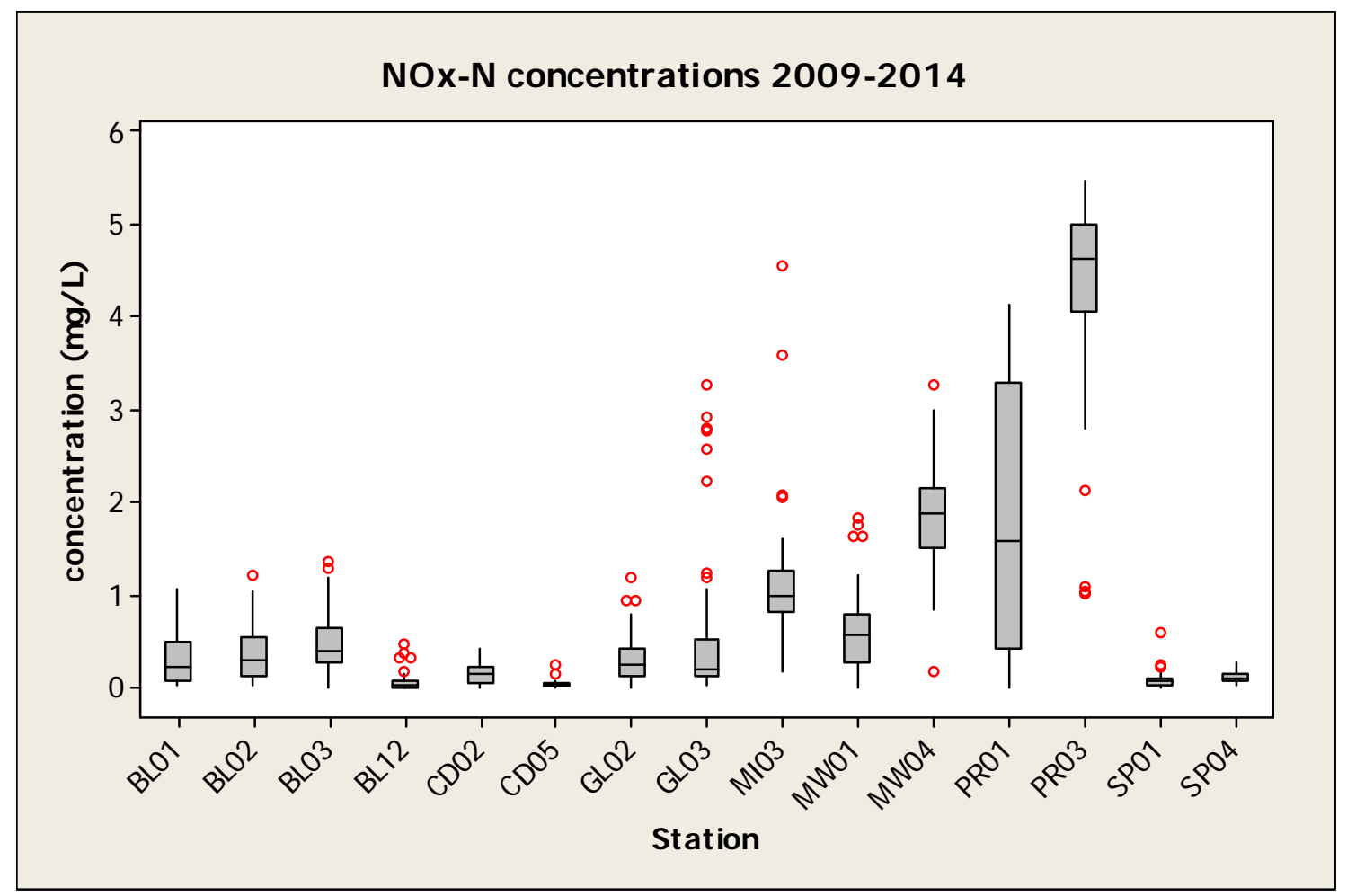

Figure 12: Box-plots of NOx-N concentrations for water quality stations (2009-2014)

Lastly, the NH3-N pairwise comparisons for 2009-2014 determined that the most distinguishable water quality stations were station GL02, on the Goulds Canal, and station CD05, on the Cutler Drain Canal. Station GL02 differed significantly from 12 
other stations while station CD05 differed significantly from 10 other stations. In addition, stations CD02 on the Cutler Drain Canal and station PR03 on the Princeton Canal both differed significantly from 9 other stations. Table 20 provides the complete results for all of the pairwise comparisons among the stations regarding NH3-N concentrations for 2009-2014. The box-plots for the 15 water quality stations regarding NH3-N concentrations for this time period are provided in Figure 13.

Table 20: Pairwise comparisons for NH3-N concentrations among stations (2009-2014)

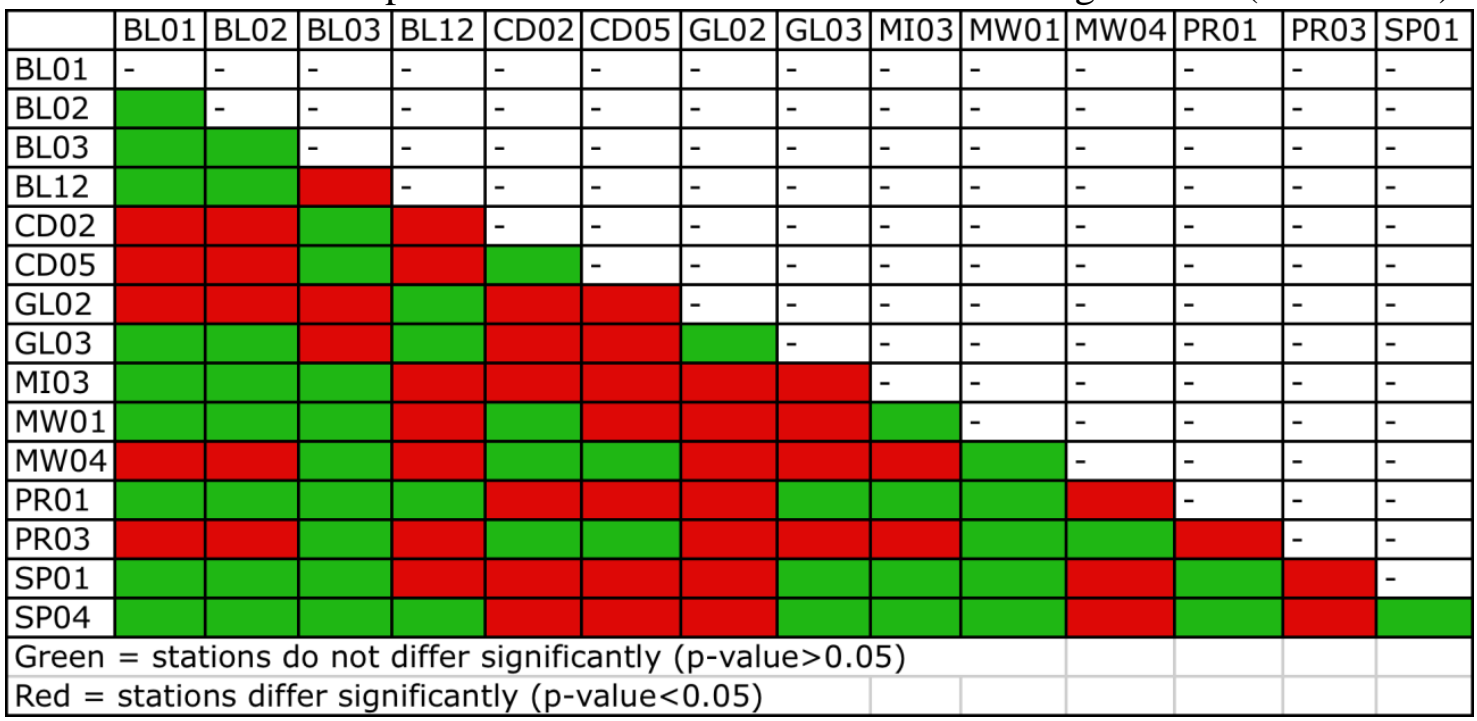




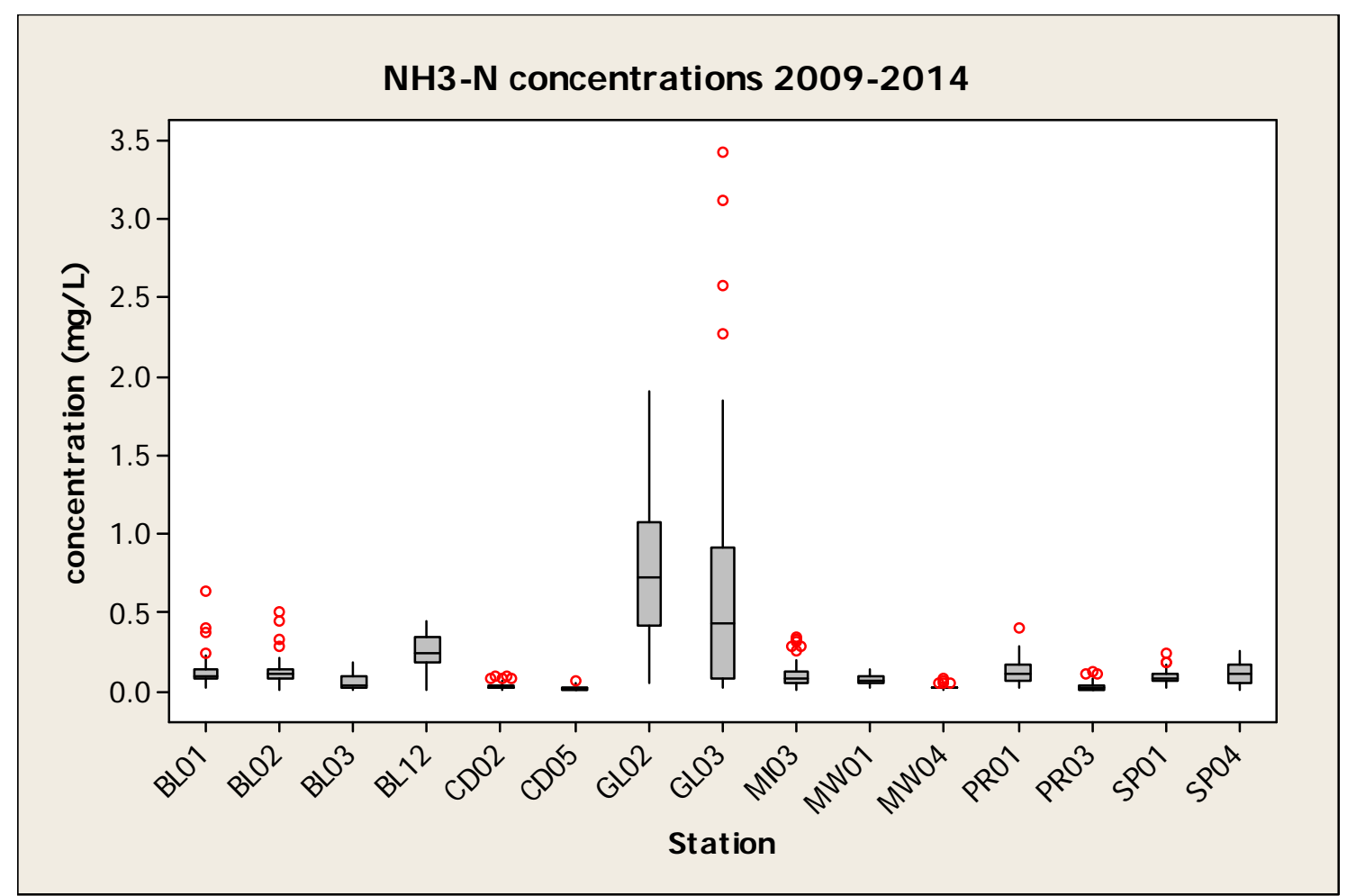

Figure 13: Box-plots of NH3-N concentrations for water quality stations (2009-2014)

\section{Objective 3}

The ArcMap geoprocessing procedures outlined in the methodologies for this objective were successfully completed for the Miami Dade County land use geospatial datasets for 1994 and 2013. Figures 14, 15, and 16 have been provided to display the land use for the area of interest in 1994 and 2013. Both geospatial datasets were clipped to the SFWMD AHED watershed feature class, 1000 meter canal buffers, and 500 meter water quality station buffers. For the watershed feature class, it was shown that the water quality stations were spread across 11 distinct watersheds (Figure 17). In ArcMap, land use summaries for both 1994 and 2013 were calculated for each watershed to determine their percent makeup of distinct land use categories defined by the Miami Dade County Department of Planning and Zoning Land Use Numeric Classification. These results were 


\section{Land Use in Southern Miami Dade County (1994)}

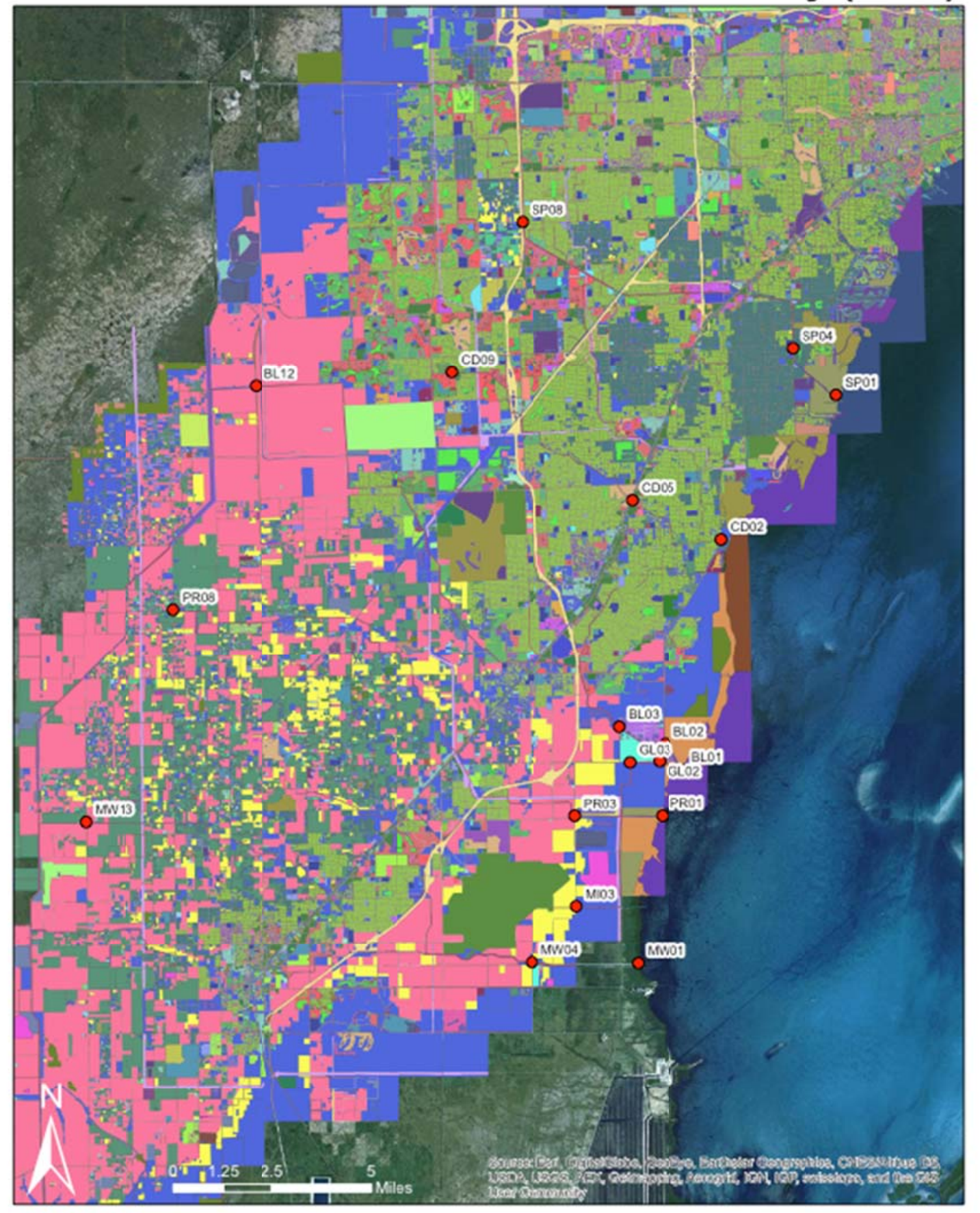

Figure 14: Map of land use classifications in Southern Miami Dade County for 1994 


\section{Land Use in Southern Miami Dade County (2013)}

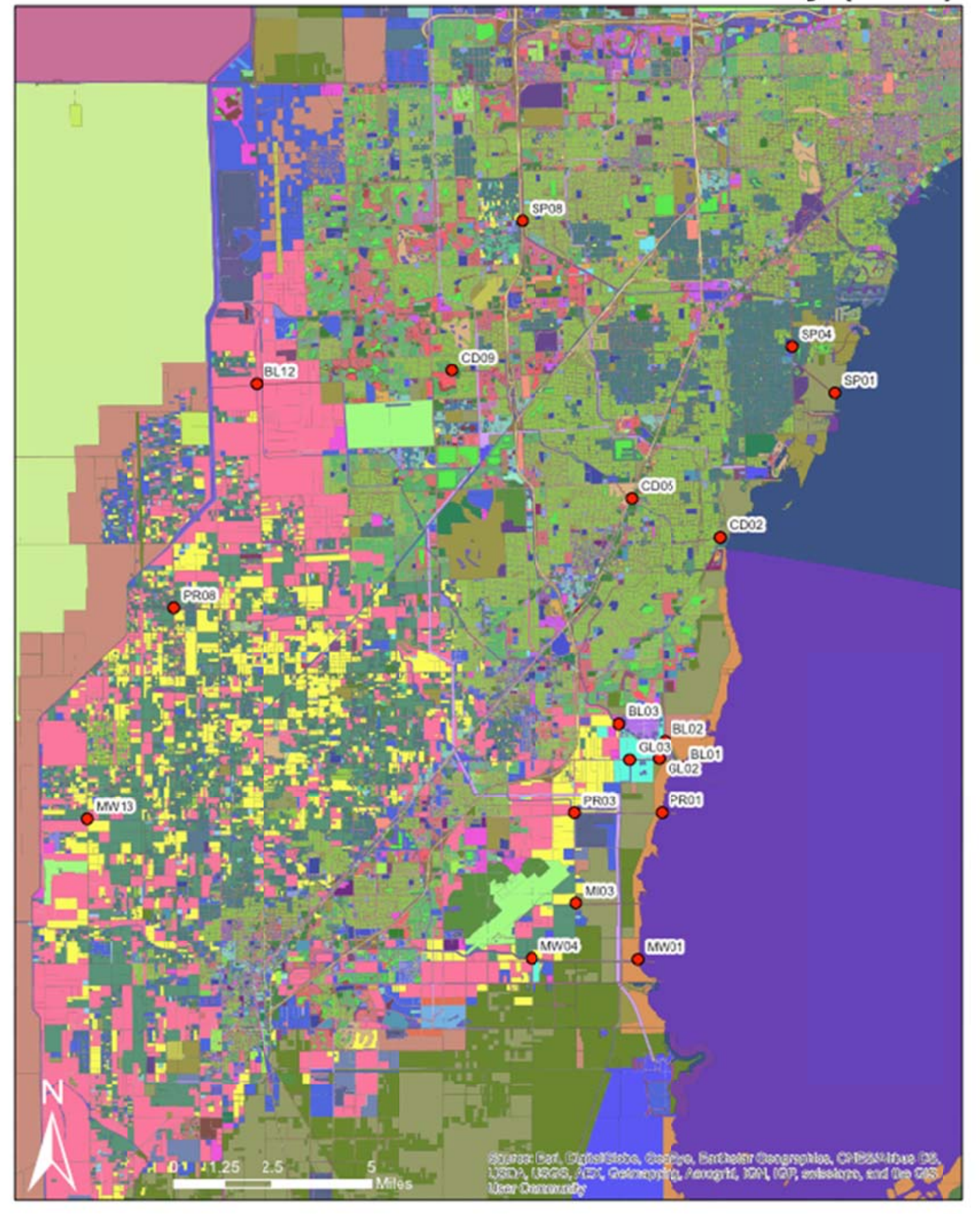

Figure 15: Map of land use classifications in Southern Miami Dade County for 2013 


\begin{tabular}{|c|c|c|c|}
\hline \multicolumn{4}{|l|}{ Legend } \\
\hline 0 Water Quality Stations & Golf courses, Public and Private. & Office Building. & Road Maintenance and Storage Yards, and Motor Pools. \\
\hline MDC Land Use & Governmental/Public Administrtation (Other than Military or Penal). & Office and/or Business and other services (ground level) & Row and Field Cropland. \\
\hline Descriptions & Groves. & Office/Business/Hotel/Residential & Sales and Services \\
\hline Agriculture, Other (Exotic Birds, Monkeys, Research Facilities). & Highways and Expressways right-of-way and associated open and landscaped areas & Oil and Gas Storage (Tank Farms). & Sewerage Treatment Plants. \\
\hline Airports (other than Military and Small Grass Airports). & Horse Training and Stables. & Other Nature Preserves and Protected Areas & Shopping Centers (Regional and Community). \\
\hline Antenna Arrays. & Hospitals, Nursing Homes and Adult Congregate Living Quarters. & Other inland water bodies & Single-Family, High Density \\
\hline Beaches. & Houses of Worship and Religious. & Parking - Public and Private Garages and Lots. & Single-Family, Low-Density \\
\hline Biscayne National Park. & Industrial Extensive & Pasture (Grazing, Animal Farming, Dairy Farms and Animal Feed Lots) & Single-Family, Med.-Density \\
\hline Bus/TruckFFreight Forwarding Terminals. & Industrial Intensive, Office type of use & Paved Highways, Expressways and Ramps. & Small Grass Airports (Includes Crop Dusting Activities). \\
\hline Canal right-of-way. & Industrial Intensive, heary-light manufacturing, and warehousing-storage type of use & Penal and Correctional. & Social Services, Fraternal, Charitable (Shrines, Elks, Moose, Lions Club). \\
\hline Cemeteries. & Industrial intensive, Commercial Condominium type of use & Plant Nurseries (Includes Sod Farms and Ornamental Nurseries). & Solid Waste Disposal and Transfer \\
\hline Coastal Water (Bay only) & Inland water bodies (Lakes, Ponds, and Watercourses) & Poultry. & Sports Stadiums, Arenas, and Tracks. \\
\hline Coastal Water (Bay only) & Inland water bodies (Lakes, Rock Pits) & Private Drives. & Street right-of-way and entrance features \\
\hline Coastal Water (Ocean only) & Inland water bodies (Lakes, Watercourses) & Private Recreational Camps/Areas & Streets and Roads, except Expressways and Private Drives. \\
\hline Coastal Waters within Everglades National Park. & Junk Yard. & Private Recreational Facilities & TRANSIENT-RESIDENTIAL (HOTEL-MOTEL) \\
\hline Colleges and Universities, Including Research Centers & Major Approved Projects. & Private Schools, Including Playgrounds & TRANSPORTATION, COMMUNICATION,AND UTLLTIES \\
\hline Communications & Major Transmission Lines. & Public Schools, Including Playgrounds & Townhouses. \\
\hline County Operated Parks. & Marina complexes & Railroads - Terminals, Trackage, and Yards. & Two-Family (Duplexes). \\
\hline Cultural & Marine commercial & Recreational Vehicle Parks/Camps. & Vacant Government owned or controlled. \\
\hline Electric Power (Generator and Substation, and Service Yards). & Military Facilities. & Remaining Bay Waters (Excluding Ocean). & Vacant, Non-Protected, Privately-Owned. \\
\hline Everglades National Park. & Mobile Home Parks and Permanent Mobile Homes. & Remaining Ocean Waters (Excluding Bay). & Vacant, Protected, Government-Owned or controlled. \\
\hline Extraction, Excavation, Quarrying, Rock-Mining & Multi-Family, High Density (Over 25 DU/Gross Acre). & Residential MF & Vacant, Protected, Privately-Owned. \\
\hline Fallow. & Mutti-Family, Low-Density (Under 25 DU/Gross Acre). & Residential SF--government-owned or government subsidized & Water Conservation Areas \\
\hline Farm Storage Areas (Storage Structures or Lots for Farm Implements). & Municipal Operated Parks & Residential predominantly & Water Supply Plants. \\
\hline Fish Farms (Includes Tropical Fish Aquariums, Fish and Alligator Farms). & Ocean Ship Terminals and Port Facilities, Bay and River Based. & Rivers and Canals.(Water) & Well fields. \\
\hline
\end{tabular}

Figure 16: Shared legend for land use maps displayed in Figures 14 and 15 
then introduced into RStudio where the kmeans() function from the stats package was applied to perform the K-means clustering analysis. The R output derived 5 distinct cluster groups for each time period for the 11 watersheds, meaning there were five different land use syndromes identified for the watersheds. Tables 21 and 22 show the results of the K-means clustering analysis for the watersheds and corresponding land uses for 1994 and 2013. 


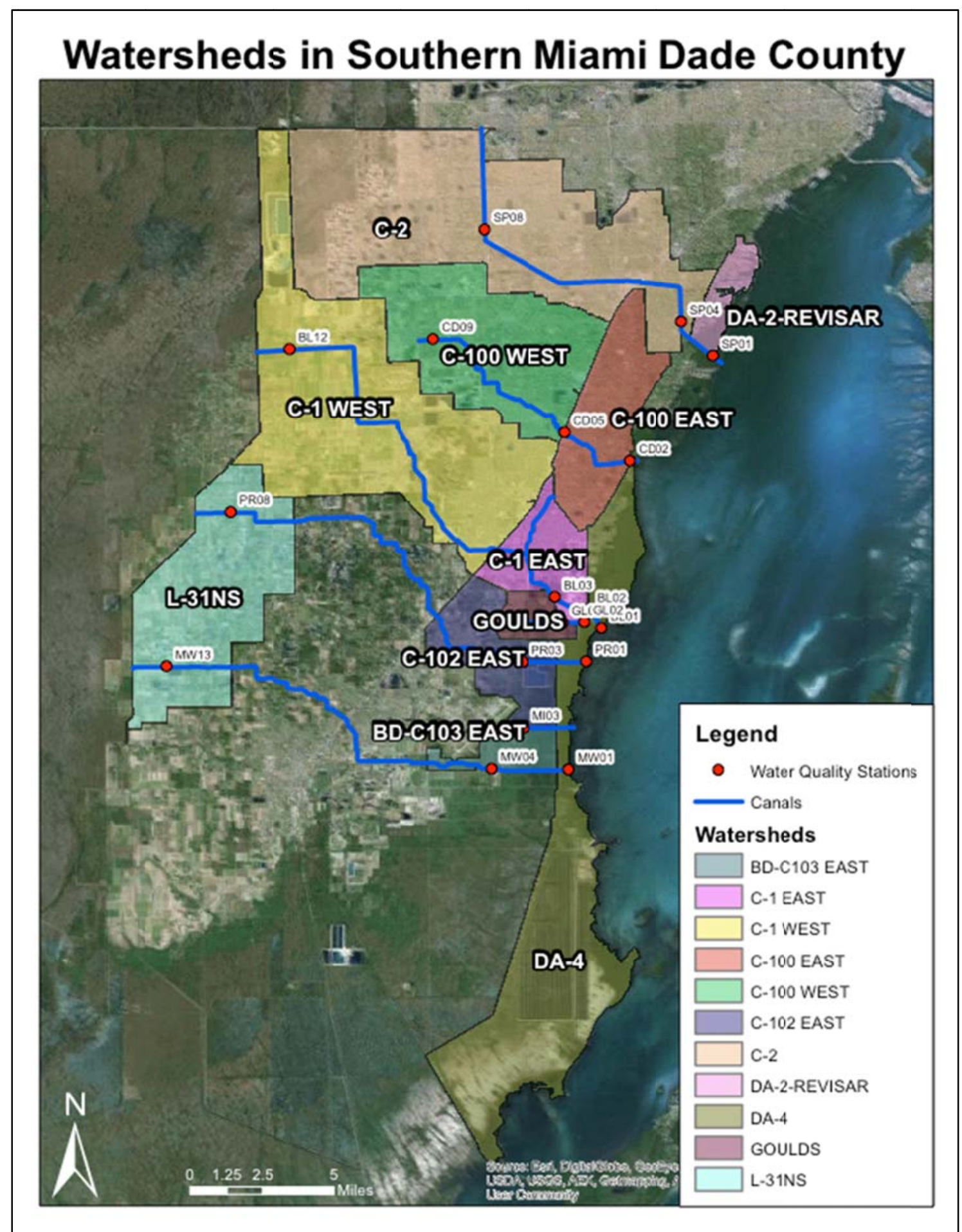

Figure 17: Map of watersheds in Southern Miami Dade County 
Table 21: K-means clustering analysis results for 1994 land use at Watershed scale

\begin{tabular}{ccc}
\hline Watershed & Cluster Group & Land Use Syndrome \\
\hline BDC103E & 1 & Nurseries-Row and Field Croplands \\
C1 East & 3 & High Urban Residential-Roads \\
C1 West & 2 & Groves-Row and Field Croplands \\
C2 & 3 & High Urban Residential-Roads \\
C100 East & 3 & High Urban Residential-Roads \\
C100 West & 3 & High Urban Residential-Roads \\
C102 East & 1 & Nurseries-Row and Field Croplands \\
DA2REVISAR & 4 & Residential-Preserves \\
DA4 & 5 & Vacant Lands \\
Goulds & 1 & Nurseries-Row and Field Croplands \\
L31 NS & 2 & Groves-Row and Field Croplands \\
\hline
\end{tabular}


Table 22: K-means clustering results for 2013 land use at Watershed scale

\begin{tabular}{ccc}
\hline Watershed & Cluster Group & Land Use Syndrome \\
\hline BDC103E & 4 & Vacant Land-Parks-Row and Field Croplands \\
C1 East & 3 & Urban Residential-Roads \\
C1 West & 4 & Vacant Land-Parks-Row and Field Croplands \\
C2 & 3 & Urban Residential-Roads \\
C100 East & 3 & Urban Residential-Roads \\
C100 West & 3 & Urban Residential-Roads \\
C102 East & 4 & Vacant Land-Parks-Row and Field Croplands \\
DA2REVISAR & 1 & Residential-Preserves \\
DA4 & 5 & Vacant Lands-Institutional \\
Goulds & 2 & Nurseries-Row and Field Croplands \\
L31 NS & 2 & Nurseries-Row and Field Croplands \\
\hline
\end{tabular}

Land use summaries for both 1994 and 2013 were also calculated for each of the seven 1000 meter canal buffers to distinguish their land use category compositions (Figure 18). The K-means clustering analysis showed that there were three groups of clusters for each time period for the seven canals, meaning there were three different land use syndromes. Tables 23 and 24 show the results of the K-means clustering analysis for the canal buffers and corresponding land uses for 1994 and 2013. 


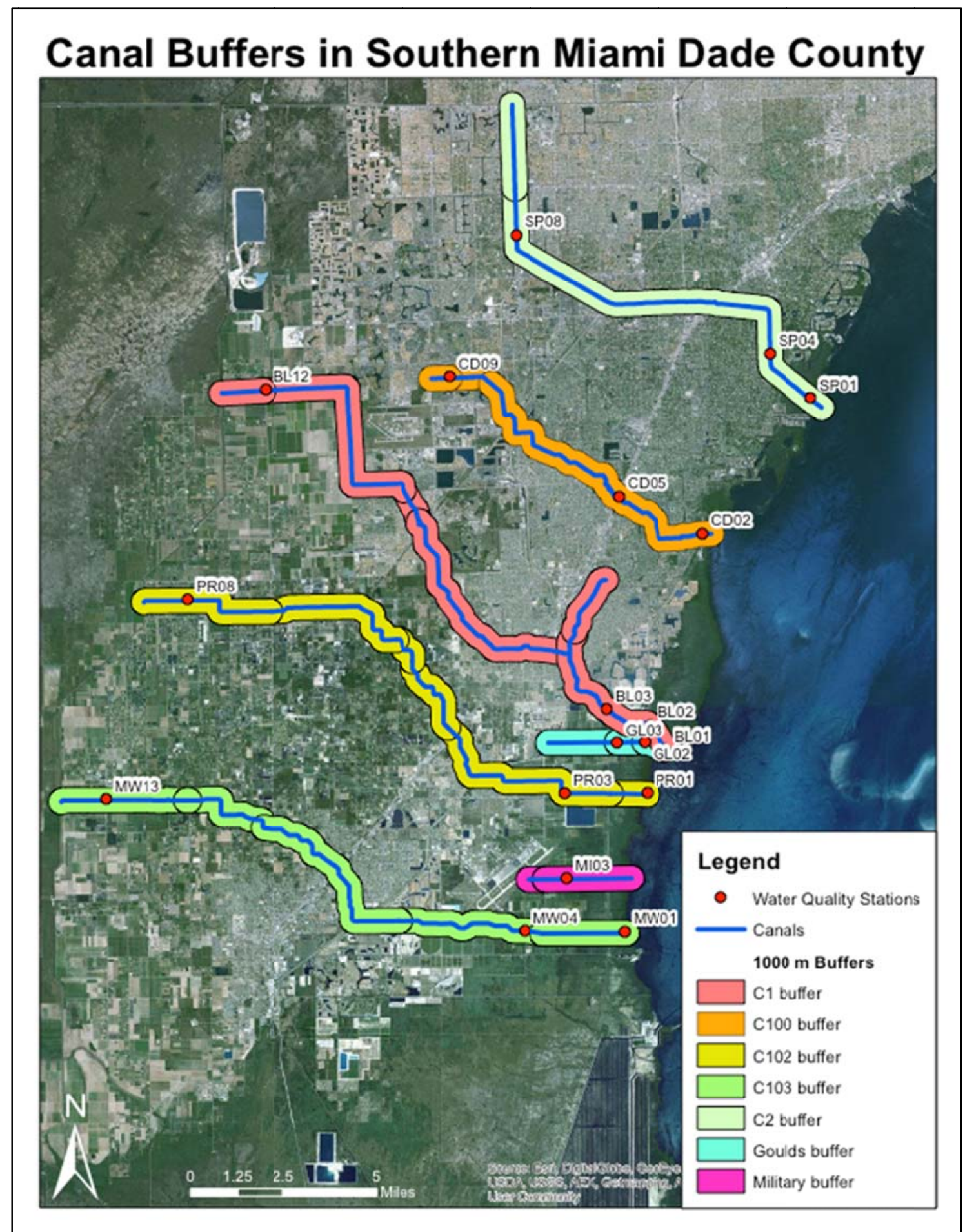

Figure 18: Map of canal buffers in Southern Miami Dade County 
Table 23: K-means clustering results for 1994 land use at Canal Buffer scale

\begin{tabular}{ccc}
\hline Canal & Cluster Group & Land Use Syndrome \\
\hline C1 & 3 & Row and Field Croplands-Vacant Lands \\
C2 & 1 & Urban Residential-Roads \\
C100 & 1 & Urban Residential-Roads \\
C102 & 3 & Row and Field Croplands-Vacant Lands \\
C103 & 3 & Row and Field Croplands-Vacant Lands \\
Goulds & 3 & Row and Field Croplands-Vacant Lands \\
Military & 2 & Vacant-Institutional \\
\hline
\end{tabular}

Table 24: K-means clustering results for 2013 land use at Canal Buffer scale

\begin{tabular}{ccc}
\hline Canal & Cluster Group & Land Use Syndrome \\
\hline C1 & 2 & Urban Residential-Roads \\
C2 & 2 & Urban Residential-Roads \\
C100 & 2 & Urban Residential-Roads \\
C102 & 1 & Nurseries-Row and Field Croplands-Vacant \\
C103 & 1 & Nurseries-Row and Field Croplands-Vacant \\
Goulds & 1 & Nurseries-Row and Field Croplands-Vacant \\
Military & 3 & Park Preserve-Institutional \\
\hline
\end{tabular}

The third spatial scale analyzed to determine land use composition summaries from both the 1994 and 2013 land use datasets was the 500 meter water quality station buffer (Figure 19). Land use data was summarized for 18 water quality station buffers for the 1994 land use dataset and for 15 water quality station buffers for the 2013 land use dataset. Again, the reason for this is because the water quality data spanning from 20092014 is only available from 15 water quality stations. Therefore, the intention is to match 
the temporal criteria of the land use datasets with that of the nutrient concentrations data. The results for the K-means clustering analysis showed that there was six cluster groups identifying land use syndromes in the 1994 and 2013 land use datasets. Tables 25 and 26 provide the detailed results of the clustering analysis. 
Figure 19: Map of water quality buffers in Southern Miami Dade County

\section{WQ Station Buffers in Southern Miami Dade County}

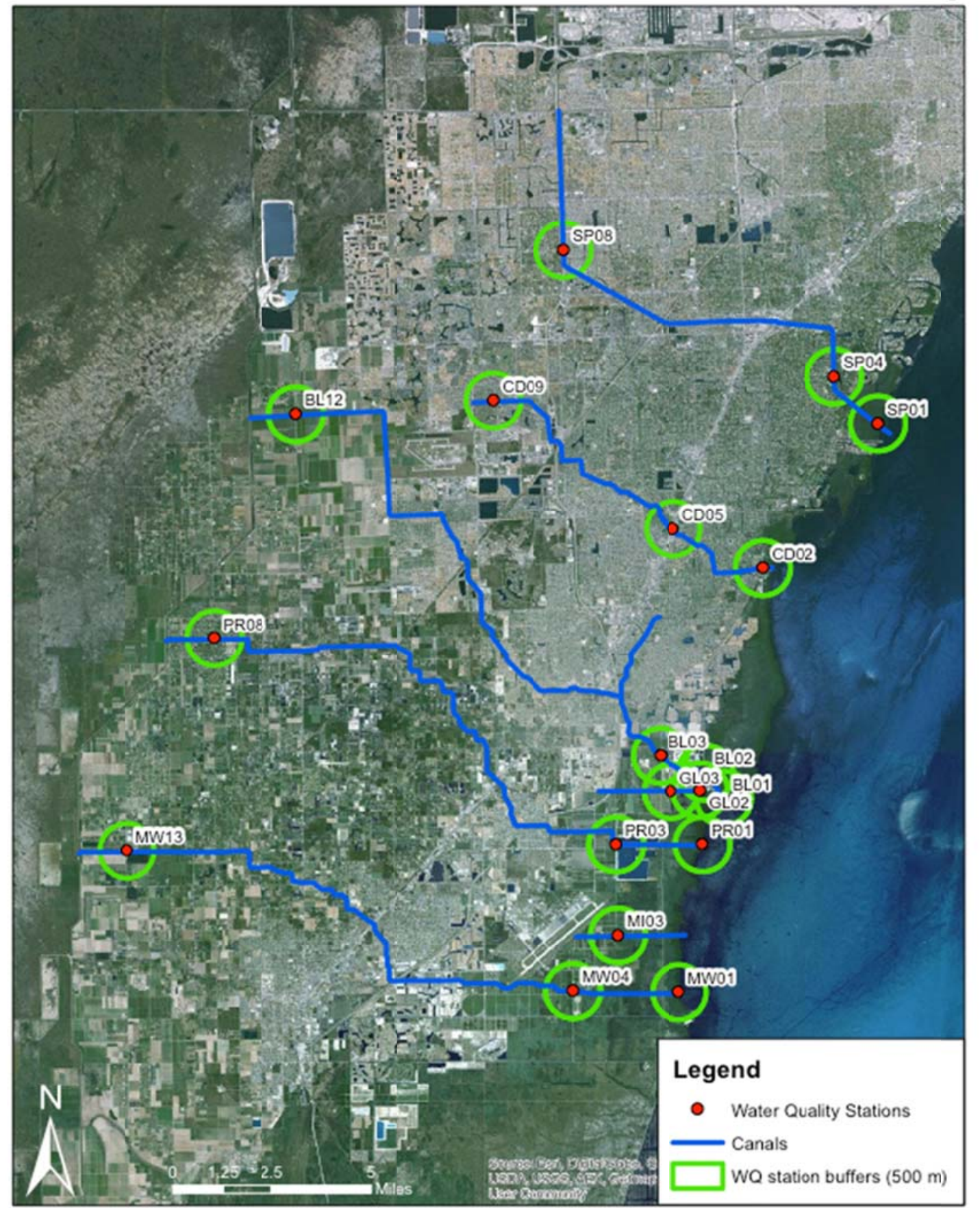


Table 25: K-means clustering results for 1994 land use at WQ Station Buffer scale

\begin{tabular}{ccc}
\hline Station & Cluster Group & Land Use Syndrome \\
\hline BL01 & 1 & Biscayne National Park \\
BL02 & 3 & Vacant-Preserves-Biscayne Bay \\
BL03 & 2 & Vacant-Nurseries-Solid Waste Disposal \\
BL12 & 6 & Row and Field Croplands \\
CD02 & 3 & Vacant-Preserves-Biscayne Bay \\
CD09 & 4 & Urban Residential-Roads \\
GL02 & 3 & Vacant-Preserves-Biscayne Bay \\
GL03 & 2 & Vacant-Nurseries-Solid Waste Disposal \\
MI03 & 2 & Vacant-Nurseries-Solid Waste Disposal \\
MW01 & 1 & Broves-Nurseries-Row and Field Croplands \\
MW04 & 5 & Groves-Nurseries-Row and Field Croplands \\
MW13 & 5 & Biscayne National Park \\
PR01 & 1 & Groves-Nurseries-Row and Field Croplands \\
PR03 & 5 & Groves-Nurseries-Row and Field Croplands \\
PR08 & 5 & Vacant-Preserves-Biscayne Bay \\
SP01 & 3 & Urban Residential-Roads \\
SP04 & 4 & Urban Residential-Roads \\
SP08 & 4 &
\end{tabular}


Table 26: K-means clustering results for 2013 land use at WQ Station Buffer scale

\begin{tabular}{ccc}
\hline Station & Cluster Group & Land Use Syndrome \\
\hline BL01 & 1 & Biscayne National Park \\
BL02 & 3 & Solid Waste Disposal-Preserves-Vacant Lands \\
BL03 & 2 & Nurseries-Row and Field Croplands-Vacant Lands \\
BL12 & 6 & Row and Field Croplands \\
CD02 & 5 & Urban Residential-Roads \\
CD05 & 5 & Urban Residential-Roads \\
GL02 & 3 & Solid Waste Disposal-Preserves-Vacant Lands \\
GL03 & 3 & Solid Waste Disposal-Preserves-Vacant Lands \\
MI03 & 2 & Nurseries-Row and Field Croplands-Vacant Lands \\
MW01 & 1 & Biscayne National Park \\
MW04 & 2 & Nurseries-Row and Field Croplands-Vacant Lands \\
PR01 & 1 & Biscayne National Park \\
PR03 & 2 & Nurseries-Row and Field Croplands-Vacant Lands \\
SP01 & 4 & Biscayne Bay-Parks Preserves \\
SP04 & 5 & Urban Residential-Roads \\
\hline
\end{tabular}

For the conclusion of this analysis, regression models were developed that relate the stations' mean nutrient concentrations (TP, NOx-N, and NH3-N) to the land use syndromes derived in the previous K-means clustering analysis for each of the spatial scales. The corresponding data was entered in RStudio and the output provided the regressor coefficients to fit the model, the coefficient of determination, $R^{2}$, and the mean squared error of the residuals, $M S E_{\text {Res }}$. A very important step in the process was converting the categorical variable representing the different land use syndromes into 
indicator variables. Two separate regression models were developed for each water quality parameter to account for the separate time periods for which water quality data is available. As stated earlier, the significance of constructing such models is that we gain insight into determining if land use is helpful in explaining the varying nutrient concentrations across sites at various canals, and if so, at what spatial scale the relationship between the two variables is most pronounced.

The regression models developed for the nutrient concentrations at the watershed scale showed mixed results. For example, the NOx-N fitted model for 1990-2003 fitted its corresponding data the best $\left(R^{2}=0.6168\right)$. In other words, this model could explain $61.68 \%$ of the variation in the response variable. However, the NOx-N fitted model for 2009-2014 did not provide the same results. In addition, the watershed scale did not provide good results in regards to predicting TP concentrations, although the 2009-2014 model had a significantly better $R^{2}$. The same was the case with the NH3-N concentrations. The complete sets of results are provided in Tables 27 and 28.

Table 27: Regression model results for nutrients at watershed scale (1990-2003)

\begin{tabular}{cccc}
\hline $\begin{array}{c}\text { Water Quality } \\
\text { Constituent }\end{array}$ & Fitted Model & $R^{2}$ & MSE \\
\hline TP & $\mathrm{y}=-4.5477-0.0035 \times 1-0.0467 \times 2-0.0777 \times 3+0.2047 \times 4$ & 0.0985 & 0.1235 \\
NOx-N & $\mathrm{y}=2.1471-2.0563 \times 1-2.0089 \times 2-2.0879 \times 3-1.5440 \times 4$ & 0.6168 & 0.5649 \\
NH3-N & $\mathrm{y}=0.1438+0.1639 \times 1-0.0029 \times 2-0.0707 \times 3+0.7552 \times 4$ & 0.2016 & 0.5227 \\
\hline
\end{tabular}


Table 28: Regression model results for nutrients at watershed scale (2009-2014)

\begin{tabular}{cccc}
\hline $\begin{array}{c}\text { Water Quality } \\
\text { Constituent }\end{array}$ & Fitted Model & $R^{2}$ & $M^{2} E_{\text {Res }}$ \\
\hline TP & $\mathrm{y}=0.0072+0.0017 \times 1+0.0008 \times 2-0.0015 \times 3+0.0011 \times 4$ & 0.3211 & $4.00 \mathrm{E}-06$ \\
NOx-N & $\mathrm{y}=0.0944+0.4433 \times 1+0.1420 \times 2+1.7067 \times 3+0.6639 \times 4$ & 0.3557 & 1.1173 \\
NH3-N & $\mathrm{y}=0.0921+0.5419 \times 1-0.0207 \times 2+0.012 \times 3+0.178 \times 4$ & 0.4738 & 0.0363 \\
\hline
\end{tabular}

For the 1000 meter canal buffer scale, the model with the best fit was for NH3-N concentrations from 1990-2003. However, the model for NH3-N concentrations from 2009-2014 did not perform nearly as well. For TP concentrations, the regression models indicate poor fit for both time periods. In the case of NOx-N the model fit the data much better in the time period 2009-2014 than in 1990-2003. The results are presented in Tables 29 and 30 .

Table 29: Regression model results for nutrients at canal buffer scale (1990-2003)

\begin{tabular}{cccc}
\hline $\begin{array}{c}\text { Water Quality } \\
\text { Constituent }\end{array}$ & Fitted Model & $R^{2}$ & $M S E_{\text {Res }}$ \\
\hline TP & $\mathrm{y}=0.0107+0.0009 \times 1+0.001 \times 2$ & 0.0125 & $1.70 \mathrm{E}-05$ \\
NOx-N & $\mathrm{y}=0.1015+0.5598 \times 1+0.8146 \times 2$ & 0.1222 & 1.1215 \\
NH3-N & $\mathrm{y}=0.1125-0.0635 \times 1+0.3377 \mathrm{x} 2$ & 0.4568 & 0.0574 \\
\hline
\end{tabular}

Table 30: Regression model results for nutrients at canal buffer scale (2009-2014)

\begin{tabular}{cccc}
\hline $\begin{array}{c}\text { Water Quality } \\
\text { Constituent }\end{array}$ & Fitted Model & $R^{2}$ & $M S E_{\text {Res }}$ \\
\hline TP & $\mathrm{y}=0.0073+0.0004 \times 1-0.0008 \times 2$ & 0.0266 & $5.00 \mathrm{E}-06$ \\
NOx-N & $\mathrm{y}=1.5546-1.3471 \times 1-0.4910 \times 2$ & 0.3628 & 0.9214 \\
NH3-N & $\mathrm{y}=0.275-0.1715 \times 1-0.1735 \times 2$ & 0.1537 & 1.1859 \\
\hline
\end{tabular}

The regression models for the third spatial scale of 500 meter water quality station buffers resulted in poor fitments for all three nutrient constituents for the time period of 
1990-2003. The NOx-N model had the highest coefficient of determination $\left(R^{2}=\right.$ 0.3628). However, for the time period 2009-2014, all three models provided significantly better results. The coefficients of determination for the TP and NH3-N models were 0.6437 and 0.6563 respectively. The complete results of the models can be found below on Table 31 and 32.

Table 31: Regression model results for nutrients at WQ station buffer scale (1990-2003)

\begin{tabular}{cccc}
\hline $\begin{array}{c}\text { Water } \\
\text { Quality } \\
\text { Constituent }\end{array}$ & Fitted Model & $R^{2}$ & $M S E_{\text {Res }}$ \\
\hline TP & $\mathrm{y}=0.0112+0.002 \times 1+0.0016 \times 2+0.0002 \times 3-0.0023 \times 4-0.0003 \times 5$ & 0.1642 & $1.80 \mathrm{E}-05$ \\
NOx-N & $\mathrm{y}=0.75997+0.0903 \times 1-0.6441 \times 2-0.6517 \times 3+0.8703 \times 4-0.7378 \times 5$ & 0.3342 & 1.063 \\
NH3-N & $\mathrm{y}=0.1599=0.0379 \times 1+0.7138 \times 2-0.0097 \times 3-0.0075 \times 4+0.226 \times 5$ & 0.1819 & 0.5802 \\
\hline
\end{tabular}

Table 32: Regression model results for nutrients at WQ station buffer scale (2009-2014)

\begin{tabular}{cccc}
\hline $\begin{array}{c}\text { Water Quality } \\
\text { Constituent }\end{array}$ & Fitted Model & $R^{2}$ & $M^{2} E_{\mathrm{Res}}$ \\
\hline TP & $\mathrm{y}=0.0069-0.0015 \times 1+0.0027 \times 2+0.0003 \times 3+0.0019 \times 4-0.0001 \times 5$ & 0.6437 & $2.00 \mathrm{E}-06$ \\
NOx-N & $\mathrm{y}=0.9046+1.0011 \times 1-0.4957 \times 2-0.8102 \times 3-0.7960 \times 4-0.8367 \times 5$ & 0.4524 & 1.0568 \\
NH3-N & $\mathrm{y}=0.1066-0.0507 \times 1+0.3993 \times 2-0.0145 \times 3-0.0488 \times 4+0.1464 \times 5$ & 0.6563 & 0.0264 \\
\hline
\end{tabular}

\section{Objective 4}

The seasonal Kendall test was applied to 18 water quality stations across seven different canals for the time period 1990-2003 to determine the trends of TP, NOx-N, and NH3-N concentrations at each of these sites. The test was also applied to 15 water quality stations (14 of which are the same ones from the 1990-2003 time period) for the time period 2009-2014 in order to detect trends at each site for the aforementioned nutrient constituents. The individual seasonal Kendall test for each water quality station for each nutrient constituent was carried out in RStudio using the rkt() function (Marchetto 2015). 
When this $r k t()$ function is applied to the specified dataset, it provides an output that displays Kendall's tau $(\tau)$, the Kendall S score $\left(S_{k}\right)$ and corresponding variance, and the two-sided p-value for the test statistic $\left(Z_{S k}\right)$.

For the time period 1990-2003 the seasonal Kendall test for TP concentrations at the water quality stations resulted in only four stations having decreasing trends. All other stations gave a result of no trend due to the p-value of the test statistic being above the level of significance 0.05 . The four stations with detectable trends were station BL03, on the Black Creek Canal, station CD02, on the Cutler Drain Canal, station GL02, on the Goulds Canal, and station MI03, on the Military Canal. For these stations, Kendall's tau statistics were small negative values, which is indicative of weak negative correlation between the X (time) and Y (TP concentration) variables. Out of the four stations, MI03 had the strongest negative correlation and smallest p-value $(\tau=-0.2878$, p-value $<0.005$ ). These stations also had very small p-values that were below 0.01, meaning that the decreasing trends were very significant. The results of this trend test on TP are provided in Table 33. 
Table 33: Seasonal Kendall trend test results for TP concentrations (1990-2003)

\begin{tabular}{|c|c|c|c|c|c|}
\hline Station & Observations & Kendall's tau & Kendall S score & p-value & Trend \\
\hline BL01 & 114 & 0.0745 & 238 & 0.2462 & no trend \\
\hline BL02 & 115 & -0.0384 & -125 & 0.5501 & no trend \\
\hline BL03 & 109 & -0.1934 & -564 & 0.0032 & decreasing \\
\hline BL12 & 98 & -0.1364 & -321 & 0.0503 & marginal \\
\hline CD02 & 105 & -0.2604 & -704 & 0.0001 & decreasing \\
\hline CD09 & 87 & -0.02376 & -43 & 0.7549 & no trend \\
\hline GL02 & 119 & -0.1678 & -584 & 0.0077 & decreasing \\
\hline GL03 & 118 & -0.0887 & -299 & 0.163 & no trend \\
\hline MI03 & 117 & -0.2878 & -968 & 0.000005 & decreasing \\
\hline MW01 & 102 & 0.03163 & 76 & 0.6516 & no trend \\
\hline MW04 & 83 & -0.0142 & -24 & 0.856 & no trend \\
\hline MW13 & 92 & -0.1381 & -274 & 0.0577 & no trend \\
\hline PR01 & 101 & -0.0518 & -127 & 0.4546 & no trend \\
\hline PR03 & 78 & 0.0706 & 102 & 0.3716 & no trend \\
\hline PR08 & 92 & -0.0533 & -108 & 0.4635 & no trend \\
\hline SP01 & 106 & -0.1316 & -329 & 0.0547 & no trend \\
\hline SP04 & 100 & -0.1176 & -271 & 0.0924 & no trend \\
\hline SP08 & 98 & -0.0911 & -210 & 0.1933 & no trend \\
\hline
\end{tabular}

The seasonal Kendall test for NOx-concentrations in time period 1990-2003 demonstrated that only six stations had significant trends. All six stations had increasing trends of NOx-N. The stations featuring this increasing trend were stations BL01, BL02, and BL03, all on the Black Creek Canal, station GL02, on the Goulds Canal, station MW04, on the Mowry Canal, and station PR03, on the Princeton Canal. The Kendall's 
tau statistics for these stations were small positive values indicating a weak positive correlation between the $\mathrm{X}$ (time) and $\mathrm{Y}(\mathrm{NOx}-\mathrm{N}$ concentration) variables. The stations with the strongest positive correlation and smallest p-value were station $\operatorname{PR03}$ ( $\tau=$ 0.3559, p-value $=8.08 \mathrm{E}-08)$ and station BL03 $(\tau=0.3476$, p-value $=2.49 \mathrm{E}-08)$. The null hypothesis could not be rejected for all the other stations as their p-values for the test statistic $Z_{S k}$ were above the level of significance 0.05 , therefore the results for these stations were determined as no trend. The results of this trend test on NOx-N are provided in Table 34 . 
Table 34: Seasonal Kendall trend test results for NOx-N concentrations (1990-2003)

\begin{tabular}{|c|c|c|c|c|c|}
\hline Station & Observations & Kendall's tau & Kendall S score & p-value & Trend \\
\hline BL01 & 124 & 0.179 & 677 & 0.0036 & increasing \\
\hline BL02 & 124 & 0.2063 & 781 & 0.0008 & increasing \\
\hline BL03 & 121 & 0.3476 & 1252 & 2.49E-08 & increasing \\
\hline BL12 & 72 & -0.0483 & -61 & 0.5396 & no trend \\
\hline CD02 & 103 & 0.0614 & 161 & 0.3691 & no trend \\
\hline CD09 & 108 & -0.0527 & -0.0527 & 0.4274 & no trend \\
\hline GL02 & 122 & 0.1269 & 465 & 0.0408 & increasing \\
\hline GL03 & 125 & -0.0169 & -65 & 0.7859 & no trend \\
\hline MI03 & 117 & -0.0161 & -54 & 0.8039 & no trend \\
\hline MW01 & 111 & 0.066 & 200 & 0.3146 & no trend \\
\hline MW04 & 108 & 0.291 & 833 & 0.000011 & increasing \\
\hline MW13 & 94 & -0.0902 & -195 & 0.2057 & no trend \\
\hline PR01 & 115 & 0.0785 & 255 & 0.2222 & no trend \\
\hline PR03 & 108 & 0.3559 & 1020 & 8.08E-08 & increasing \\
\hline PR08 & 90 & -0.0813 & -161 & 0.2603 & no trend \\
\hline SP01 & 97 & 0.0056 & 13 & 0.9403 & no trend \\
\hline SP04 & 108 & -0.0681 & -195 & 0.3042 & no trend \\
\hline SP08 & 102 & -0.0972 & -248 & 0.1531 & no trend \\
\hline
\end{tabular}

For NH3-N concentrations in the time period 1990-2003, the seasonal Kendall test for the water quality stations showed that 11 stations had detectable trends. Stations BL01, BL12, CD02, CD09, MW04, MW13, PR01, PR03, PR08, and SP08 all had decreasing trends of NH3-N. The station with the strongest negative correlation and lowest p-value was station BL12 on the Black Creek Canal ( $\tau=-0.3097$, p-value $=2.4 \mathrm{E}$ - 
06). Only one station had an increasing trend of NH3-N. That was station GL02 on the Goulds Canal $(\tau=0.148$, $\mathrm{p}$-value $=0.0155)$. The rest of the stations resulted as no trend. The following table provides the results of the trend test of NH3-N for all the stations. Table 35: Seasonal Kendall trend test results for NH3-N concentrations (1990-2003)

\begin{tabular}{|c|c|c|c|c|c|}
\hline Station & Observations & Kendall's tau & Kendall S Score & p-value & Trend \\
\hline BL01 & 124 & -0.1533 & -580 & 0.0128 & decreasing \\
\hline BL02 & 124 & -0.0883 & -334 & 0.1524 & no trend \\
\hline BL03 & 110 & 0.0852 & 253 & 0.1931 & no trend \\
\hline BL12 & 110 & -0.3097 & -921 & 0.0000024 & decreasing \\
\hline CD02 & 95 & -0.1474 & -326 & 0.0365 & decreasing \\
\hline CD09 & 98 & -0.1824 & -429 & 0.0081 & decreasing \\
\hline GL02 & 126 & 0.148 & 578 & 0.0155 & increasing \\
\hline GL03 & 119 & 0.0689 & 240 & 0.2749 & no trend \\
\hline MI03 & 115 & -0.0862 & -280 & 0.1765 & no trend \\
\hline MW01 & 113 & -0.043 & -135 & 0.5072 & no trend \\
\hline MW04 & 92 & -0.2416 & -501 & 0.00071 & decreasing \\
\hline MW13 & 110 & -0.192 & -571 & 0.0035 & decreasing \\
\hline PR01 & 113 & -0.1939 & -608 & 0.0027 & decreasing \\
\hline PR03 & 92 & -0.3032 & -628 & 0.000022 & decreasing \\
\hline PR08 & 110 & -0.1814 & -539 & 0.0057 & decreasing \\
\hline SP01 & 113 & -0.0344 & -108 & 0.5951 & no trend \\
\hline SP04 & 94 & -0.1221 & -264 & 0.0863 & no trend \\
\hline SP08 & 108 & -0.2078 & -595 & 0.0017 & decreasing \\
\hline
\end{tabular}

For the time period of 2009-2014, the seasonal Kendall test for TP concentrations resulted in only three stations out of the 15 analyzed having detectable trends. All the 
others were determined as having no trend. Station MI03, on the Military Canal, and station MW04 on the Mowry Canal had a decreasing trend of TP concentrations while station GL03, on the Goulds Canal, had an increasing trend. The TP trend test for the previous time period (1990-2003) showed that only four stations had detected trends, but none of them had an increasing trend. Station MI03 is the only station that the two time periods have in common in terms of continuing trend (decreasing trend in both time periods). As for station GL03, no significant trend was detected in the previous time period. The complete results for the 2009-2014 TP trend test are presented in Table 36. 
Table 36: Seasonal Kendall trend test results for TP concentrations (2009-2014).

\begin{tabular}{cccccc}
\hline Station & Observations & Kendall's tau & Kendall S score & p-value & Trend \\
\hline BL01 & 62 & -0.014 & -13 & 0.8836 & no trend \\
BL02 & 64 & 0.1031 & 96 & 0.2458 & no trend \\
BL03 & 59 & -0.0785 & -66 & 0.3841 & no trend \\
BL12 & 61 & -0.0975 & -82 & 0.2871 & no trend \\
CD02 & 64 & 0.0499 & 42 & 0.5924 & no trend \\
CD05 & 61 & -0.0178 & -15 & 0.8552 & no trend \\
GL02 & 60 & 0.0904 & 76 & 0.3292 & no trend \\
GL03 & 75 & 0.2739 & 255 & 0.002 & increasing \\
MI03 & 58 & -0.2709 & -220 & 0.0031 & decreasing \\
MW01 & 65 & 0.1064 & 109 & 0.2093 & no trend \\
MW04 & 56 & -0.1849 & -140 & 0.0403 & decreasing \\
PR01 & 60 & 0.0878 & 74 & 0.3405 & no trend \\
PR03 & 56 & -0.1564 & -110 & 0.0969 & no trend \\
SP01 & 61 & 0.0975 & 82 & 0.2865 & no trend \\
SP04 & 59 & 0.1463 & 123 & 0.1081 & no trend \\
\hline
\end{tabular}

The seasonal Kendall test for NOx-N concentrations at the water quality stations from 2009 through 2014 showed that only two out of the 15 stations had trends. The two stations (GL03 and PR01) had decreasing trends of NOx-N. The results of this trend test are quite different from those of the previous time period (1990-2003). In the previous time period, six stations had significant trends, all of which were increasing. Stations GL03 and PR01 both had no trends in the previous time period. In addition, the correlation of X (time) and Y (nutrient concentration) for station GL03 is one of the most 
pronounced of all for both time periods and water quality parameters ( $\tau=-0.4486$, pvalue $=2.60 \mathrm{E}-08$ ). The trend test results are provided below in Table 37.

Table 37: Seasonal Kendall trend test results for NOx-N concentrations (2009-2014)

\begin{tabular}{cccccc}
\hline Station & Observations & Kendall's tau & Kendall S score & p-value & Trend \\
\hline BL01 & 58 & -0.0332 & -27 & 0.7303 & no trend \\
BL02 & 59 & 0.1507 & 127 & 0.1043 & no trend \\
BL03 & 57 & -0.0013 & -1 & 1 & no trend \\
BL12 & 43 & 0.0249 & 11 & 0.833 & no trend \\
CD02 & 63 & 0.0135 & 13 & 0.888 & no trend \\
CD05 & 35 & 0.173 & 50 & 0.1613 & no trend \\
GL02 & 60 & 0.0172 & 15 & 0.8598 & no trend \\
GL03 & 63 & -0.4486 & -615 & $2.60 \mathrm{E}-08$ & decreasing \\
MI03 & 59 & -0.0461 & -88 & 0.5386 & no trend \\
MW01 & 61 & -0.0499 & -45 & 0.5891 & no trend \\
MW04 & 60 & 0.0885 & 77 & 0.3375 & no trend \\
PR01 & 60 & -0.1865 & -163 & 0.0422 & decreasing \\
PR03 & 62 & -0.1493 & -139 & 0.0976 & no trend \\
SP01 & 54 & 0.14873 & 105 & 0.1237 & no trend \\
SP04 & 59 & -0.132 & -111 & 0.1512 & no trend \\
\hline
\end{tabular}

Lastly, the results for the seasonal Kendall test for NH3-N concentrations for the stations in 2009-2014 demonstrate that only one station had a trend. Station MI03, on the Military Canal, had a decreasing trend of NH3-N concentrations ( $\tau=-0.2193$, p-value $=0.0159)$. In the previous time period, ten stations had decreasing trends for this water quality parameter. Also, the trend test for station GL02 resulted in no trend. This is 
significant because in the previous time period, this station had an increasing trend of NH3-N. The results of this trend test for each station are provided in Table 38.

Table 38: Seasonal Kendall trend test results for NH3-N concentrations (2009-2014)

\begin{tabular}{cccccc}
\hline Station & Observations & Kendall's tau & Kendall S score & p-value & Trend \\
\hline BL01 & 62 & -0.114 & -106 & 0.2045 & no trend \\
BL02 & 62 & -0.1097 & -102 & 0.2217 & no trend \\
BL03 & 46 & 0.0447 & 23 & 0.6847 & no trend \\
BL12 & 63 & -0.0895 & -86 & 0.3179 & no trend \\
CD02 & 56 & -0.0118 & -9 & 0.9093 & no trend \\
CD05 & 47 & -0.0378 & -20 & 0.714 & no trend \\
GL02 & 61 & -0.1267 & -114 & 0.1642 & no trend \\
GL03 & 64 & 0.1148 & 114 & 0.195 & no trend \\
MI03 & 60 & -0.2193 & -191 & 0.0159 & decreasing \\
MW01 & 67 & -0.0193 & 21 & 0.8291 & no trend \\
MW04 & 44 & -0.0216 & -10 & 0.8518 & no trend \\
PR01 & 61 & 0.0432 & 39 & 0.6395 & no trend \\
PR03 & 37 & 0.2186 & 80 & 0.0725 & no trend \\
SP01 & 62 & 0.1353 & 126 & 0.1297 & no trend \\
SP04 & 57 & 0.1492 & 117 & 0.1132 & no trend \\
\hline
\end{tabular}




\section{CHAPTER 5: CONCLUSIONS}

The primary purpose for conducting this research was to attempt to gain a better understanding of the correlations between land use and water quality in southern Miami Dade County. This research took on the task by seeking out land use datasets of greater resolution and finer categorical detail to see what more could be gained and contributed to the existing knowledge we have about land use and water quality dynamics in Miami Dade County. Based on results presented in Chapter 4 along with the information provided in the previous chapter, certain conclusions can be reached.

At the end of Chapter 1, questions were asked and hypotheses were devised that were intended to address the essence of this research's objectives. The following chapters included the literature review, methodologies, and results, all of which enabled answering said questions. Before arriving at conclusions, these questions and hypothesis should be repeated.

- Question: What is the status of nutrient concentrations in the canals of southern Miami Dade County that flow through agricultural lands?

- Hypothesis: Nutrient concentrations in the canals will differ, considering the different land use practices. There will be differences between canals that flow through urban-residential areas and canals that flow through agricultural lands. Certain types of agricultural practices may influence water quality at specific sites. Those land use practices related to specific sites will be identified.

The status of nutrient concentrations in the canals of the study area were addresses by identifying water quality stations found along the canals of southern Miami Dade County 
that were not meeting the water quality standards set in place by federal, state and local government agencies. Clearly identifying the stations that surpass legal thresholds invites subsequent, comparisons among the possible causes of nutrient impairment. Researchers point out that land use types are one of the primary factors of potential causation. In the case of total phosphorous (TP), we observed that none of stations surpassed the nutrient criteria set in place for these canals, which are, for the most part, coastal canals that drain into southern Biscayne Bay. However, a number of water quality stations did surpass the nutrient thresholds for NOx-N and NH3-N concentrations. For example, station PR03, in the Princeton Canal, had mean concentrations grossly above the rest of the other stations. This is a water quality station immediately surrounded by plant nurseries and agricultural lands devoted to row and field croplands. This is known because of the results provided in Objective 3 of this research involving the GIS geoprocessing analysis and clustering procedures. In the case of GL02, it is located on the Goulds Canal right next to Biscayne Bay, protected mangroves, and expanses of vacant lots. However, the station is on a canal that flows on the southern end of the South Dade Landfill. Researchers in this area have documented well the high NH3-N concentrations in the nearby waters of the landfill along with the consequences of leachate pollution to southern Biscayne Bay (Caccia \& Boyer 2005; Caccia \& Boyer 2007) while others have identified the South Dade Wastewater Treatment Plant as another potential source of elevated NH3-N in the near vicinity (Carey et al. 2011).

- Question: Do the nutrient concentrations among the canals differ from each other? 
- Hypothesis: The nutrient concentrations across not only the canals, but across canal sites will differ considering the different land use compositions at each site.

The results of the Kruskal-Wallis nonparametric test in this project affirmed what was expected. The null hypothesis (Ho) that the median concentrations are equal for each of the water quality stations was easily rejected for all water quality parameters. Considering the varying land use compositions that surround the water quality stations and the stark differences between mean concentrations for the period of records and other summary statistics, it was not surprising that the test confirmed that the stations had different distributions of nutrient concentrations. The presentation of the box-plots provided graphical evidence of the test result, further strengthening the validity of this conclusion. Also, the implementation of the Kruskal-Wallis test was robust considering that in Objective 1, almost all the water quality stations for each nutrient parameter rejected the null hypothesis of the Shapiro-Wilk test (Ho: Distribution functions for the samples are normal).

- Question: What are the dominant land use types/land use syndromes for the canals being analyzed? Can the land use syndromes predict nutrient concentrations for the canals? Does spatial scale play a role?

- Hypothesis: Land use syndromes for the canals will differ due to different combination of land uses. Land use syndromes can predict nutrient concentrations as land use is related to water quality. The finer the spatial scale, the more relevant the results. 
The results for Objective 3 demonstrated the different land use syndromes that exist for each water quality station at three different spatial scales: watershed, 1000 meter canal buffer, and 500 meter station buffer. Determining if land use syndromes can predict nutrient concentrations and the relevance of spatial scale was ultimately defined by the K-means clustering analysis and regression model building. Overall, it provided mixed results for each of the nutrient parameters at each of the spatial scales. Also, the finest spatial scale (500 meter station buffer) did not provide the most relevant results in all cases. What this indicates is that correlations between land use and water quality are embedded with complexities due to the role other factors, especially biological ones, which play significant role in influencing water quality. However, the results did demonstrate that land use is a critical factor in determining surface water nutrient concentrations. The models at the three spatial scales predicted NOx-N concentrations much more successfully than TP concentrations, and to a certain extent, NH3-N concentrations. Some reasons that may explain why these models could not predict TP concentrations include the limiting nature of phosphorus in the South Florida natural environment. The soil, geology, and hydrology all play significant roles in immobilizing phosphorus in the environment such as through adsorption to calcium carbonate and other particulate matter or co-precipitation to calcium in the water column (Noe et al. 2001; Lietz 1999). To build a model that can better predict TP concentrations, other regressors/independent variables can be included that account for factors such as soil types, rainfall amounts, and runoff capabilities or percentage of impervious surfaces.

- Question: Is there a trend for the nutrient concentrations at the canals and their corresponding sampling sites? 
- Hypothesis: There will be detectable trends for nutrient concentrations at the canals and sites considering the land use change the study region has undergone.

Lastly, the seasonal Kendall trend test results showed that for the most part the trends for each of the nutrient constituents were either decreasing for the water quality stations or displaying no trend at all. Therefore, the null hypothesis (given seasonality, no correlation between X-time and Y-nutrient concentrations) could be rejected in many cases and not be rejected in many other ones. However, from 1990-2003, it appeared that NOx-N concentrations increased at a number of stations situated in lands dedicated to agricultural practices. In addition, it is unfortunate that water quality data for the period 2009-2014 obviously only spans a total of five years while the previous water quality period of record spans more than twice as along. It would be prudent to continue water quality sampling for the next couple of years for the purpose of developing a long enough period of record so that when a trend test is applied, such as the seasonal Kendall test, one can arrive to a more robust long-term trend of nutrient concentrations in these canal waters.

\section{Future Work}

With South Florida's population continuing to increase and applying pressure to housing availability, land use will continue to change as it has done so for the last two decades. The lands dedicated for agricultural purposes that serve as protective buffers to federally protected lands will continue to decline and this will pose new complex challenges to land managers responsible for protecting natural resources and ensuring the ecosystem viability of nearby parks, such as Everglades National Park and Biscayne 
National Park. By understanding the present nature of the relationship of land use and water quality, land managers can start to prepare for the future and begin the process of designing management plans with the participation of stakeholders that intend to anticipate the effects of land use change on not only water quality, but the rest of the landscape as well.

Furthermore, future research on this subject matter can focus on land use change in relation to changes in nutrient concentrations. In this thesis research, land use was statistically analyzed at two separate time periods and so was water quality for a number of different sites across seven canals. The logical manner to proceed with this research is to identify which watersheds, canal buffers, and water quality station buffers changed the most in terms of land use from one time period to the other and determine if the stations found in each of these spatial scales demonstrate changes in nutrient concentrations as well from one time period to another.

Lastly, total phosphorous must be more closely examined. Researchers have recognized that total phosphorous pollution and loading has chronically occurred in the northern end of Biscayne Bay, as evidenced by a higher abundance of phytoplankton in this part of the bay (Brand et al, 1991). As mentioned in the Chapter 4, the stations on these canals feeding the southern portion of bay are not surpassing nutrient thresholds. That does not mean that there is no cause for concern. Some of the canals in this part of southern Miami Dade were built upon preexisting coastal creeks that connected to the transverse glades, bringing in freshwater from the Everglades into Biscayne Bay in times of excess rainfall. However, in this present day, these canals are legally classified and have been set for a standard of TP concentration thresholds different from the Everglades. 
Therefore, it must be considered that although the canals are not officially flowing with nutrient impaired waters, the quality of the water may possibly still be harmful to the bay. Also, determining the flow of water at the mouth of canals analyzed in this thesis research needs to be considered by future researchers. By determining which water quality stations were not meeting nutrient criteria standards it is known which canals are introducing impaired waters to Biscayne Bay. The next step is to obtain flow rates at the mouth of these canals in order to derive some kind of quantifiable measure of nutrient pollution entering the bay. Considering that the waters in the canals are highly managed by the SFWMD, this flow data should be available. 


\section{REFERENCES}

Abbott, E., Alleman, R., Barnes, T., Bauer, M., Bennett, R., Chamberlain, R., ... Wan, Y. (2005). Chapter 12: Management and Restoration of Coastal Ecosystems. In 2005 South Florida Environmental Report. Retrieved from http://www.sfwmd.gov/portal/page/portal/pg_grp_sfwmd_sfer/portlet_prevreport/2 005/volume1/chapters/V1_Ch12.pdf

Abtew, W., Pathak, C., Huebner, R. S., \& Ciuca, V. (2010). Hydrology of the South Florida Environment. In 2010 South Florida Environmental Report (Chapter 2). Retrieved from http://my.sfwmd.gov/portal/page/portal/xweb\%20about\%20us/agency\%20reports

Alberti, M. (2008). Advances in Urban Ecology: Integrating Humans and Ecological Processes in Urban Ecosystems. New York, NY: Springer Science+Business Media.

Bates, A.L., Orem, W.H., Harvey, J.W., \& Spiker, E.C. (2002). Tracing sources of sulfur in the Florida Everglades. Journal of Environmental Quality, 31, 287-299.

Brand, L.E., Gottfired, M.D., Baylon, C.C. \& Romer, N.S. (1991). Spatial and Temporal Distribution of Phytoplankton in Biscayne Bay, Florida. Bulletin of Marine Science, 49, 599-613.

Briceño, H.O., Boyer, J.N., \& Harlem, P.W. (2011). Ecological Impacts on Biscayne Bay and Biscayne National Park from Proposed South Miami-Dade County Development, and Derivation of Numeric Nutrient Criteria for South Florida Estuaries and Coastal Waters. NPS TA\# J5297-08- 0085, Florida International University, Southeast Environmental Research Center Contribution \# T- 530, 145 p.

Briceño, H.O., Boyer, J.N., Castro, J., \& Harlem, P. (2013). Biogeochemical classification of South Florida's estuarine and coastal waters. Marine Pollution Bulletin, 75, 187-204.

Broussard, W. \& Turner, E. (2009). A century of changing land-use and water quality relationships in the continental US. Frontiers in Ecology and Environment, 7, 302307.

Browder, J.A., Gleason, P.J., \& Swift, D.R. (1994). Periphyton in the Everglades: Spatial variation, environmental correlates, and ecological implications. In Everglades: The Ecosystem and Its Restoration (S. M. Davis and J. C. Ogden, eds) pp. 357-378. Delray Beach, FL: St. Lucie Press.

Caccia, V.G. \& Boyer, J.N. (2005). Spatial patterning of water quality in Biscayne Bay, 
Florida as a function of land use and water management. Marine Pollution Bulletin, 50, 1416-1429.

Caccia, V.G. \& Boyer, J.N. (2007). A nutrient loading budget for Biscayne Bay, Florida. Marine Pollution Bulletin, 54, 994-1008.

Carey, R.O., Migliaccio, K.W., \& Brown, M.T. (2011). Nutrient discharges to Biscayne Bay, Florida: Trends, loads, and a pollutant index. Science of the Total Environment, 409, 530-539.

Changnon, S.A., \& Demissie, M. (1996). Detection of changes in streamflow and floods resulting from climate fluctuations and land use drainage changes. Climatic Change, 32, 411-421.

Conover, W. J. (1999). Practical Nonparametric Statistics ( $3^{\text {rd }}$ ed.). New York, NY: John Wiley \& Sons.

Davis, S. \& Ogden, J.C. (1994). Everglades: The Ecosystem and Its Restoration. Delray Beach, FL: St. Lucie Press.

Fisher, D.S., Steiner, J.L., Wilkinson, S.R. (2000). The relationship of land use practices to surface water quality in the Upper Oconee Watershed of Georgia. Forest Ecology and Management, 128, 39-48.

Flaig, E.G., \& Reddy, K.R. (1995). Fate of Phosphorous in the Lake Okeechobee watershed, Florida, USA: Overview and recommendations. Ecological Engineering, 5, 127-142.

Gbureck, W.J., \& Folmar, G.J. (1999). Flow and chemical contributions to streamflow in an upland watershed: a baseflow survey. Journal of Hydrology, 217, 1-18.

Grimm, N.B., Sheibley, R.W., Crenshaw, C.L., Dahm, C.N., Roach, W.J., \& Zeglin, L.H. (2005). Nutrient retention and transformation in urban streams. Journal of the North American Benthological Society, 24, 626-642.

Groffman, P.M., Pouyat, R.V., Cadenasso, M.L., Zipperer, W.C., Szlavecz, K., Yesilonis, I.D., Band, L.E., \& Brush, G.S. (2006). Land use context and natural soil controls on plant community composition and soil nitrogen and carbon dynamics in urban and rural forests. Forest Ecology and Management, 236, 177-192.

Heckathorn, H.A. \& Deetz, A.C. (2012). Variations in statewide water quality of New Jersey streams, water years 1998-2009: U.S. Geological Survey Scientific Investigations Report 2012-5047, 54 p. 
Helsel, D.R. (2005). Nondetects and Data Analysis:Statistics for censored environmental data. New York, NY: John Wiley and Sons.

Helsel, D. R. \& Hirsch, R.M. (1993). Statistical Methods in Water Resources. New York, NY: Elsevier Science.

Holden, J., Chapman, P.J., \& Labadz, J.C. (2004). Artificial drainage of peatlands: hydrological and hydrochemical process and wetland restoration. Progress in Physical Geography, 28, 95-123.

Howie, B. (1986). Effects of agriculture on groundwater quality in Dade County, Florida. USGS Water Resources Division Miami, Florida, 8 pp.

Ierodiaconou, D., Laurenson, L., Leblanc, M., Stagnitti, F., Duff, G., Salzman, S. \& Versace, V. (2005). The consequences of land use change on nutrient exports: a regional scale assessment in south-west Victoria, Australia. Journal of Environmental Management, 74, 305-316.

Kaye, J.P., McCulley, R.L., \& Burke, I.C. (2005). Carbon fluxes, nitrogen cycling, and soil microbial communities in adjacent urban, native and agricultural ecosystems. Global Change Biology, 11, 575-587.

Key, P.B., Fulton, M.H., Harman-Fetcho, J.A., \& McConnell, L.L. (2003). Acetylcholinesterase Activity in Grass Shrimp and Aqueous Pesticide Levels from South Florida Drainage Canals. Archives of Environmental Contamination and Toxicology, 45, 371-377.

Kruskal, W.H. \& Wallis, W.A. (1952). Use of ranks on one-criterion variance analysis. Journal of the American Statistical Association, 47, 583-621.

Law, N.L., Band, L.E., \& Grove, J.M. (2004). Nitrogen Input from Residential Lawn Care Practices in Suburban Watersheds in Baltimore County, MD. Journal of Environmental Planning and Management, 47, 737-755.

LeBlanc, R.T., Brown, R.D. and FitzGibbon, J.E. (1997). Modeling the effects of land use change on the water temperature in unregulated urban streams. Journal of Environmental Management, 49, 445-469.

Lietz, A.C. (1999). Methodology for Estimating Nutrient Loads Discharged from the East Coast Canals to Biscayne Bay, Miami-Dade County, Florida. U.S. Geological Survey Water-Resources Investigations Report 99-4094, 36 p.

Mander, U., Kull, A., Tamm, V., Kuusemets, V., \& Karjus, R. (1998). Impact of climatic fluctuations and land use change on runoff and nutrient losses in rural landscapes. Landscape and Urban Planning, 41, 229-238. 
Mann, H.B. (1945). Nonparametric tests against trend. Econometrica, 13, 245-259.

Marchetto, A. (2015). Mann-Kendall Test, Seasonal and Regional Kendall Tests (rkt). R Package.

Mattikalli, N.M., \& Richards, K.S. (1996). Estimation of Surface Water Quality Changes in Response to Land Use Change: Application of The Export Coefficient Model Using Remote Sensing and Geographical Information System. Journal of Environmental Management, 48, 263-282.

McQueen, J.B. (1967). Some methods of classification and analysis of multivariate observations. In Proc. $5^{\text {th }}$ Berkeley Symposium of Mathematical Statistics and Probability, pp. 281-297. Berkeley, CA.

Meissner, R., Seeger, J., Rupp, H., \& Balla, H. (1999). Assessing the impacts of agricultural land use changes on water quality. Water Science Technology, 40, 110 .

Miles, C.J. \& Pfeuffer, R.J. (1997). Pesticides in canals of South Florida. Archives of Environmental Contamination and Toxicology, 32, 331-347.

Miller R.L., McPherson, B.F., Sobczack, R., \& Clark, C. (2004). Water Quality in Big Cypress National Preserve and Everglades National Park - Trends and Spatial Characteristics of Selected Constituents. U.S. Geological Survey Water-Resources Investigations Report 03-4249, $34 \mathrm{p}$.

Mitsch, W. J. \& Gosselink, J. G. (2007). Wetlands ( $4^{\text {th }}$ ed.). Hoboken, NJ: John Wiley and Sons.

Moore, D.S., McCabe, G.P., \& Craig, B.A. (2012). Introduction to the Practice of Statistics $\left(7^{\text {th }}\right.$ ed.). New York, NY: W.H. Freeman and Company.

Montgomery, D.C., Peck, E.A., \& Vining, G.G. (2012). Introduction to Linear Regression Analysis ( $5^{\text {th }}$ ed.). Hoboken, NJ: John Wiley and Sons.

Noe, G.B., Childers, D.L., \& Jones, R.D. (2001). Phosphorus Biogeochemistry and the Impact of Phosphorus Enrichment: Why Is the Everglades so Unique? Ecosystems, 4, 603-624.

Polhert, T. (2014). The Pairwise Multiple Comparison of Means Rank Package (PMCMR). R Package. 
R Core Team (2012). R: A language and environment for statistical computing. RFoundation for Statistical Computing, Vienna, Austria. ISBN 3-900051-07-0, URL http://www.Rproject.org/.

Sachs, L. (1997). Angewandte Statistik ( $8^{\text {th }}$ ed.). Berlin, Germany: Springer

Shapiro, S.S., \& Wilk, M.B. (1965). An analysis of variance test for normality (complete samples). Biometrika, 52, 591-611.

SFWMD. (1995). An update of the surface water improvement and management plan for Biscayne Bay. Technical Supporting Document and Appendices. South Florida Water Management District, West Palm Beach, Florida.

Solecki, W.D. (2001). The role of global-to-local linkages in land use/land cover change in South Florida. Ecological Economics, 37, 339-356.

Tong, S.T.Y., \& Chen, W. (2002). Modeling the relationship between land use and surface water quality. Journal of Environmental Management, 66, 377-393.+

Valz, P., McLeod, A.I., \& Thompson, M.E. (1995). Cumulant generation function and tail probability approximations for Kendall's score with tied rankings. Annals of Statistics, 23, 144-160.

USEPA. (2013). Nutrients Water Quality Standards for the State of Florida. Retrieved from http://water.epa.gov/lawsregs/rulesregs/florida-index.cfm

USEPA. (2014). Clean Water Act Methods: Approved General-Purpose Methods. Retrieved from http://water.epa.gov/scitech/methods/cwa/methods_index.cfm

Walsh, C.J., Fletcher, T.D., \& Ladson, A.R. (2005). Stream restoration in urban catchments through redesigning stormwater systems: Looking to the catchment to save the stream. Journal of the North American Benthological Society, 24, 690705.

Wetzel, P. (2001). Nutrient and fire disturbance and model evaluation documentation for the Across Trophic Level System Simulation (ATLSS): Retrieved from http://www.tiem.utk.edu/ sylv/HTML/Everglades/VSMod-HTML/index

Wagstaff, K., Cardie, C., Rogers, S. \& Schroedl. S. (2001). Constrained k-means clustering with background knowledge. International Conference on Machine Learning, 1, 577-584. 